San Jose State University

SJSU ScholarWorks

Mineta Transportation Institute Publications

$9-2020$

\title{
Characteristics of Effective Metropolitan Areawide Public Transit: A Comparison of European, Canadian, and Australian Case Studies
}

\author{
Michelle DeRobertis \\ Mineta Transportation Institute \\ Christopher E. Ferrell \\ Mineta Transportation Institute \\ Richard W. Lee \\ San Jose State University \\ John M. Eells \\ Mineta Transportation Institute
}

Follow this and additional works at: https://scholarworks.sjsu.edu/mti_publications

Part of the Transportation Commons, and the Transportation Engineering Commons

\begin{abstract}
Recommended Citation
Michelle DeRobertis, Christopher E. Ferrell, Richard W. Lee, and John M. Eells. "Characteristics of Effective Metropolitan Areawide Public Transit: A Comparison of European, Canadian, and Australian Case Studies" Mineta Transportation Institute Publications (2020). https://doi.org/10.31979/mti.2020.2001
\end{abstract}

This Report is brought to you for free and open access by SJSU ScholarWorks. It has been accepted for inclusion in Mineta Transportation Institute Publications by an authorized administrator of SJSU ScholarWorks. For more information, please contact scholarworks@sjsu.edu. 


\section{SISU SAN JOSÉ STATE

\section{$M T I / \equiv$}

\section{Characteristics of Effective Metropolitan Areawide Public Transit: A Comparison of European, Canadian, and Australian Case Studies}

Michelle DeRobertis, PhD

Christopher E. Ferrell, PhD

Richard W. Lee, PhD

John M. Eells, MCP

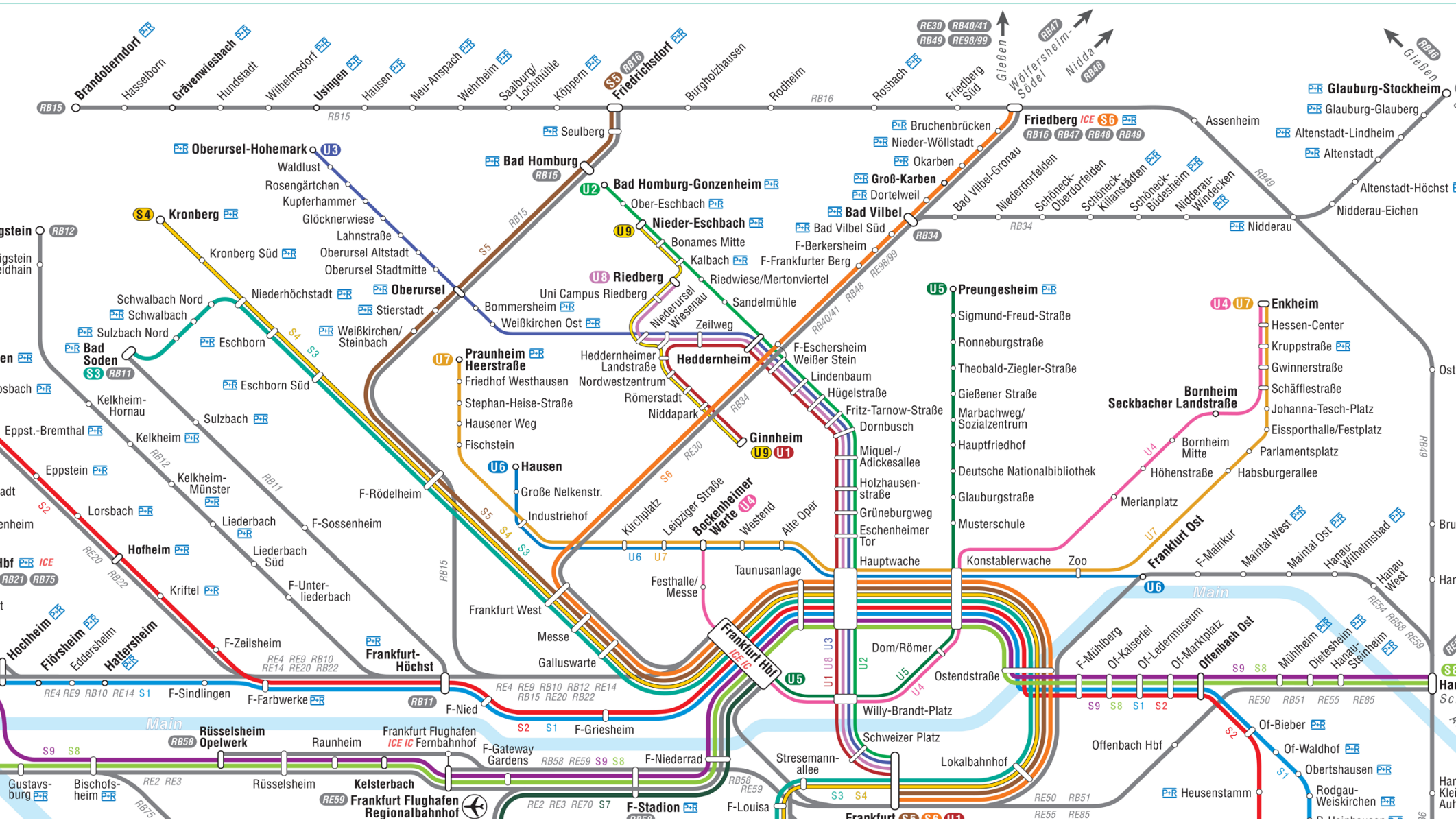




\section{MINETA TRANSPORTATION INSTITUTE LEAD UNIVERSITY OF Mineta Consortium for Transportation Mobility}

Founded in 1991, the Mineta Transportation Institute (MTI), an organized research and training unit in partnership with the Lucas College and Graduate School of Business at San José State University (SJSU), increases mobility for all by improving the safety, efficiency, accessibility, and convenience of our nation's transportation system. Through research, education, workforce development, and technology transfer, we help create a connected world. MTI leads the four-university Mineta Consortium for Transportation Mobility, a Tier I University Transportation Center funded by the U.S. Department of Transportation's Office of the Assistant Secretary for Research and Technology (OST-R), the California Department of Transportation (Caltrans), and by private grants and donations.

MTl's transportation policy work is centered on three primary responsibilities:

\section{Research}

MTI works to provide policy-oriented research for all levels of government and the $P$ rivate sector to foster the development of optimum surface transportation systems. Research areas include: bicycle and pedestrian issues; financing public and private sector transportation improvements; intermodal connectivity and integration; safety and security of transportation systems; sustainability of transportation systems; transportation / land use / environment; and transportation planning and policy development. Certified Research Associates conduct the research. Certification requires an advanced degree, generally a Ph.D., a record of academic publications, and professional references. Research projects culminate in a peer-reviewed publication, available on TransWeb, the MTI website (http://transweb.sjsu.edu).

\section{Education}

The Institute supports education programs for students seeking a career in the development and operation of surface transportation systems. MTI, through San José State University, offers an AACSBaccredited Master of Science in Transportation Management and graduate certificates in Transportation Management,Transportation Security, and High-Speed Rail Management that serve to prepare the nation's transportation managers for the 2 I st century. With the active assistance of the California Department of Transportation (Caltrans), MTI delivers its classes over a state-of-the-art videoconference network throughout the state of California and via webcasting beyond, allowing working transportation professionals to pursue an advanced degree regardless of their location. To meet the needs of employers seeking a diverse workforce, MTl's education program promotes enrollment to under-represented groups.

\section{Information and Technology Transfer}

MTI utilizes a diverse array of dissemination methods and media to ensure research results reach those responsible for managing change. These methods include publication, seminars, workshops, websites, social media, webinars, and other technology transfer mechanisms. Additionally, MTI promotes the availability of completed research to professional organizations and journals and works to integrate the research findings into the graduate education program. MTl's extensive collection of transportation- related publications is integrated into San José State University's world-class Martin Luther King, Jr. Library.

\section{Disclaimer}

The contents of this report reflect the views of the authors, who are responsible for the facts and accuracy of the information presented herein. This document is disseminated in the interest of information exchange. The report is funded, partially or entirely, by a grant from the U.S. Department of Transportation's University Transportation Centers Program. This report does not necessarily reflect the official views or policies of the U.S. government, State of California, or the Mineta Transportation Institute, who assume no liability for the contents or use thereof. This report does not constitute a standard specification, design standard, or regulation. 
REPORT 20-42

\title{
CHARACTERISTICS OF EFFECTIVE METROPOLITAN AREAWIDE PUBLIC TRANSIT: A COMPARISON OF EUROPEAN, CANADIAN, AND AUSTRALIAN CASE STUDIES
}

\author{
Michelle DeRobertis, PhD \\ Christopher E. Ferrell, PhD \\ Richard W. Lee, PhD \\ John M. Eells, MCP
}

September 2020

A publication of

Mineta Transportation Institute

Created by Congress in 1991

College of Business

San José State University

San José, CA 95192-0219 


\section{TECHNICAL REPORT DOCUMENTATION PAGE}

1. Report No. 20-42

4. Title and Subtitle

Characteristics of Effective Metropolitan Areawide Public Transit: A Comparison of European, Canadian, and Australian Case Studies
3. Recipient's Catalog No.

5. Report Date

September 2020

6. Performing Organization Code

8. Performing Organization Report CA-MTI-2001

10. Work Unit No.

11. Contract or Grant No.

69A3551747127

13. Type of Report and Period Covered Final Report

14. Sponsoring Agency Code
12. Sponsoring Agency Name and Address

U.S. Department of Transportation

Office of the Assistant Secretary for

Research and Technology

University Transportation Centers Program

1200 New Jersey Avenue, SE

Washington, DC 20590

\section{Supplemental Notes}

10.31979/mti.2020.2001

\section{Abstract}

This research project investigates the replicable characteristics, policies, and practices of successful metropolitan areawide public transportation networks that contribute to high usage and make transit an effective competitor to the private motor vehicle. The research method involves the qualitative and quantitative analysis of ten international (non-U.S.) case studies. The principal methods employed were web-based research and data collection, as well as telephone interviews with transit agency staff or regional planners as needed. The case studies were limited to developed western countries with similar metropolitan conditions to those in the United States.

This research focuses on key characteristics of highly effective regional transit systems from the perspective of the metropolitan area, not the individual transit operators. These characteristics fall within three broad categories: the setting of the metropolitan area; the customer-apparent transit service features; and the behind-the-scenes or institutional characteristics.

Key findings are: (1) all ten case studies have a metropolitan areawide regional transit coordinator (RTC); (2) RTCs yield benefits in terms of ridership and operating efficiencies that are discernable from the effects of high transit funding and subsidies; (3) all case studies had some degree of fare integration, and most had complete regionwide fare integration; and (4) transit service was frequent, abundant, and affordable in all cases.

The features of excellent regionwide transit systems that have been identified in this research can be applied to U.S. metropolitan areas with multiple players, yielding effective, efficient, and high mode share public transit at the regional level. The research can help U.S. policy makers and planners begin to improve the appropriate aspects of their own regional transit systems, including by improving coordination and organizational structures.

\section{Key Words}

Transit integration, public transit, public transport association, regional coordination, Europe

\section{Distribution Statement}

No restrictions. This document is available to the public through The National Technical Information Service, Springfield, VA 22161 


\title{
Copyright () 2020 \\ by Mineta Transportation Institute \\ All rights reserved
}

DOI: 10.31979/mti.2020.2001

\author{
Mineta Transportation Institute \\ College of Business \\ San José State University \\ San José, CA 95192-0219 \\ Tel: (408) 924-7560 \\ Fax: (408) 924-7565 \\ Email: mineta-institute@sjsu.edu
}

transweb.sjsu.edu 


\section{ACKNOWLEDGMENTS}

The authors would like to thank MTI Executive Director Dr. Karen Philbrick as well as Dr. Hilary Nixon, Director of Research and Technology Transfer, for their support and encouragement during the proposal phase.

The authors would also like to thank the professionals who live in, work in, or are otherwise familiar with the ten metropolitan areas we researched, especially those who work for the various transit system owners, operators or regional coordinating agencies, including Aaron Murray, Transport for New South Wales, Australia; Bri-ana Ingram, TransLink, Vancouver, Canada; Antoine Belaieff, Metrolinx, Toronto, Canada; Patrizia Malgieri, Board Member, Local Public Transport Agency, Milan, Italy; Gisela Gräfin von Schlieffen, RMV, Frankfurt, Germany; John Hultén, K2Cen-trum, Sweden; and Eric Eidlin, Cities Fellow, German Marshall Fund of the U.S. We are grateful for the time they took to respond to our emails and phone calls in order to provide pertinent tips and data links and to answer our clarifying questions about the relevant regional transit network in their area. Special thanks to lan Griffiths, Policy Director of Seamless Bay Area, for his advice, support, and insights through-out the process of completing this project. Finally, we are grateful to Joseph Kott, who brought the authors of this report together under the umbrella of Transportation Choices for Sustainable Communities, a 501c3 nonprofit: we thank Transportation Choices for Sustainable Communities for providing the authors with a weekly forum to advance this research.

Cover image: Thank you to Rhein-Main-Verkehrsverbund GmbH for permission to use their image showing the regional transit network of the metropolitan area of Frankfurt, Germany. 


\section{TABLE OF CONTENTS}

List of Figures vii

List of Tables ix

Executive Summary 1

Preface: Terminology $\quad 6$

$\begin{array}{ll}\text { Transit Service Players } & 6\end{array}$

Terms for Levels of Government and Governmental Agencies 10

I. Introduction 14

$\begin{array}{ll}\text { Purpose } & 14\end{array}$

$\begin{array}{ll}\text { Methodology } & 15\end{array}$

Selection of the Case Study Metropolitan Areas 16

II. Metropolitan Area Case Study Descriptive Information and Analysis 20

$\begin{array}{ll}\text { Population } & 20\end{array}$

$\begin{array}{ll}\text { Primacy } & 21\end{array}$

Population Density $\quad 22$

Transit Ridership $\quad 23$

$\begin{array}{ll}\text { Transit Riders per Capita } & 24\end{array}$

III.Regional Transit Coordination, Institutional climate, and Governance Setting 26

$\begin{array}{ll}\text { Barcelona, Spain } & 28\end{array}$

Milan, Italy 32

Lyon and Rhône, France $\quad 36$

$\begin{array}{ll}\text { Stuttgart, Germany } & 39\end{array}$

Frankfurt, Germany $\quad 41$

Stockholm, Sweden $\quad 44$

Vancouver, Canada $\quad 46$

Toronto, Canada $\quad 52$

$\begin{array}{ll}\text { Sydney, Australia } & 60\end{array}$

Perth, Australia $\quad 63$

$\begin{array}{ll}\text { Summary } & 66\end{array}$ 
IV. Customer-Apparent Characteristics

Travel Speeds

Transit Supply: Coverage and Frequency

Fares and Fare Policy 75

Relative Transit Affordability in Europe

90

V. Transit Finance Data and Analysis

Transit Expenditures

Transit Expenditures per Capita

Transit Expenditures per Rider 95

Transit Farebox Recovery 96

Transit Subsidy per Capita 98

Transit Subsidy per Rider 99

VI. Summary and Discussion 101

Findings on Institutions and Governance 102

Findings on Customer-Apparent Features 109

Regional Coordination and Subsidies

General Observations

Recommendations for Further Research

APPENDIX A: HEAVY RAIL AGENCIES IN THE USA

Abbreviations and Acronyms 


\section{LIST OF FIGURES}

1. Three Levels Involved in German Public Transit 7

2. Population of Each Case Study Metropolitan Area and Main City 20

3. Main City's Percentage Share of its Metropolitan Population (Pri macy)

4. Main City and Metropolitan Area Population Density 22

5. Annual Transit Ridership for Metropolitan Area Case Studies 23

6. Annual Transit Ridership per Capita for Metropolitan Area Case Studies

7. Barcelona Metropolitan Area 29

8. Barcelona Authority of Metropolitan Transport 30

9. Milan Area of Public Transport Coordination 33

10. SYTRAL Service Area of Lyon and Rhône 37

11. Operation Area of SYTRAL, Lyon and Rhône 38

12. Stuttgart Metropolitan Area 40

13. Frankfurt Metropolitan Area 42

14. Stockholm Metropolitan Area 44

15. Vancouver Metropolitan Area 47

16. Vancouver's TransLink Organization Chart 49

17. Current City of Toronto, a Single-Tier Municipality since 1998

18. Communities in the Greater Toronto and Hamilton Area 54

19. Communities in the Greater Golden Horseshoe Area 55

20. GTHA Metropolitan Area 58

21. Greater Sydney Metropolitan Area 61

22. Greater Perth Metropolitan Area 64

23. Stuttgart's VVS Fare Zones 78 
24. Fare Zones in the Milan Area

25. TransLink Fare Zones, Vancouver

87

26. Annual Metropolitan Area Transit Budget (Operations)

93

27. Annual Metropolitan Area Transit Operations Budget (Cost) per Capita

94

28. Annual Metropolitan Area Transit Operations Budget (Cost) per Transit Rider

95

29. Share of Total Metropolitan Budget from Farebox Revenues (Fare box Recovery Ratio) 97

30. Metropolitan Area Transit Subsidy per Capita 98

31. Metropolitan Area Transit Subsidy per Transit Rider 99

32. Frankfurt Urban Rail Transit System Map 102

33. Phases of Public Transit Ownership and Management 103 


\section{LIST OF TABLES}

1. Administrative Divisions of State and Local Governments in the U.S. Compared to Case Study Countries

2. Considered and Selected Case Study Metropolitan Areas

3. Year Created: Regional Transit Coordination versus Regional Governmental Organizations

4. Key Milestones in the Evolution of Transperth

5. Number of Transit Vehicle Hours per Capita (Transit Service Area ant) in Five of the European Case Study Metropolitan Areas Plus Toronto: All Transit Modes and Rail Modes Only

6. Suburban (Commuter) Rail Network Route-Kilometers per Million Inhabit-ants and Number of Suburban (Commuter) Rail Lines in the Six European Case Study Metropolitan Areas Plus Toronto and Chicago

7. Car Availability in the Main Cities of Four European Case Study Metropolitan Areas

8. Key Fare Policies of Metropolitan Case Studies

9. Milan's Fare Structure

10. SL's Single Journey Ticket Prices

84

11. SL's Travel Card Prices 84

12. Vancouver TransLink's Fare Discounts System 86

13. Sydney's Distance-Based Fare System 88

14. Comparison of European Metropolitan Area Fare System Prices 91

15. Roles and Responsibilities of Regional Coordinators 106

16. Sample Fare Integration Programs and Ridership Impact 


\section{EXECUTIVE SUMMARY}

\section{INTRODUCTION AND METHODOLOGY}

The purpose of this research is to identify the specific characteristics, policies, and practices that are apparent to the customer, as well as the institutional characteristics, that make possible a high-functioning, world class metropolitan transit system. The research question to be answered in this study is: "What are the replicable factors in metropolitan public transportation that make transit an effective competitor to the private motor vehicle?" It employs a set of case studies from ten metropolitan areas in Europe, Canada, and Australia to identify these success factors. The characteristics investigated fall into four main categories:

1. Metropolitan Area Background and Setting: Data such as population, land area, and political setting.

2. Regional Transit Coordinating Agency: Existence of an agency responsible for regional transit coordination, as well as its structure and relation to political jurisdictions.

3. Customer-Apparent Characteristics: Quality/level of service, mode diversity, regional fare structure, service coordination, and so on.

4. Transit Finance: Regional transit budgets, funding sources, and investments in public transit.

While the results may not be statistically significant, they are nevertheless illustrative of which regional characteristics, policies, and practices are associated with effective, well patronized transit networks. The findings are intended to be suggestive, rather than definitive, and thereby they are meant to identify promising policies and concepts for further, more in-depth research. This research is a strong contribution to the literature since most past research focused on individual agencies or modes and did not address the regional aspects or the interdependency of the modes and operators.

\section{FINDINGS}

\section{Institutional Findings}

All case study metropolitan areas had a Regional Transit Coordinator (RTC). These regional transit coordinating agencies came into being on a variety of different paths. While some have been in place with more or less the same structure for decades, many took considerable time to evolve to their present high level of sophistication and coordination. Others established in the past have recently been restructured. Finally, others are still relatively new agencies formed within the past ten years. 
The RTCs covered in this research fall into three categories; even so, there is wide variation within these three models.

- Coordination Only: The RTC agency is the coordinating body of many individual transit systems owned and operated by different governmental political jurisdictions at different levels of government: cities, provinces, regions, and/or the state.

- Coordination and Regional Transit Provider: The RTC agency also owns and manages the regional transit system. For example, Metrolinx in Ontario, Canada runs the regional transit (rail and bus) service branded as GO Transit.

- Complete Consolidation: All public transportation in the metropolitan area is run by one agency, and this single agency is by default the Regional Transit Coordinator (RTC).

The details of these RTCs' roles vary, but in general, the roles are as depicted in Table ES-1.

\section{Customer-Facing Components of Multiple Providers and Modes}

The second issue this research addresses is what we call customer-facing or customer-apparent. This encompasses all aspects of using public transit that the customer experiences directly, such as fares and headways, as opposed to the behind-the-scenes issues of governance and coordination.

Frequency of service (that is, short headways and timed transfers) are an important component of the passenger experience, particularly when changing between modes or transit systems. The role of the RTC is to ensure that the transfers between parts of the system are as coordinated as possible. Moreover, if both services have short headways, timed transfers are moot.

Another potentially inhibiting component of transfers is the fare. Without exception, the ten case study metropolitan areas have moved toward a single regionwide integrated fare policy, with most having fully embraced it (all six European cities and Vancouver; see Table 8). Research both in the U.S. and abroad has shown that ridership increases once single-ticket journey-based fare policies (free transfers) are implemented. 
Table ES-1: Roles and Responsibilities of Regional Coordinators (RTCs)

\begin{tabular}{|c|c|c|c|c|c|c|c|c|}
\hline $\begin{array}{l}\text { Name of } \\
\text { RTC (Major } \\
\text { City) }\end{array}$ & $\begin{array}{l}\text { Plan- } \\
\text { ning }\end{array}$ & $\begin{array}{l}\text { Single- } \\
\text { Ticket } \\
\text { Policy }\end{array}$ & $\begin{array}{l}\text { Schedule } \\
\text { Coordi- } \\
\text { nation }\end{array}$ & $\begin{array}{l}\text { Market- } \\
\text { ing/Pub- } \\
\text { lic Info } \\
\text { Services }\end{array}$ & $\begin{array}{l}\text { Pro- } \\
\text { cure- } \\
\text { ment/ } \\
\text { Con- } \\
\text { tracting }\end{array}$ & $\begin{array}{l}\text { Monitoring } \\
\text { (e.g., punc- } \\
\text { tuality, rid- } \\
\text { ership) }\end{array}$ & $\begin{array}{l}\text { Transit Op- } \\
\text { erations as } \\
\text { well as Co- } \\
\text { ordination? }\end{array}$ & $\begin{array}{l}\text { Other } \\
\text { Transpor- } \\
\text { tation Re- } \\
\text { sponsibil- } \\
\text { ities? }\end{array}$ \\
\hline $\begin{array}{l}\text { TransLink } \\
\text { (Vancou- } \\
\text { ver) }\end{array}$ & Yes & Yes & Yes & Yes & Yes & Yes & $\begin{array}{l}\text { Yes, all } \\
\text { public } \\
\text { transit in } \\
\text { Greater } \\
\text { Vancouver }\end{array}$ & Yes (3) \\
\hline $\begin{array}{l}\text { Metrolinx } \\
\text { (Toronto) }\end{array}$ & Yes & No (1) & Yes & No & Yes & No & $\begin{array}{l}\text { Yes, } \\
\text { owner-op- } \\
\text { erator of } \\
\text { GO Transit, } \\
\text { regional rail } \\
\text { \& buses }\end{array}$ & No \\
\hline $\begin{array}{l}\text { TPL (Mi- } \\
\text { lan) }\end{array}$ & Yes & Yes & Yes & $\begin{array}{l}\text { Yes* (in } \\
\text { pro- } \\
\text { gress) }\end{array}$ & No & Yes & No & No \\
\hline $\begin{array}{l}\text { SYTRAL } \\
\text { (Lyon) }\end{array}$ & Yes & $\begin{array}{l}\text { Yes } \\
(2)\end{array}$ & Yes & No & Yes & Yes & No & No \\
\hline $\begin{array}{l}\text { TFV } \\
\text { (Stock- } \\
\text { holm) }\end{array}$ & Yes & Yes & Yes & Yes & Yes & Yes & Yes & $\begin{array}{l}\text { No, but } \\
\text { within } \\
\text { county } \\
\text { responsi- } \\
\text { bilities (3) }\end{array}$ \\
\hline $\begin{array}{l}\text { RMV } \\
\text { (Frankfurt) }\end{array}$ & Yes & Yes & Yes & Yes & Yes & Yes & No & No \\
\hline $\begin{array}{l}\text { VVS } \\
\text { (Stuttgart) }\end{array}$ & Yes & Yes & Yes & Yes & No & Yes & No & No \\
\hline $\begin{array}{l}\text { ATM (Bar- } \\
\text { celona) }\end{array}$ & Yes & Yes & Yes & Yes & Yes & Yes & No & No \\
\hline $\begin{array}{l}\text { Transperth } \\
\text { (Perth) }\end{array}$ & Yes & Yes & Yes & Yes & Yes & Yes & $\begin{array}{l}\text { Yes, all } \\
\text { public } \\
\text { transit in } \\
\text { the Greater } \\
\text { Perth }\end{array}$ & No \\
\hline $\begin{array}{l}\text { TfNSW } \\
\text { (Sydney) }\end{array}$ & Yes & No & Yes & Yes & Yes & Yes & $\begin{array}{l}\text { Yes, all } \\
\text { public } \\
\text { transit in } \\
\text { Greater } \\
\text { Sydney and } \\
\text { New South } \\
\text { Wales (4) }\end{array}$ & Yes (5) \\
\hline
\end{tabular}


(2) Single fare applies to the entire metropolitan which is served by TCL ( 73 communities). To include all the areas managed by SYTRAL (TCL plus the two rural areas), there is a daily pass, a monthly pass, and a yearly pass. So, alt-

hough Greater Lyon has only one zone, in practice there are two zones for the area coordinated by SYTRAL.

(3) Major roads and bridges.

(3) Has separate oversight committee which is under the County Council Assembly.

(4) The transit agencies are separate government agencies under this government agency.

(5) Since 2019 the agency is also responsible for building and maintaining road infrastructure, managing day-to-day

compliance and safety for roads and waterways, and vehicle and driving license registrations.

A regional fully-integrated fare policy includes:

- Regions with multiple systems, owners, and/or modes, each system owner does not set its own fares; there is only one fare structure for the whole region and all the transit systems.

- A single ticket regardless of transfers between modes or systems. The fare policy is to price the whole journey rather than individual trips, thus it is mode- and operator-blind.

- This single fare structure applies to the single-ride (single-journey) fare as well as passes.

- Consequently, any applicable discounts are uniform throughout the region such as those for students, seniors, weekend travel, families, etc.

- Whether a flat fare or distance-based fare is purchased, there is still only one ticket; there is no additional fare payment for changing vehicles or modes, regardless of the system owner.

- Most but not all integrated fares policies also have an option for daily, weekly, and/ or monthly passes, which again are valid for all modes and all systems.

Complete consolidation is not necessary for complete fare integration. In fact, there are metropolitan areas with complete consolidation that do not have complete fare integration and vice versa. In addition, smart cards are extremely useful for complete fare integration but are not essential to the concept of a regionally integrated single-ticket policy. Free transfers and passes (for one day's travel or more) do exist and have existed without smart cards.

\section{Financial}

A focused analysis of four case study regions-Stockholm, Vancouver, Lyon, and Barcelona-suggests that regional coordination can increase ridership on its own, without high levels of spending and subsidies. 


\section{CONCLUSION}

One of the key factors behind the outcome of high transit use that emerged during the course of this study was the presence of a regional coordination agency. Such an agency ensures the following: (1) that schedules between modes are coordinated; 2) long-range planning among modes is also coordinated; and (3) there is a single regionwide fare policy and it is journey-based. In other words, it is both mode- and operator-blind. From a transit system design perspective, there is a regionwide trunk rail network supplemented by regional buses, particularly to locations not served by rail. Within major cities there is a citywide metro (subway) and/or light rail as well as local buses. European regions have invested in rail and contain up to five overlapping layers of rail transit: trams/light rail; metro/subway system; suburban commuter trains; interregional or intercity rail run by the state; and the national railway. If funiculars and aerial gondolas are present, there could be six.

Overall, in the case study locations, public transit is reliable, frequent, affordable, and abundant. Furthermore, there is a financial commitment, both past and present, to building and maintaining the infrastructure and necessary operations. A steady, sufficient, reliable funding stream is the backbone to world-class, reliable transit.

This research answers and raises numerous questions. Further research is recommended in several areas. They include: analyzing specific metropolitan areas in the U.S. with respect to the findings of this report; further analysis of areas with excellent public transit in terms of their commitment to fund and expand mass transit systems and the sources of public funding for said expansions; customerfacing outcomes such as transfer and travel time; and identification of the tools needed by regional transit coordinators to fulfill their mandate to affect said coordination such as the issues listed in Table ES-1. 


\section{PREFACE: TERMINOLOGY}

Given the wide variations in the meaning and interpretation of terminology between and even within the countries considered, it is necessary to reach a common understanding of what is meant by various terms. This section will define terms relating to two main areas of discussion in this report: the entities involved in providing transit service, and the various jurisdictional levels of political/government bodies. Foreign terms and words will be italicized for emphasis and to differentiate them from their English usage. German nouns are capitalized as per German grammar.

\section{TRANSIT SERVICE PLAYERS}

This paper discusses public transportation in seven countries outside the United States. Since the entity with the mandate to provide public transit service in these countries is often different than in the U.S., and given that the entities providing public transit service are organized differently, the concept of a "transit agency" and a "transit operator" differ between the non-U.S. case studies and the typical U.S. situation. Terms like "transit manager," "transit provider," or "transit company" can also mean different things in different contexts. To clarify, first a U.S.-style transit agency is briefly described, and then a German example is presented to illustrate a typical European model.

In the U.S., the transit service provider, referred to as the "transit agency," is most often either a quasi-independent entity authorized by state law as a special district or an agency owned and operated by the city or county. In the case of special district transit agencies, the transit system is not owned or operated by a political government jurisdiction, Yet the transit agency is dependent on various government entities for funding (both to provide public funding and/or to allow them to collect taxes). The transit agency is additionally dependent on permission to access roads and curbs for bus stops. Most of the transit districts for large cities are set up this way. In fact, some metropolitan areas have more than one special transit district: e.g., the Chicago metropolitan area and the San Francisco Bay Area. Those transit agencies owned by a city or county tend to be small and/or rural ${ }^{1}$ such as Asheville, NC, or Sonoma County, CA. The City and County of San Francisco is one of the large city exceptions. Boston is unique in that the Massachusetts Bay Transportation Authority (MBTA) falls under the State of Massachusetts. ${ }^{2}$ However, to put the MBTA in context, Massachusetts is an unusual state in that almost all of its population and economic activity is concentrated in one metropolitan area, which is also home to the state capital. ${ }^{3}$

The German model of public transit provision is often described as a model with three functional levels (see Figure 1). The levels are as follows:

1. The political authorities. The political authorities are the political government jurisdictions. This includes the state (Land), the counties, and the cities. 
2. The transit operators. The transit operators vary significantly; they could be departments of these cities, counties or states; and/or governmentowned companies; and/or private companies hired as contractors.

3. The regional transit coordinator (RTC), called the Verkehrsverbund (VVB) in German. The VVB /RTC ensures that all the transit actors within the same metropolitan area provide coordinated transit service in terms of schedules, fares, planning, and so on.

Thus, in Germany (and the rest of Europe), the provision of public transit is always directly tied to a local or state government (e.g., a city, county, or state), and said government takes ownership and responsibility for its performance and funding. The German word for this role is Aufgabenträger, which translates literally as "task carry-outer", that is, the person or group that carries out the task. (The other key difference between German public transit and U.S. transit is the existence of the RTC, which will be explored further in this research.)

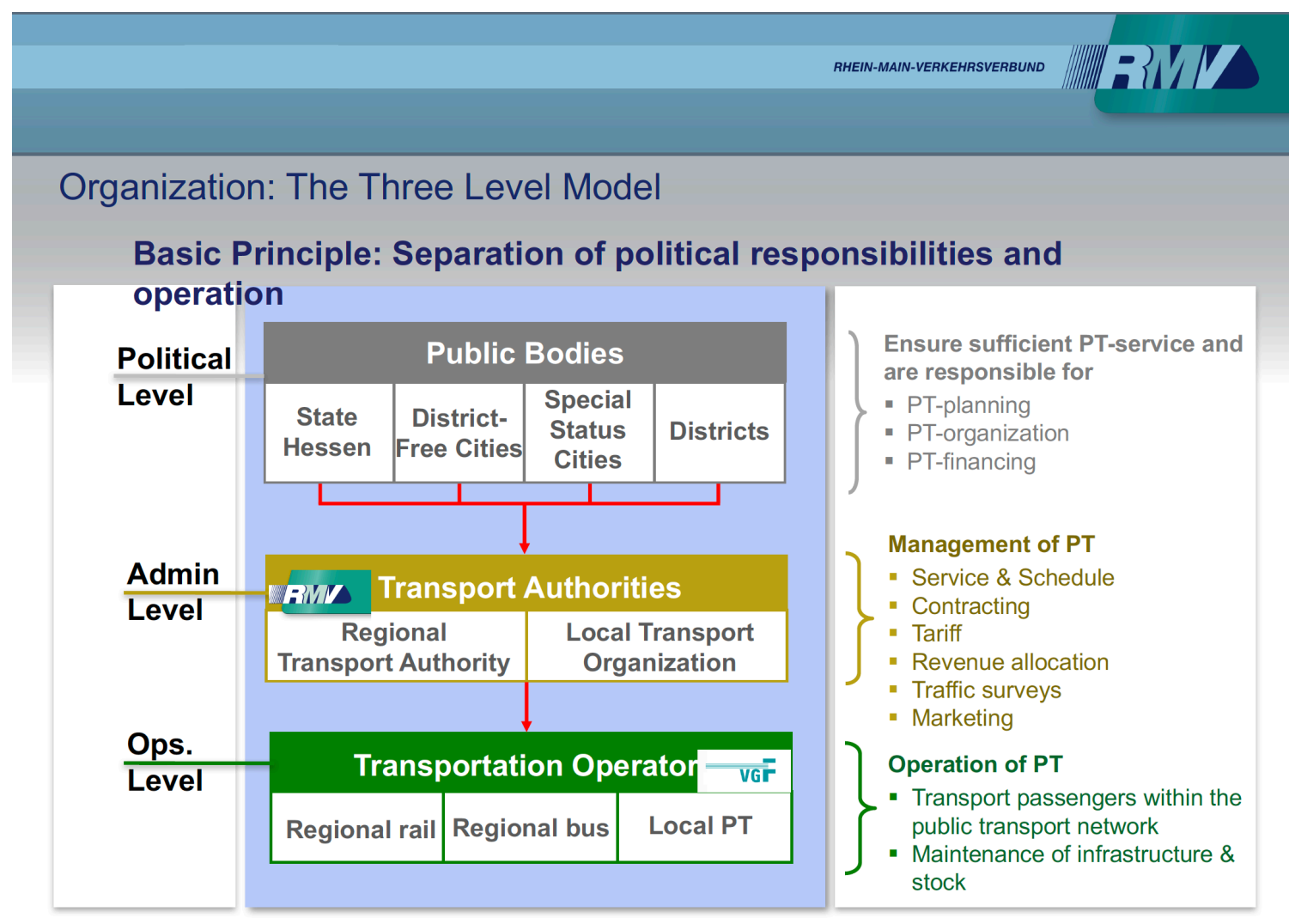

Figure 1. Three Levels Involved in German Public Transit ${ }^{4}$

For large European cities, these city transit departments (or city-owned transit companies such as SL in Stockholm, ATM in Milan, and TLC in Lyon) are from a 
user's perspective what the U.S. would call a "transit agency"; they are the "brand" that the customer sees, and they plan, design, and operate the transit service in their geographic area. The fact that the ownership and ultimate responsibility for public transit is tied directly to a political jurisdiction, however, is in contrast to many (if not most) U.S. transit agencies, which are organized as "special districts" or "joint powers authorities" with no direct tie to a political jurisdiction. ${ }^{5}$

Given the differences between the overall ownership and ultimate authority of these major European, Canadian, and Australian transit entities, and to avoid confusion with the U.S. model, this paper will avoid using the term "transit agency." The various terms will be used as follows.

\section{Regional Transit Coordinator (RTC)}

The Regional Transit Coordinator (RTC) is the entity responsible for ensuring that all the transit services in the same metropolitan area function as seamlessly as possible in terms of scheduling, transfers, single fare payment, long range planning, branding, marketing, etc. Except in those few metropolitan areas where there is only one Transit System Owner, the RTC typically functions as an alliance or association of the many system owners and the larger transit operators. Such an entity is called Verkehrsverbund in German; ${ }^{6}$ the English term often used in Europe is "Metropolitan Transport Authority" (MTA), and they themselves have organized as an association called European Metropolitan Transport Authorities (EMTA).

\section{The Public Transit System Owner}

The Public Transit System Owner is the entity that has the role and responsibility to plan and deliver transit service in a given geographic region. It could be the county or a major city, or even the national government, but it is responsible for a specific public transit service in its locale. As mentioned previously, the German word for this role is Aufgabenträger. The details of this structure and the specific duties conducted by the owner versus the operator vary considerably (e.g., who plans the routes), but the Public Transit System Owner is the ultimate responsible entity.

In Europe and in the Canadian and Australian case studies, the Transit System Owner is always a political jurisdiction: either a city, county, province, region, ${ }^{7}$ state or even national government. ${ }^{8}$ These governmental bodies provide the public funding necessary to provide transit service. Thus, the entities who provide the funding and the entities responsible for providing the transit service are the same. In the U.S., by contrast, the local Transit System Owner is often a quasi-independent special district with no direct ties to a governmental political jurisdiction.

With respect to operations, the Transit System Owner ensures that there is transit service by either operating the service in-house or contracting out the operations. The Transit System Owner typically sets the service terms (frequency and routes) 
to be performed by the operator. The Transit System Owner also ensures the development of short- and long-term plans that maintain, improve, and expand service. It is the overall director, manager, or overseer. If there is a Regional Transit Coordinator, some of these duties may be done by the RTC instead, such as hiring the operators and even determining the level of service.

\section{Transit Operator}

The Public Transit Operator is the entity delegated by the Transit System Owner to operate the specified transit service. Other terms used to refer to the operator are "transit company" or "transit provider." This report will use the term "operator."

The operator is responsible for putting the vehicles into service, hiring drivers, and maintaining the vehicles, if they own them. In general, the operator does not set the routes, the service frequency, or the fares, but rather it does what is specified by the system owner (or, in some cases, the RTC). For larger cities, the operators are typically: (a) a department of the city, county, or state government; (b) government-owned companies ${ }^{9}$ which run all modes of transit (in these cases some of the key decisions may be delegated to them by the Transit System Owner); or (c) an outside contractor hired to perform the service under terms specified in a contract. ${ }^{10}$ These latter two cases will be described in greater detail below.

An analogy for the role of a transit operator versus the system owner, when the owner is a local government, is street repaving. Some cities have their own internal street paving crews, whereas other cities tender it out to private contractors. In both cases, the streets are owned by the city and the work to be done is clearly specified by another process. Similarly, the transit service is the ultimate responsibility of the city, county, or state, and major infrastructure such as rail lines and bus stations are owned by the governmental political jurisdiction, but service operations, whether it be bus or rail, can either be tendered out to an operator or operated in-house.

\section{City-Owned Transit Companies}

A common organizational structure in Europe for transit operations is the cityowned, county-owned, or state-owned transit company. This company is the customer-facing brand name. To the casual observer, they may seem similar to a U.S.-style large "transit agency," but in these cases the owner is a city, county, or state, not a special district, and the government has direct accountability and indeed "ownership" in the success of the transit service. Examples are SSB light rail in Stuttgart, ATM in Milan, TCL in Lyon, TTC in Toronto, and TreNord in the state of Lombardy, Italy. ${ }^{11}$

\section{Transit Contractor}

A type of public transit operator, a transit contractor is an entity (private or public) that has been hired (typically via competitive bidding) by a transit entity (system 
owner or RTC) to provide a specific level of transit operations; most often it is bus service, but even rail operations can be tendered. Given the cost, transit operations contracts are often for long terms, such as ten years. It is typically these operators, not system owners, who are counted when describing the number of transit agencies or entities that an RTC coordinates. A not-so-unusual example of how this works is that ATM, the city-owned company that operates the Milan metro, trams, and buses, is also the contractor-operator of the Copenhagen metro/subway.

\section{TERMS FOR LEVELS OF GOVERNMENT AND GOVERNMENTAL AGENCIES}

\section{Governmental Political Jurisdiction}

For the purposes of this report, a governmental political jurisdiction is a state or local government administrative division with elected representatives, such as a state, county, or city with defined geographic boundaries, the ability to make laws and ordinances, and executive, judicial, legislative, enforcement, regulatory, and taxing authority. Just as important from the point of view of public transit is that the governmental political jurisdiction, most often the city, owns the roads on which surface public transit must operate. In this report, the terms governmental political jurisdiction, state or local government, or simply government will be used interchangeably.

In the ten case studies, these levels of government have various names and forms, even within the same countries-not all countries have the U.S. hierarchical system of city/municipality, county, state, and national levels. Furthermore, translations are often confusing; for example, the French régions and Italian regioni (regione in the singular) are both governmental political jurisdictions, but "region" in the U.S. has no connotation of being a government. The terms in the original languages and how they compare to U.S. levels of government are shown in Table 1 below.

Verband Region Stuttgart (VRS) of Stuttgart is a governmental political jurisdiction because it has directly elected political representatives. It is the only regional government found in these case studies, that is, a level in between the county and the state, and indeed it is the only example in Germany.

\section{State-Authorized Regional District}

For the purposes of this report, a "State-Authorized Regional District" is a government entity that operates under legislation from the higher governmental body which sets its governance structure and assigns it responsibility to deliver service to all municipalities within the same region on one or more issues of regional import such as transportation, water, and public safety. It is a separate political entity from existing governmental political jurisdictions, and it has taxation and sometimes land use authority. However, it does not meet the definition of a governmental political jurisdiction as defined by this report, as there is no tier of elected politicians. 
State-authorized regional districts have more power than regional coordinating bodies (see below) but do not have all the power and responsibility that goes with being a city or county. They can be considered hybrids in terms of form and function.

This research found three State-Authorized Regional Districts. Two were in Vancouver: the Greater Vancouver Regional District (GVRD) known as Metro Vancouver, and the separate entity in the same metropolitan area, TransLink. The third example was the Greater Manchester Combined Authority. ${ }^{12}$ Regarding TransLink, it is a distinct agency from Metro Vancouver, and it has two levels of governing boards. Furthermore, it has the taxation authority typically granted to governments and receives tax revenues directly from a variety of sources, including property taxes, fuel taxes, parking taxes, and auto toll revenues.

\section{Government Agency or Department}

A government agency or government department is a functional unit of an elected governmental political jurisdiction (or a State-Authorized Regional District) that implements the regulations and duties assigned to it by the governing council of its respective government. It is typically run by a hired or appointed department head, not an elected official. The title of the person in charge varies: e.g., secretary, general manager, chief executive, and executive director. An example of such an agency is Transperth, an agency of Public Transport Authority (PTA) which in turn is an agency of the State of Western Australia.

\section{Regional Coordinating Body}

A Regional Coordinating Body $(\mathrm{RCB})$ is an entity with specific duties with respect to an issue of regional concern involving the coordination of multiple municipalities and counties. Although usually not state government agencies (Perth and Sydney being exceptions), they are typically created from state legislation but have narrow scope and no taxation authority. For the purposes of this report, when an RCB is created for the specific issue of regional public transit coordination, it is called a Regional Transit Coordinator (RTC). Several of the case study areas have RCBs that manage other aspects of regional concern such as waste management, water, parks and open space, and/or public health.

\section{Special District Transit Agencies}

Although not found in this research, "Special District Transit Agencies" are defined here since they are a common structure in U.S. Such agencies are authorized by state law to provide a specific type of transit service in a specific geographic area but typically have no other purview or authority such as taxation, use of public streets, or land use. Thus, they must negotiate with the cities in which they operate for everything from bus-only lanes to signal preemption to bus stop locations. Funding comes from a variety of sources that vary widely depending on the county or state. Funding rarely comes from the cities they serve, despite the cities having 
land use approval authority and the authority to enact developer fees.

\section{Region Versus Metropolitan Area Versus Greater City}

This report generally uses the terms "region" and "metropolitan area" interchangeably, recognizing that in some European countries, "region" could refer to governmental political jurisdictions. For example, regione in Italian and région in French refer to the state-level governmental body, and län is often translated from Swedish as either region or county. Other countries use other terms for a metropolitan area, including conurbation and agglomeration, which may or may not refer to an official organization, alliance, or consortium of several governmental bodies.

Some metropolitan areas, particularly in the Commonwealth countries, use the term "Greater"-which is a bit ambiguous, since the definition varies across time and geographic location. It could refer to a geographic area with either specific or general boundaries or to a government body or agency. In some cases, foreign metropolitan areas have also been translated as "Greater," e.g., Greater Stuttgart, Greater Lyon, and Greater Barcelona. 
Table 1. Administrative Divisions of State and Local Governments in the U.S. Compared to Case Study Countries

\begin{tabular}{|c|c|}
\hline U.S. Term & Terms Used in Other Countries (foreign words are italicized) \\
\hline $\begin{array}{l}\text { City, Town, } \\
\text { Village, Mu- } \\
\text { nicipality }\end{array}$ & $\begin{array}{l}\text { Canada: City, town, municipal borough, urban district, urban authority } \\
\text { Australia: local government area (LGA) (1) } \\
\text { Terms in other languages: comune (IT), commune (FR), Stadt or Gemeinde (DE), stad (SE), } \\
\text { municipios or concejos (ES) }\end{array}$ \\
\hline County & $\begin{array}{l}\text { France: department; some are now metropolis(es) (métropole(s). } \\
\text { Germany: Landkreis, often translated as "rural district". Larger cities including Stuttgart and } \\
\text { Frankfurt are not part of such a level of government. They can be considered city-counties. (4) } \\
\text { Italy: provincia; some are now metropolitan cities. } \\
\text { Spain: provincias (províncies in Catalan). } \\
\text { Sweden: län. Note there is only one level between city-municipal level and the national level; } \\
\text { they can be considered states or counties. } \\
\text { Australia: none. (2) } \\
\text { Canada: depends on the province. Ontario: county (rural areas) or regional municipalities; sin- } \\
\text { gle-tier cities like Toronto and Hamilton are not part of either a county or a regional municipal- } \\
\text { ity. British Columbia: no counties; there are five regional districts. (3) }\end{array}$ \\
\hline State & $\begin{array}{l}\text { France: région (there are } 13 \text { régions in Europe, } 12 \text { on the continent plus Corsica). } \\
\text { Germany: Land (there are } 16 \text { Länder). } \\
\text { Italy: regione (there are } 20 \text { regioni). } \\
\text { Spain: Comunidades autónomas (Spanish), comunitats autònomes (Catalan), autonomous } \\
\text { communities or "autonomies" (English); there are } 17 . \\
\text { Sweden: län. Note there is only one level between city-municipal level and the national level; } \\
\text { they can be considered states or counties. There are } 21 \text { länen. } \\
\text { Australia: state (there are six states plus territories). } \\
\text { Canada: province (there are ten provinces plus three territories) }\end{array}$ \\
\hline Country & $\begin{array}{l}\text { State, sovereign state, country } \\
\text { Terms in other languages: état or pays (FR), paese or stato (IT), Bundesland (DE), land (SE) }\end{array}$ \\
\hline \multicolumn{2}{|c|}{$\begin{array}{l}\text { AU=Australia; CA=Canada; DE=Germany; ES=Spain; FR= France; IT=Italy; SE=Sweden. } \\
\text { Notes: } \\
\text { (1) Australia local governments have a variety of names including "borough," "city," "district," "municipality," "village," or "re- } \\
\text { gion." The term "local government area" (LGA) is used to refer collectively to all local governments, whilst the local jurisdiction } \\
\text { itself is generally known as a council. In general, an urban or suburban LGA is called a city. } \\
\text { (2) In Australia, there is only one level of local government in each state, there is no level in between the smallest unit, i.e., the } \\
\text { LGA, and the state. } \\
\text { (3) In British Columbia, there are no counties but there are regional districts which have different authority than counties. } \\
\text { (4) Smaller towns are all part of a Landkreis or rural district. Larger cities, typically with more than } 100,000 \text { inhabitants (smaller } \\
\text { towns in some states), do not belong to a Landkreis district, they are their own district-somewhat similar to a city-county in } \\
\text { the USA. There are } 294 \text { Landkreis and } 107 \text { city-districts. }\end{array}$} \\
\hline
\end{tabular}




\section{INTRODUCTION}

\section{PURPOSE}

A well designed and properly managed regional public transportation system is a critical component of the major and medium-sized metropolitan areas in the developed world. Convenient, reliable, fast, and affordable public transit provides access to jobs and other necessities, reduces automobile dependence, promotes livable communities, and contributes to the overall economic vitality of the metropolitan area. ${ }^{13}$ An effective and well utilized transit system is also important to reduce the use of fossil fuels and the adverse impacts of automobiles on the environment, including greenhouse gas emissions and other contributors to climate change, while improving public health and reducing traffic fatalities and injuries. However, in the U.S., questions remain about how to improve transit services, and, ultimately, how to increase transit mode share. Recent calls have sought major new sources of transportation funding at all levels of government, such as the Green New Deal proposal at the national level and the proposed regional transportation funding measures at the metropolitan level in the San Francisco Bay Area. Hence, it is a timely pursuit to describe objectively and (wherever possible) quantifiably what features of metropolitan area transit systems, both those that passengers directly experience and those that are "behind the scenes," contribute to the high ridership and mode share seen in some metropolitan areas.

The urgency of this issue is illustrated by the recently published Transit Cooperative Research Program (TCRP) Research Report Analysis of Recent Public Transit Ridership Trends ${ }^{14}$, which found that transit ridership in the U.S. has decreased across all modes except commuter rail. Bus ridership has declined the most in midsize cities (populations of 200,000-500,000), and it is at its lowest level overall since the $1970 \mathrm{~s} .{ }^{15}$ As of the writing of this paper, the COVID-19 pandemic has created still greater urgency to address the underlying conditions that lead to low transit ridership and/or ridership growth in the United States. Many transit agencies are facing historic service cuts due to revenue shortfalls that could further reduce transit use.

The research question to be answered in this study is: "What are the replicable factors in metropolitan public transportation that make transit an effective competitor to the private motor vehicle?" The research hypothesis is that there are replicable factors for success that contribute to making transit a highly competitive travel mode across a region. This project seeks to identify the key characteristics of highly effective transit networks from the perspective of the metropolitan area, not individual transit operators. These characteristics include both the customerapparent features such as fare policy and transit frequency and the organizational, governing, and coordination features necessary at the regional scale.

Once the features of excellent regionwide transit service are identified, it is hoped that policy makers and planners in the U.S. can work to change the appropriate aspects of their own regional transit networks and organizational structures, with 
the aim of improving public transit in U.S. metropolitan areas, yielding more effective, higher ridership and more accessible public transit systems.

\section{METHODOLOGY}

This project will identify the specific characteristics, policies, and practices that are apparent to the customer and the institutional characteristics that make for a highfunctioning, world-class metropolitan transit system. It employs a scan of case studies from ten metropolitan areas in Europe, Canada, and Australia to identify these success factors ${ }^{16}$. As this study was not an in-depth evaluation of each of the ten metropolitan areas, the findings are intended to be suggestive, rather than definitive, and thus it is meant to identify promising policies and concepts for further, more in-depth research.

The principal methods employed were a scan of the available documents and literature, web-based research and data collection, and direct questions to staff or regional planners as needed. Case studies in foreign metropolitan areas were limited to the developed western countries of Canada, Australia, and countries in western Europe since their cities and metropolitan areas are the most similar to those of the U.S. in terms of population, density, and culture, including wealth and car ownership, as compared to countries in China and South America, for example.

The first step of the research was the selection of the specific metropolitan areas to serve as case studies, described in more detail below. The next phase involved compiling and evaluating data describing the characteristics of each of the regional mass transit systems within these metropolitan areas and identifying the common characteristics of these successful and effective transit systems. While the results may not be statistically significant, they are nevertheless intended to be illustrative of which regional characteristics, policies, and practices are associated with effective, well patronized transit networks. This research fills a gap in the literature since it focuses on the whole metropolitan area, whereas past research has focused on individual agencies or modes without addressing the regional aspects or the interdependency of multiple modes and/ or operators.

The characteristics to be investigated fall into four main categories:

4. Metropolitan Area Background and Setting: Data such as population, land area, and political setting.

5. Regional Transit Coordinating Agency: Existence of an agency responsible for regional transit coordination, as well as its structure and relation to political jurisdictions.

6. Customer-Apparent Characteristics: Quality/level of service, mode diversity, regional fare structure, service coordination, etc.

7. Transit Finance: Regional transit budgets, funding sources, and investments in public transit. 


\section{SELECTION OF THE CASE STUDY METROPOLITAN AREAS}

Potential case studies were selected from medium and large metropolitan areas of the larger western European countries (France, Spain, Italy, Germany, England, Austria, Sweden, Denmark, and Norway) plus Canada and Australia. The population data and other characteristics of the main cities of these countries were reviewed. The ten case studies from metropolitan areas were selected based on the following criteria:

- Size: Similarity to a large range of U.S. metropolitan areas; a population range of the $4^{\text {th }}$ through $54^{\text {th }}$ most populous U.S. regions translates to a population between about 8 million (e.g., Dallas-Fort Worth with 7.5 million) and 1.5 million (e.g., Milwaukee metropolitan area with 1.6 million).

- Governmental and Institutional Structures: Case study metropolitan areas were selected in part to ensure that a variety of governmental structures were represented (e.g., those metropolitan areas contained within one geographic governmental political jurisdiction-such as one county-and those comprising several such jurisdictions).

- Transit Performance: The research team selected metropolitan areas with higher-performing transit systems relative to other cities in their countries, both in terms of transit mode share for the region and the major city.

- Data Availability: Access to data was an important consideration for determining which metropolitan areas would be included in this study. Therefore, throughout the process of reviewing potential candidate case studies, the research team continually assessed the viability of each case based on data access and usefulness.

Of the metropolitan areas within the population range, it was desired to have both polycentric and monocentric metropolitan areas ${ }^{17}$ and a variety of government structures. No more than two metropolitan areas per country were selected to prevent findings that would be biased based on one country's approach. Of the remaining metropolitan areas, those with the highest transit mode share for both the major city and the region as a whole were selected for further study. The final metropolitan areas were also selected in order to include a diversity of metropolitan urban forms, e.g. including variation in size of the major city with respect to the rest of the metropolitan area. For European cases, there was a tendency to select areas belonging to the European Metropolitan Transport Authorities (EMTA) in order to facilitate data collection and consistency: five of the six European cases selected are EMTA members. At least one case study each from Canada and Australia was desired (if found to have high public transit use), since their metropolitan land use patterns and cultures are generally similar to those found in the U.S. and might offer some useful insights. Table 2 presents the list of cities/regions from which the final ten regions were selected, identifying the final ten in bold text. 
The ten selected cases studies:

- $\quad$ are from western/developed economies

- are members of the Organization for Economic Cooperation and Development (OECD) (35 member countries)

- have a metropolitan area population size between 2 and 6 million inhabitants

- are areas with a regional transit mode share of $15 \%$ or higher (except for the area of Greater Perth) and a major city transit mode share between $23 \%$ and $40 \%$

- have car ownership rates of at least the average of the European OECD states $(475$ per 1,000$)$

- include metropolitan areas contained within a single political jurisdiction as well as metropolitan areas composed of many separate jurisdictions,

- include polycentric and monocentric regions, and

- include two regions from Canada and Australia. 
Table 2. Considered and Selected Case Study Metropolitan Areas

\begin{tabular}{|c|c|c|c|c|}
\hline $\begin{array}{l}\text { Major City in } \\
\text { Metropolitan } \\
\text { Area }\end{array}$ & $\begin{array}{l}\text { City/Metro. Area Popula- } \\
\text { tion (1,000 inhabitants) } \\
\text { (1) }\end{array}$ & $\begin{array}{l}\text { Cars per } 1,000 \text { Inhabit- } \\
\text { ants } \\
C=\text { citywide; } R=\text { regionwide; } \\
N=\text { nationwide (2) }\end{array}$ & $\begin{array}{l}\text { Major City } \\
\text { Transit Mode } \\
\text { Share (3) }\end{array}$ & $\begin{array}{l}\text { Metropolitan } \\
\text { Area Transit } \\
\text { Mode Share (3) }\end{array}$ \\
\hline Copenhagen & $718 / 1,919$ & $438-\mathrm{N}$ & 17 (all) & 9 (all) \\
\hline Oslo & $673 / 1,381$ & $514-\mathrm{N}$ & 33 (all) & 26 (all) \\
\hline Stockholm & $950 / 2,270$ & $479-\mathrm{N}$ & 40 (all) & 37 (all) \\
\hline Lyon & $655 / 1,952$ & $478-\mathrm{N}$ & 25 (all) & 19 (all) \\
\hline Frankfurt & $742 / 5,400$ & $561-\mathrm{N}$ & 40 (all) & 19 (all) \\
\hline Stuttgart & 632 / 2,737 & $570-\mathrm{R}(4) / 561-\mathrm{N}$ & 23 (all) & N/A \\
\hline Turin (5) & $883 / 1,760$ & 677-R (5) / 615-C (5) & 24 (all) & 16 (all) \\
\hline Milan (5) & $1,352 / 5,101$ & $513-\mathrm{C} / 561-\mathrm{R}(5) / 625-\mathrm{N}$ & 38 (all) & 21 (all) \\
\hline Barcelona & $1,620 / 4,926$ & $504-\mathrm{N}$ & 34 (all) & 20 (all) \\
\hline Valencia & $788 / 1,734$ & $504-\mathrm{N}$ & 21 (all) & 14 (all) \\
\hline Vancouver & 632 / 2,457 & $685-\mathrm{N}$ & $\begin{array}{l}18 \text { (all) } \\
25 \text { (work) }\end{array}$ & $\begin{array}{l}12 \text { (all) } \\
18 \text { (work) }\end{array}$ \\
\hline Toronto & 2,954 / 6,895 & $685-\mathrm{N}$ & 28 (all) & 16 (all) \\
\hline Montreal & $2,033 / 4,515$ & $685-\mathrm{N}$ & 25 (all) & 18 (all) \\
\hline Sydney & $208 / 5,030$ & $504-\mathrm{R} / 296-\mathrm{C}(6) / 730-\mathrm{N}$ & 35 (work) & 22.8 (work) \\
\hline Perth & $28 / 2,022$ & $730-\mathrm{N} / 646-\mathrm{R} / 367-\mathrm{C}(6)$ & 25.9 (work) & 10.3 (work) \\
\hline Manchester & $543 / 3,348$ & $471-\mathrm{N} 2017$ & 18 (all) & 13 (all) \\
\hline Helsinki & $643 / 1,490$ & 617-N 2017 & 34 (all) & 26 (all) \\
\hline \multicolumn{5}{|c|}{$\begin{array}{l}\text { Boldface indicates selected case study area. } \\
\text { Note: for mode share, it is often unclear whether the figure represents all trip purposes or only work-school trips; where it } \\
\text { could be verified, it is indicated. } \\
\text { Sources: } \\
\text { (1) City population from EMTA Barometer Report ( } 2017 \text { data) except Milan, Vancouver, Toronto, Sydney and Perth from re- } \\
\text { spective city websites. Metro area population from OECD, https://stats.oecd.org/. } \\
\text { (2) European national data from Eurostat } 2019 \text { ( } 2017 \text { data); Australia and Norway from } \\
\text { https://en.wikipedia.org/wiki/List of countries by vehicles per capita; city and regional data as indicated. } \\
\text { (3) Europe and Montreal: EMTA barometer report (2017 data) except Milan-, from Donati et al. and Frankfurt, from RMV. } \\
\text { Vancouver: Vancouver Trip Diary ( } 2017 \text { data); Toronto: Toronto Travel Survey (2016 data); Sydney and Perth: Australia Bu- } \\
\text { reau of Statistics ( } 2016 \text { census). } \\
\text { (4) Stuttgart VRS: Facts \& Figures } 2015 \text { data. } \\
\text { (5) Donati et al. (2019), } 2017 \text { data. } \\
\text { (6) Data for Sydney and Perth calculated from data from Australia Bureau of Statistics. }\end{array}$} \\
\hline
\end{tabular}


Of the ten selected case studies, data for some areas were easier to find than for others. Thus, the level of detail is not uniform for all case studies. However, given the nature and purpose of this study, the research team decided that it was better to provide more detail when possible rather than leaving out information that proved to be useful or interesting. Furthermore, in some but not all cases, a local contact was found who responded to requests for additional or clarifying information, which also contributed to greater detail in some metropolitan areas compared to others.

Finally, as Hirschhorn et al. found in their comparison of metropolitan transit governance in Europe, Australia, and Canada, the practice of systematically publishing performance data is not widespread, and terminology and calculation methods for performance metrics are not standard across different countries. ${ }^{18}$ The present research revealed the truth of this claim-not only for performance data but also for other background information, descriptive data, and general terminology (i.e., definitions and nomenclature). ${ }^{19}$ In these cases, the research team worked to provide consistent nomenclature and measurement techniques wherever possible. 


\section{METROPOLITAN AREA CASE STUDY DESCRIPTIVE INFORMATION AND ANALYSIS}

Information describing and comparing the key characteristics of the ten metropolitan areas selected as case studies and their primary cities was gathered, calculated, and evaluated. These characteristics include the following.

- Population

- "Primacy" (main city percentage share of metropolitan population)

- Surface Area (square kilometers)

- Population Density

- Metropolitan Area Transit Ridership (total annual transit patronage)

\section{POPULATION}

Figure 2 shows the population of each case study metropolitan area and its main city.

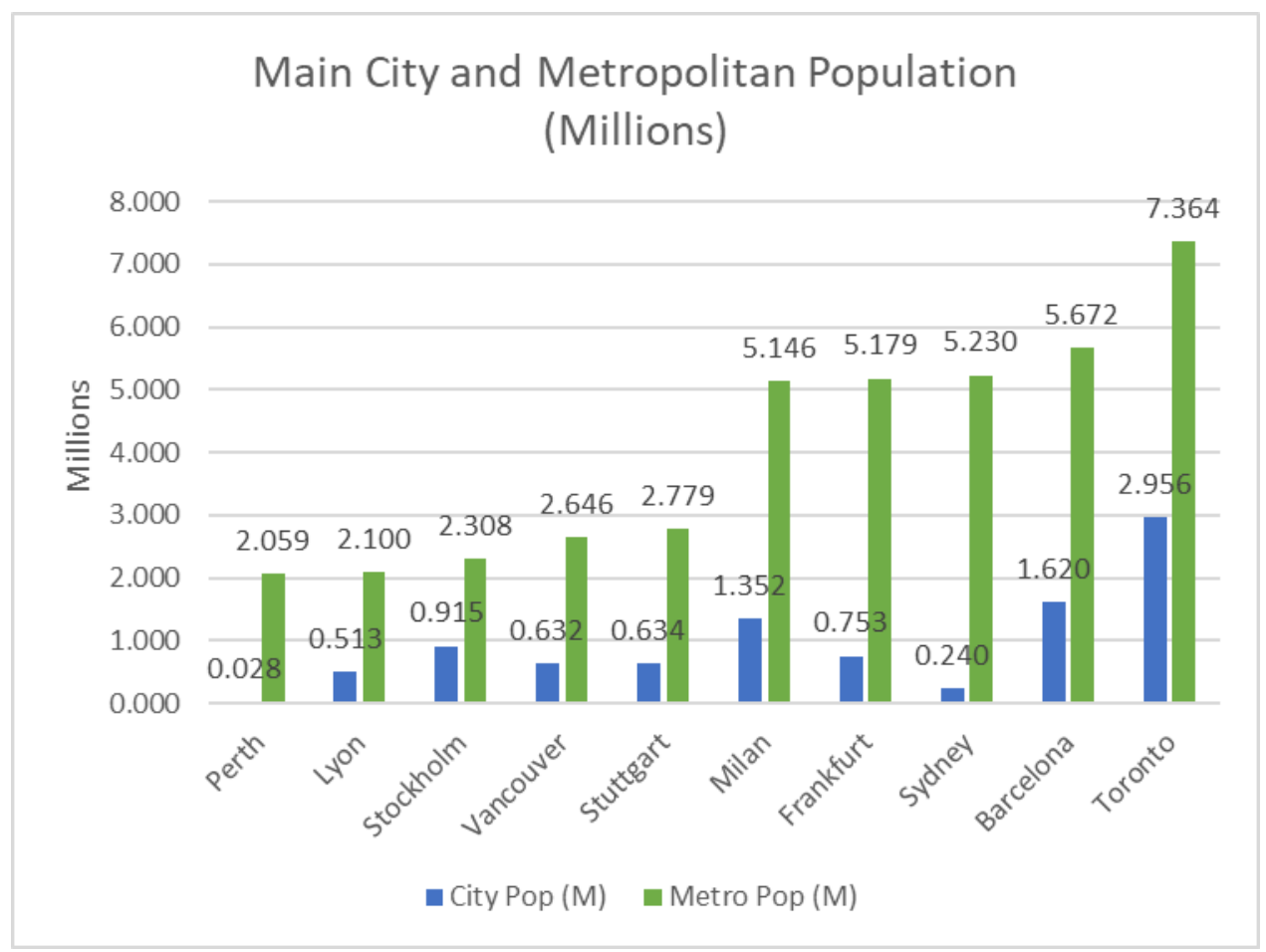

Figure 2. Population of Each Case Study Metropolitan Area and Main City ${ }^{20}$

Metropolitan area case study populations range from a low of 1.9 million for Lyon to a high of 7.4 million for Toronto. Five of the regions had populations in the 2 to 3 million range, while four regions had populations around 5 million. Among the 
case study regions, main city populations ranged from a low of 28,000 for Perth to a high of 3.0 million for Toronto.

\section{PRIMACY}

"Primacy," 21 measured here as the main (central) city's percentage share of the metropolitan area's population, can serve as a rough indicator of how much political influence the central city may have within its region. As such, primacy may also be used as an indicator of the central city's ability to influence transit services within its region.

Figure 3 shows the calculated primacy of each main city within its metropolitan region.

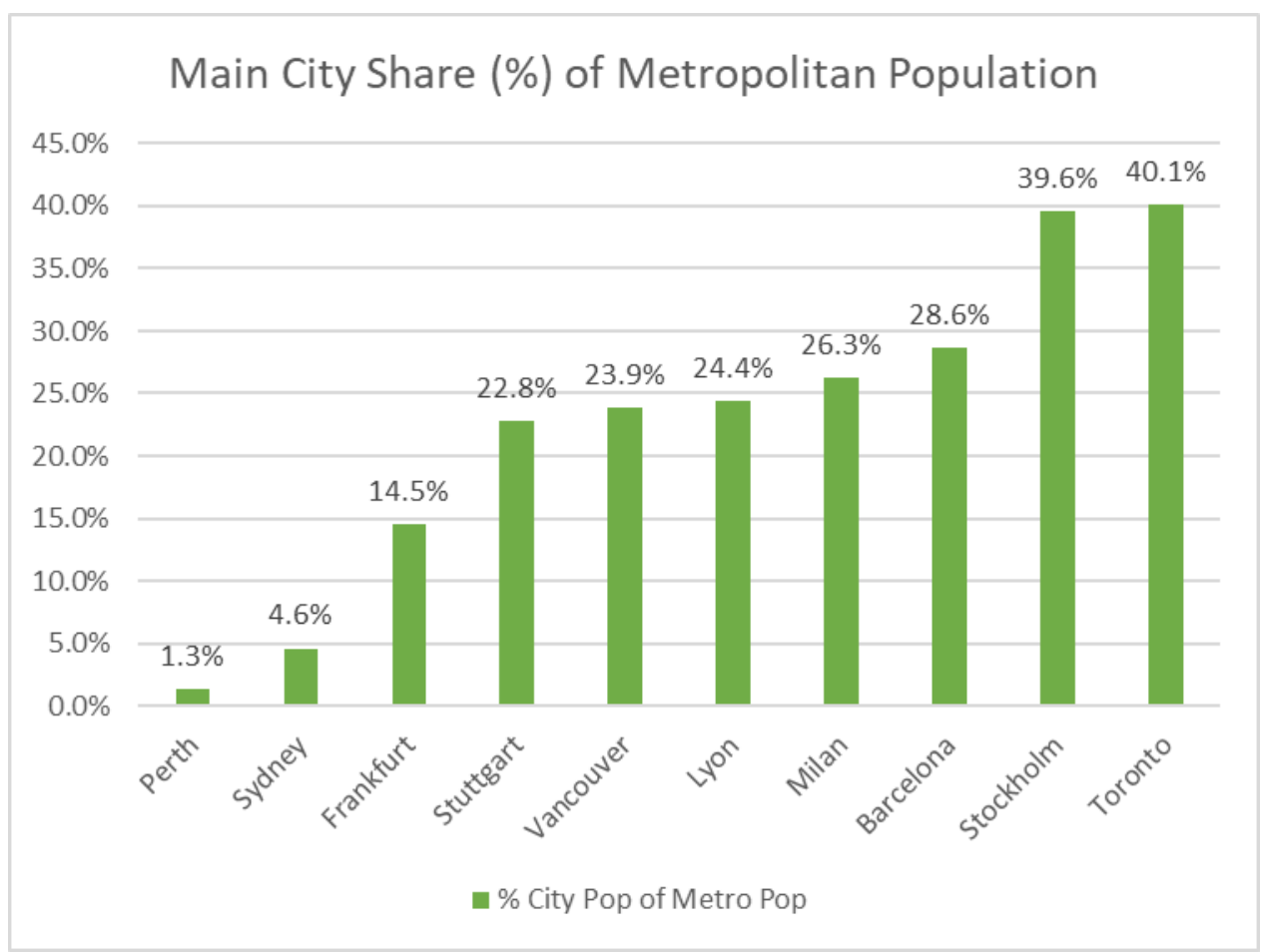

Figure 3. Main City's Percentage Share of its Metropolitan Population (Primacy) ${ }^{22}$

Main city primacy shares range from a low of 1.3 percent for Perth to a high of 40.1 percent for Toronto. While Lyon has the lowest metropolitan population, its primacy of 24.4 percent places it in the middle of the pack when it comes to the main city's potential for influencing regional transit, suggesting that if the concentration of population aligns with a concentration of political influence, then the city has greater potential than those areas with lower primacy scores (e.g., Perth or Sydney) with respect to influencing regional transit funding choices.

Perth has the lowest metropolitan and main city populations, and furthermore, it also has the lowest primacy level. Toronto has the distinction of having the 
highest metropolitan and main city populations and the highest primacy level as well.

\section{POPULATION DENSITY}

Population density is an important characteristic - at both the city and the metropolitan level-in determining transit ridership. Assuming a constant level of quality transit service, high-density urban areas will tend to have high levels of transit ridership, and transit will capture a large mode share.

Figure 4 shows the calculated densities for each main city and metropolitan region.

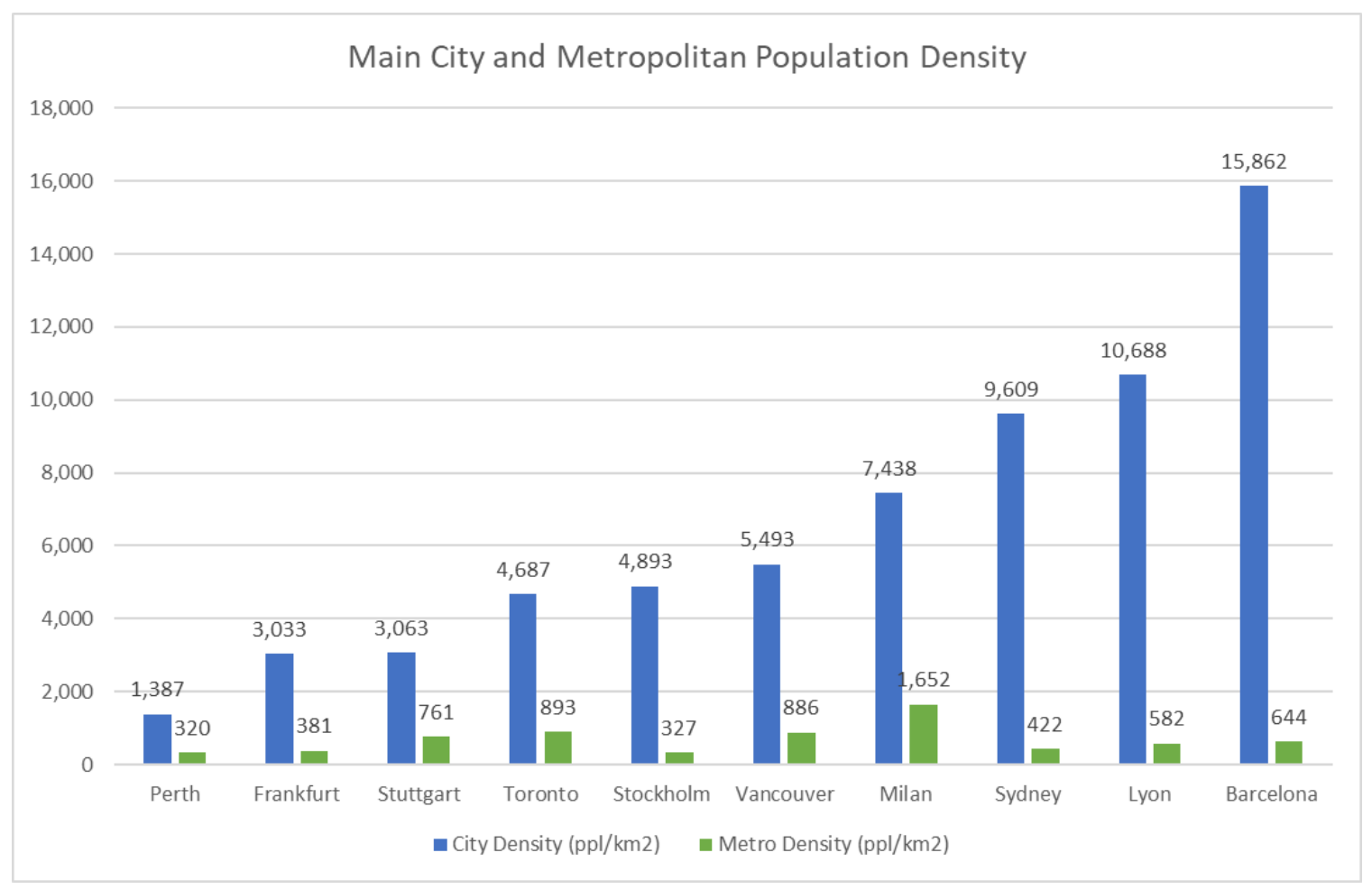

Figure 4. Main City and Metropolitan Area Population Density ${ }^{23}$

Perth, with the lowest main city population and second-lowest metropolitan population of the group, also had the lowest main city and metropolitan area densities. While Barcelona's metropolitan population placed it roughly in the middle of the case study group's distribution, it had the highest main city population density. The City of Lyon is notable here for its second-place density ranking, but it is average among the other case studies when it comes to its metropolitan density. Therefore, while the city's primacy ranking (see Figure 3 ) is very high, this potential regional influence does not appear to have translated into influence over regional land use decisions (affecting density) at the metropolitan level. Evaluation of ridership and transit finance data will follow in light of these findings. 
Consistent with expectations, the population densities of the central cities are always higher than their metropolitan regions, which typically include low-density suburbs, and in some cases, rural communities as well.

\section{TRANSIT RIDERSHIP}

It may seem reasonable to assume that total metropolitan area ridership is largely a function of population. In other words, one might expect that the larger the region, the more people will ride transit. However, as it turns out, population density and the quality of the transit service are also key factors determining total ridership. Smaller but high-density regions can generate higher total ridership than larger regions with lower densities and less transit service.

Figure 5 shows the total transit ridership for each metropolitan region.

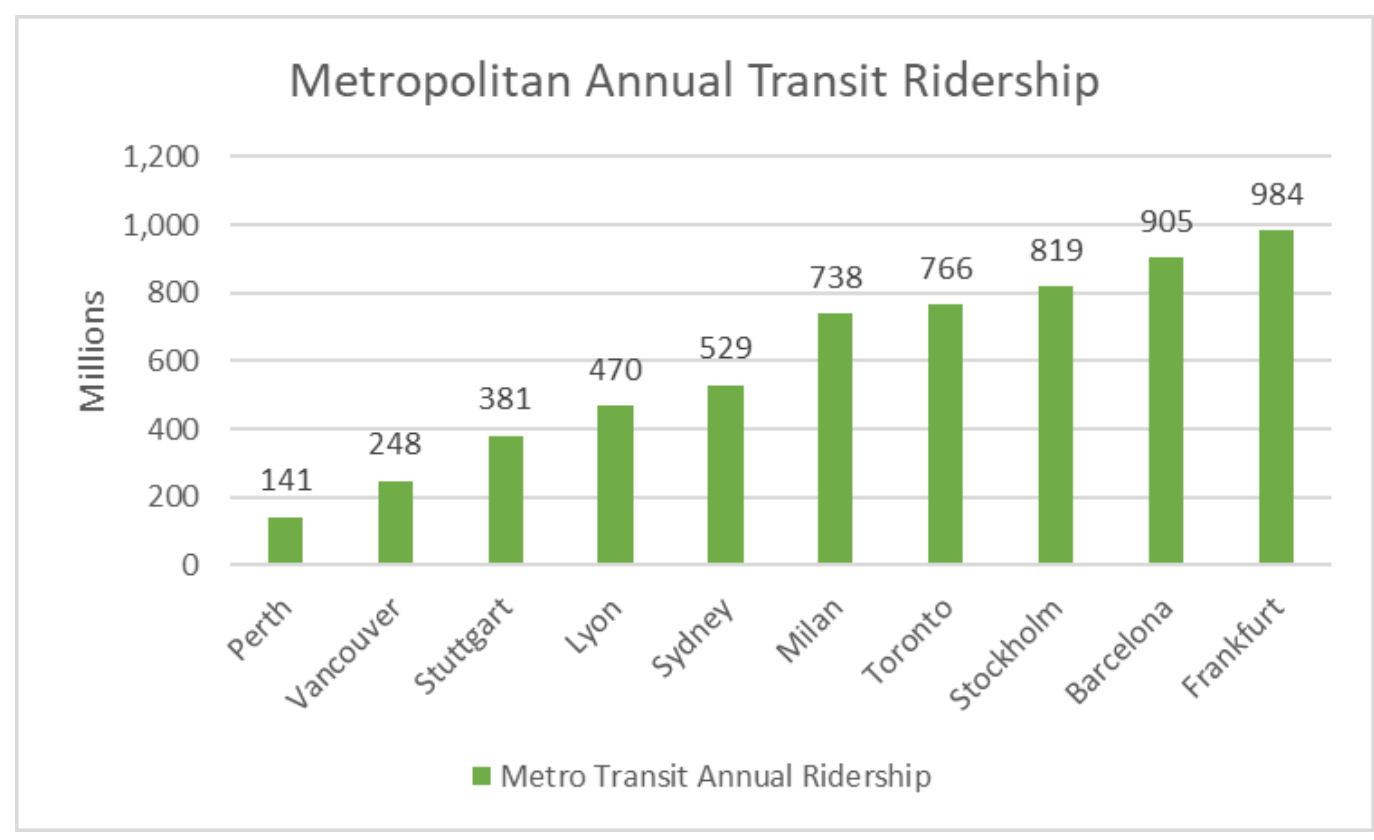

Figure 5. Annual Transit Ridership for Metropolitan Area Case Studies ${ }^{24}$

As seen with previous metrics, Perth ranked at the bottom in terms of total annual transit ridership. However, the top region in terms of annual transit ridership is not the largest (Toronto), nor the region with the largest central city relative to metropolitan population (Toronto), nor the region with the highest central city density and regional density (Barcelona). The best-performing region in terms of total transit ridership is Frankfurt.

Larger regional populations not only provide more potential riders, but they are often also developed at higher densities, providing greater incentives for people to rely on transit for their daily travel needs. In addition, large regions have more resources for transit infrastructure and operational budgets. With more investments, transit becomes more competitive with other modes, thereby increasing ridership 
in a virtuous cycle. However, political will and institutional capacity are required to ensure that the benefits of a large, metropolitan population are successfully translated into measurable transit ridership outcomes.

\section{TRANSIT RIDERS PER CAPITA}

Calculating the number of annual transit riders per capita (see Figure 6) provides a picture of the relative success of each region's efforts to capture transit mode share.

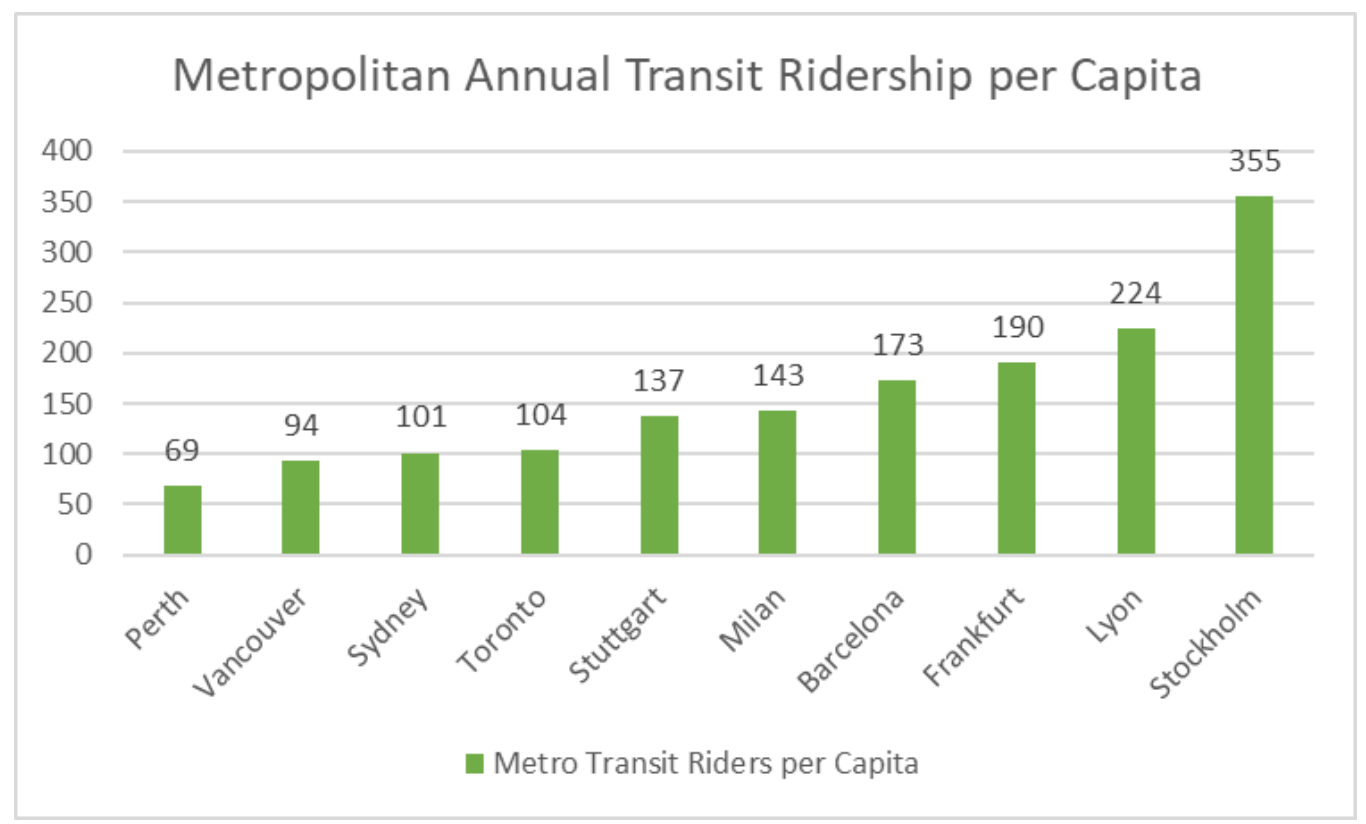

Figure 6. Annual Transit Ridership per Capita for Metropolitan Area Case Studies ${ }^{25}$

Just as seen for population, primacy, density, and transit ridership, Perth ranked among the lowest in terms of annual ridership per capita. This suggests that Perth is playing at a disadvantage compared to the other case study regions because it is relatively small, it has a small central city, and it has a relatively dispersed (lowdensity) settlement pattern. Thus, it is not surprising that its total annual ridership per capita is also the lowest of the ten case studies.

Lyon's second-place ranking in the category of riders per capita suggests that the region's high primacy score may translate into a regional priority (i.e., political will) for effective transit. In this report, subsequent evaluation of transit finance data may indicate whether this priority manifests in terms of regional spending on transit, and by implication, the degree to which Perth may be employing effective regional transit coordination methods as well.

Interestingly, despite having the lowest total population ranking of the ten case studies (just slightly higher than Perth), Stockholm ranks highest among the ten 
metropolitan areas in terms of riders per capita. In fact, Stockholm's per capita ridership is dramatically (roughly 59\%) higher than that of Lyon, its nearest peer on this scale.

This finding identifies Stockholm as a unique case study, worthy of further investigation. How has this small metropolitan region managed to capture such incredibly high transit ridership? This high ranking can be explained, at least in part, by its second-place showing in the primacy category, suggesting the central city has higher-than-normal political influence in its region compared to main cities in other case study regions. Nevertheless, its small size and mid-range population densities suggest that something else is at work. Chapter $\mathrm{V}$, which examines transit finance data, provides further investigation and illumination of this success story. 


\section{REGIONAL TRANSIT COORDINATION, INSTITUTIONAL CLIMATE, AND GOVERNANCE SETTING}

This part of the research looks at the behind-the-scenes, institutional factors that contribute to high-quality public transit and the accompanying high ridership. The following questions were considered for each selected region.

1. Does the region have an entity responsible for coordinating all transit service in the metropolitan area?

2. How is that body governed?

3. What specific roles is it responsible for coordinating?

It was indeed found that all ten of the case study metropolitan areas had such an agency, which will be referred to as a Regional Transit Coordinator (RTC). Some had been established relatively recently, and some have been in existence for decades. Many have developed and evolved over a decade or more, gradually assuming more and more duties. While they ultimately have the same role in coordinating all public transit, the governance structure of these RTCs was found to vary vastly, and there was even variation found within the same country.

Since there was no single model or governance structure for the RTCs found in this research and given the apparent influence that RTCs have on the customerfacing characteristics which leads to increased ridership (to be discussed in Chapter IV), this chapter will describe each RTC and its governance boards. The purpose is to illustrate the range of ways that RTCs have been set up, in some cases how they evolved, and how they are currently governed and managed. The following discussion will demonstrate that even though having an RTC is a common denominator, there is more than one successful model and there are a variety of ways to establish an RTC. It is this paper's intention to provide useful information from the ten case studies for those metropolitan areas that lack regional transit coordination in addition to providing novel ideas for how best to approach such issues.

Since a Regional Transit Coordinator by definition has a specific geographic area to coordinate, this chapter will first describe the geographic purview of each case study RTC, which in most areas is a well-defined metropolitan area. However, as was discovered in this study, the area considered to be the metropolitan area has often expanded over the decades along with population growth; in more recent years, sometimes an even broader geographic area than the metropolitan area has been assigned to the RTC. It was additionally found that the creation of an RTC was often-but not always-preceded by or concomitant with the creation of a regional agency of some sort at the metropolitan area level. In the case of 
Stuttgart, the reverse was found to be true: the RTC was created before the regional government. This information is summarized in Table 3.

Given the relationship between the metropolitan area and the RTC, the following discussion first presents a brief description of each metropolitan area and then describes the corresponding RTC. European case studies are presented first, followed by those from Canada and Australia.

\section{Table 3. Year Created: Regional Transit Coordination versus Regional Gov- ernmental Organizations}

\begin{tabular}{|c|c|c|c|}
\hline $\begin{array}{l}\text { Metropolitan } \\
\text { Area }\end{array}$ & $\begin{array}{l}\text { Regional Government } \\
\text { or Consortium* }\end{array}$ & $\begin{array}{l}\text { Regional Transit } \\
\text { Coordinator (RTC) }\end{array}$ & $\begin{array}{l}\text { RTC significantly reor- } \\
\text { ganized or expanded }\end{array}$ \\
\hline $\begin{array}{l}\text { Stockholm } \\
\text { County }\end{array}$ & 1967 Stockholm County & $\begin{array}{l}1967 \text { TFV (an } \\
\text { agency of Stock- } \\
\text { holm County) }\end{array}$ & - \\
\hline $\begin{array}{l}\text { Greater } \\
\text { Stuttgart }\end{array}$ & $\begin{array}{l}\text { Verband Region } \\
\text { Stuttgart (VRS) } 1994\end{array}$ & 1978 VVS & - \\
\hline $\begin{array}{l}\text { Frankfurt Rhein } \\
\text { Main }\end{array}$ & $\begin{array}{l}2011 \text { Regional Authority } \\
\text { FrankfurtRheinMain* }\end{array}$ & $1995 \mathrm{RMV}$ & - \\
\hline Greater Lyon & $\begin{array}{l}1969 \text { COURLY*; } 2015 \\
\text { Metropolis of Lyon }\end{array}$ & $\begin{array}{l}1974 \text { TCL for Lyon } \\
\text { metro area }\end{array}$ & 1985 SYTRAL \\
\hline $\begin{array}{l}\text { Greater } \\
\text { Barcelona }\end{array}$ & $\begin{array}{l}2010 \text { Metropolitan Area } \\
\text { of Barcelona (AMB) }\end{array}$ & 1997 ATM & $\begin{array}{l}2002 \text { expanded geo- } \\
\text { graphic purview }\end{array}$ \\
\hline Milan Basin & $\begin{array}{l}2015 \text { Metropolitan City } \\
\text { of Milan }\end{array}$ & 1978 SITAM & 2016 TPL \\
\hline $\begin{array}{l}\text { Greater Toronto } \\
\text { and Hamilton }\end{array}$ & none (1), & 2007 Metrolinx & $\begin{array}{l}2018 \text { expanded geo- } \\
\text { graphic purview }\end{array}$ \\
\hline $\begin{array}{l}\text { Greater Van- } \\
\text { couver }\end{array}$ & 1965 Metro Vancouver & 1999 TransLink & $\begin{array}{l}2007 \text { expanded geo- } \\
\text { graphic purview }\end{array}$ \\
\hline Greater Sydney & none & $\begin{array}{l}2011 \text { Transport for } \\
\text { New South Wales }\end{array}$ & - \\
\hline Greater Perth & none & 1986 Transperth & - \\
\hline
\end{tabular}


*An asterisk indicates this entity is a consortium or association rather than a governmental political jurisdiction. See this report's preface for definitions.

(1) An early step at regional governance was in 1998 when the City of Toronto and the adjoining five communities amalgamated into one larger City of Toronto. However, the metropolitan area of Greater Toronto is much larger than even this enlarged City of Toronto, and the metropolitan area has since expanded beyond the Greater Toronto Area to Hamilton.

\section{BARCELONA, SPAIN}

Barcelona is the capital and largest city in the autonomous community of Catalonia. It and the surrounding 35 communities are part of the official "Àrea Metropolitana de Barcelona," AMB, often translated as Greater Barcelona and formally created by Catalan legislation in 2010 (see the light green zone in Figure 7). ${ }^{26}$ These 36 cities are often referred to as the first zone, with a population of 3,220,071 and an area of $636 \mathrm{~km}^{2}$ (density 5,010 inhabitants per $\mathrm{km}^{2}$ ).

Barcelona is by far the largest city in the metropolitan area with 1.6 million inhabitants, followed by L'Hospitalet de Llobregat $(250,000)$ and Badalona $(220,000)$, and thus this region could be considered somewhat polycentric. AMB is governed by the Metropolitan Council. The Metropolitan Council's responsibilities include the appointment and dismissal of the AMB president; the approval of the Metropolitan Action Plan, which includes projects and services developed by the AMB during each president's term; the approval of laws and regulations; and the establishment of the metropolitan services fees. There are currently 90 Metropolitan Council members; each of the 36 municipalities has members in proportion to their population. The mayors of the municipalities are ex-officio members of the Council. 


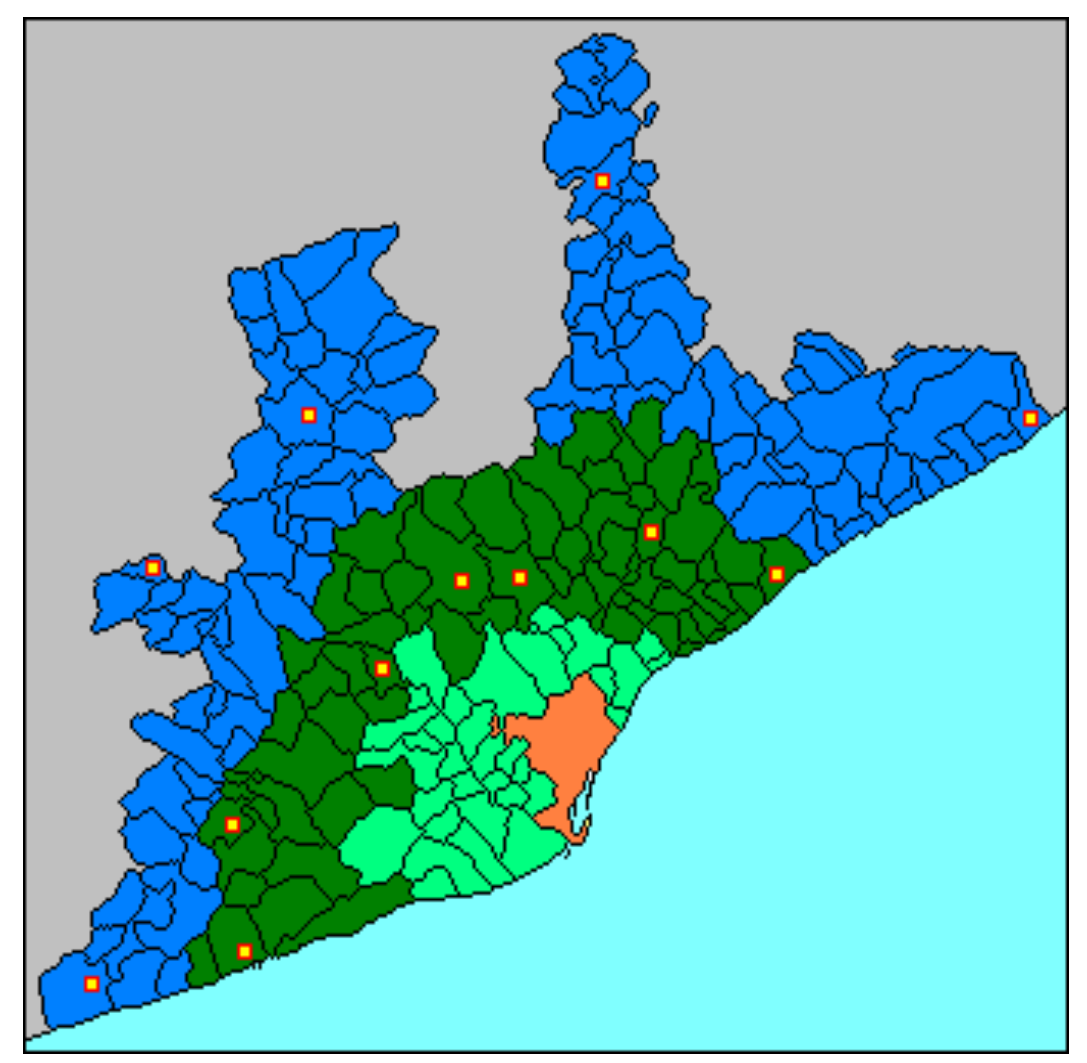

Figure 7. Barcelona Metropolitan Area

The urbanized metropolitan area is considered to be larger than AMB alone, with two other zones as shown in Figure 7. The second zone (or belt) around Barcelona (dark green) includes another 72 municipalities and 1.5 million people. The third zone (blue) has another 110 municipalities and a population of $750,000 .{ }^{27}$

\section{Description of ATM Barcelona, the Regional Transit Coordinator}

The Authority of Metropolitan Transport (ATM) was founded in 1997 as a consortium of all administrations responsible for public transport services in the metropolitan region of Barcelona (AMB), i.e., the first zone. ${ }^{28}$ In 2001,16 municipalities in the second zone formed a coalition of political interests to support public transport in their communities called AMTU. In November 2002, the AMTU joined the ATM as a full member with representatives on the board. AMTU continued to grow; by 2007, there were 55 members, and today there are 106 (Figure 8). ${ }^{29}$ 
Regional Transit Coordination, Institutional Climate, \& Governance Setting 30

\section{Greater Barcelona Area Authority of Metropolitan Transport (ATM)}

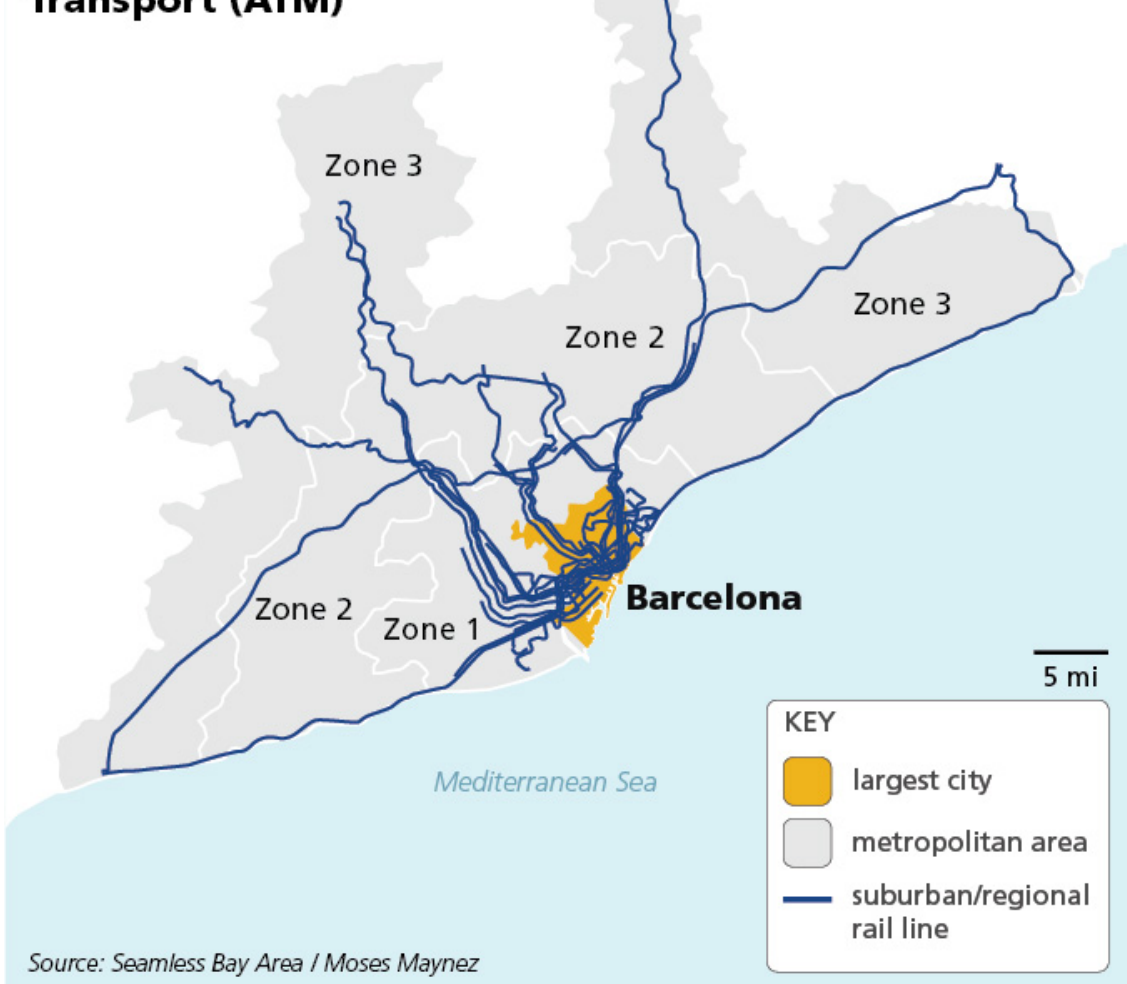

Figure 8. Barcelona Authority of Metropolitan Transport

Currently, the ATM includes the following Administrations. ${ }^{30}$

- Government of Catalonia

- Municipality of Barcelona

- $\mathrm{AMB}$, Àrea Metropolitana de Barcelona: Barcelona and the 35 first zone municipalities

- AMTU: the association that represents the municipalities outside of AMB (Associació de Municipis per la Mobilitat i el Transport Urbà, Association of Municipalities for Mobility and Urban Transport)

The Board of Directors of the ATM includes eighteen members with full voting rights:

- nine nominated by the Government of Catalonia,

- seven representing the corresponding local governments (Barcelona City Council and the Metropolitan Area of Barcelona), and 
- two representing the AMTU.

In addition, there are two representatives of the Spanish Government as observers, the general manager and the board's secretary. The conseller (minister) of Territory and Sustainability of the Government of Catalonia is the president, and there are two vice-presidents: the mayor of Barcelona and the president of the Àrea Metropolitana de Barcelona. In addition to the governing council, there are also management and advisory bodies within ATM.

The Executive Committee of the Board of Directors is made up of six members: three representing the Generalitat de Catalunya, two representing the corresponding local governments, and one representing AMTU. ${ }^{31}$ In general, this Executive is responsible for examining and presenting to the Board of Directors proposals regarding planning instruments for the Metropolitan Collective Public Transport System, financing agreements and service contracts with administrations and operators, the fare system, and annual budgets, among other issues.

\section{Role of ATM as the Regional Transit Coordinator}

The duties of ATM include a wide range of coordinating and planning activities such as the following:

- planning of infrastructure and services; development of the infrastructure Master Plan

- writing, approving, and enforcing the Mobility Master Plan for the Barcelona Metropolitan Region

- procuring contracts with operators

- financing agreements with public bodies and distribution of revenues

- developing fare policy, including fare integration and annual price review

- communication: definition and promotion of the system's corporate image

- public information and marketing; publicity, information, and relations with users

- long-term planning and necessary future regulatory framework

- developing plans for transit and the rational use of public space for transit lanes, private vehicles, parking, and pedestrians 


\section{MILAN, ITALY}

In Italy, governmental administration is organized more or less the same as in the U.S., first as municipalities (i.e., cities and towns), then provinces (province), and then states (regioni). (Of the seven case study countries, only Italy and France are organized with all three levels.) For large urban metropolitan areas, instead of provinces, there are now metropolitan cities. While the concept of metropolitan cities was first created in 1990 (Law 142/1990), they were effectively established by another law in 2014 for nine Italian cities. ${ }^{32}$ The Metropolitan City of Milan has been operative since January 1, 2015 and includes the City of Milan and 133 other municipalities. The Metropolitan City of Milan has the same geographic boundary as the former province of Milan (as do the other metropolitan cities, respectively) but has some powers that the province did not have. In addition, in recognition that the whole province should be managed as a more coherent unit, the mayor of the capital city is now also the mayor of the Metropolitan City (i.e., the former province). Thus, the mayor of Milan has much more power and influence over the rest of the metropolitan area compared to before the province of Milan became the Metropolitan City of Milan.

The metropolitan area of Milan could be defined as either the Metropolitan City only or also including the urbanized areas of adjacent provinces, particularly the province of Monza and Brianza. However, with respect to public transportation, a 2012 regional law designated the three provinces of Lodi, Monza and Brianza, and Pavia together with the Metropolitan City of Milan as falling within the same geographic area for the purposes of regional transit coordination. This area includes 438 municipalities, with a population of 4.9 million inhabitants and an area of 5,729 $\mathrm{km}^{2}$ (Figure 9). ${ }^{33}$ 


\section{Milan Basin \\ Local Public Transport Agency \\ of the Basin of Milan, Monza and Brianza, Lodi and Pavia (TPL)}

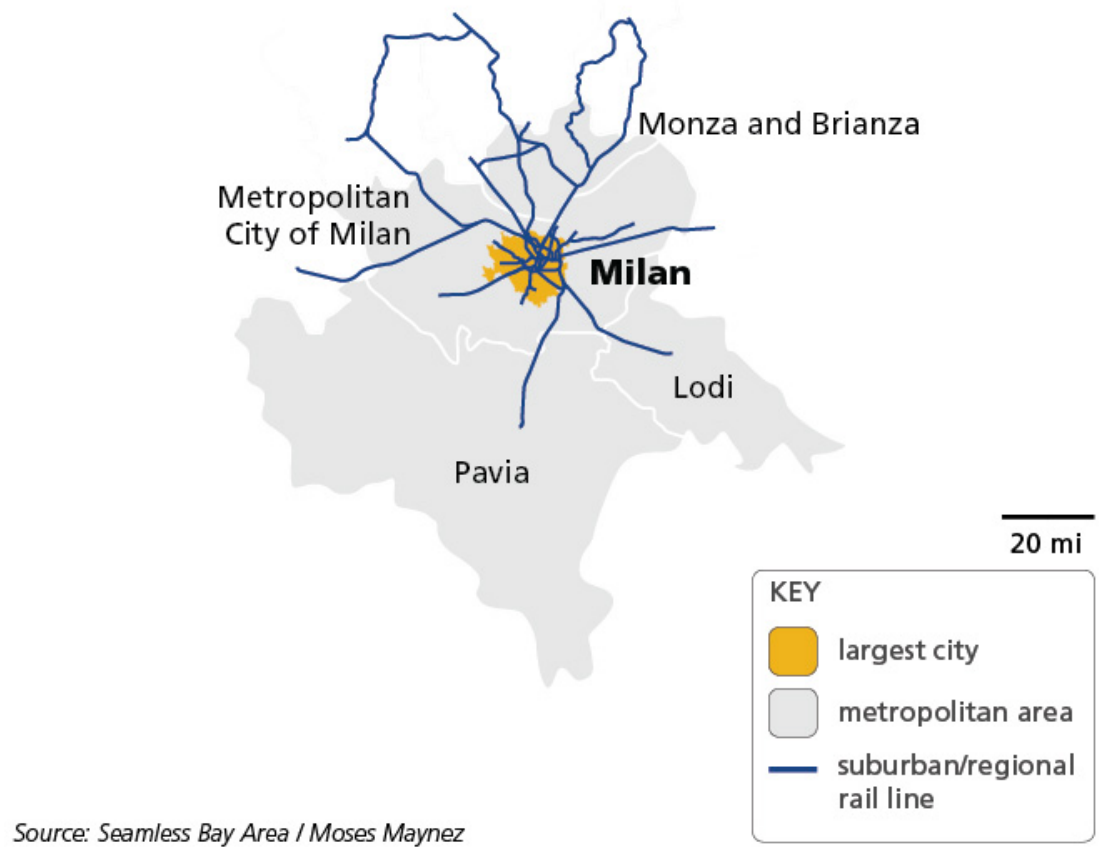

Figure 9. Milan Area of Public Transport Coordination

\section{Description of TPL, the Regional Transit Coordinator}

Fare and schedule coordination began in the Milan area in 1978 under a fare coordination scheme called SITAM (Transportation Integrated System in the Milan Area) and then with greater coordination under AMAT (Mobility Environment and Territory Agency). Regional transit coordination took a significant step forward in 2012 when the region of Lombardy passed a law creating six public transit "basins" within Lombardy, each having a corresponding public transit coordinating agency, the largest being that of the Milan metropolitan area. ${ }^{34}$ This law gave these new agencies the responsibility of programming, organizing, monitoring, controlling, and promoting transport services in their basin in an integrated manner. The agencies are non-economic public bodies with their own boards, and they have legal, organizational, and accounting autonomy. In the Milan area, the agency became active in April 2016; its full name is the Local Public Transport Agency of the Basin of Milan, Monza and Brianza, Lodi, and Pavia (TPL). ${ }^{35}$

The governing board of TPL, called the Assembly, contains representatives from the City of Milan, the Metropolitan City of Milan, the capital city of each province, and each of the three provinces, as well as the region of Lombardy. While public transport operators do not have a representative on the Assembly, these individual 
cities and provinces and the region of Lombardy are the owners/managers of their own public transit systems: so, in effect, the public transportation "agencies" have representation.

These public entities are represented on the Assembly in the following proportions. ${ }^{36}$

- Municipality of Milano (50\%)

- Municipality of Monza (3.4\%)

- Municipality of Lodi (2.4\%)

- Municipality of Pavia (6.2\%)

- Metropolitan City of Milano (12.2\%)

- Province of Monza and Brianza (7.3\%)

- Province of Lodi (2.4\%)

- Province of Pavia (6.2\%)

- State (Regione) of Lombardy (10\%)

There is also a five-member Board of Directors, one of whom is designated President of the Board. These Directors have three-year terms and are limited to two consecutive terms. The members of the Assembly and the Board of Directors carry out their activities free of charge. The General Manager is appointed by the President, following a resolution of the Board of Directors. The assignment lasts five years and is renewable only once.

\section{Role of TPL as the Regional Transit Coordinator}

The duties of TPL range from the planning, regulation, and control of public transport services to setting fares and the development and monitoring of quality standards. TPL is also responsible for communication and innovation activities. It has a management coordination function with no operational duties.

The geographic scope is within and between areas of Milan, Monza and Brianza, Lodi, and Pavia, as well as connections with other places in the region of Lombardy.

The TPL coordinates the following public transit agencies.

- ATM (Azienda Trasporti Milanesi, or Milan Transport Agency), which serves most of the metropolitan City of Milan, with four metro lines (96.8 $\mathrm{km}), 19$ tram lines $(180.2 \mathrm{~km})$, four trolley bus lines, and 131 bus lines 
- TreNord, which operates 12 suburban train lines (403 km)

- The transit systems of the cities of Monza, Lodi, and Pavia

- The transit systems of the provinces of Monza- and Brianza, Lodi, and Pavia

The ATM is by far the largest and oldest public transportation agency; it manages and operates the multimodal network in the municipality of Milan, which includes metro, trams, and buses, as well as the buses in 46 provincial towns, serving a total area with a population of 2.51 million people. ${ }^{37}$

Specific duties of TPL include the following. ${ }^{38}$

- Drafting the local public transport plan for the entire basin (a programmatic document that defines the local public transport services and their regulation and control).

- Approval of the methods for entrusting the services to operators and signing and verifying service contracts.

- Fare unification and coordination: development of the basin-wide fare system implemented in 2019.

- Planning and management of resources for the financing of local public transport services.

- Determination and monitoring of management, quality, technical, and economic standards, as well as verification of the minimum travel conditions applied by the managers and of the rules about quality and safety at work.

- Promotion of information services to users for mobile and real-time communication and awareness about the use of public transport.

- Periodic convening of a local conference of local public transport for the consultation of the stakeholders (representative associations, mobility managers, public transport companies) regarding the programming and quality of services, service contracts, fare aspects, and monitoring data.

- Preparation of opinions and proposals to increase intermodality between regional rail services and local public transport services.

- Development of initiatives for the integration of local public transport with new forms of sustainable mobility.

- Search for new forms of transport, including by means of agreements with other public and/or private entities. 
Regional Transit Coordination, Institutional Climate, \& Governance Setting 36

\section{LYON AND RHÔNE, FRANCE}

Regional cooperation in the Lyon urban area began in 1969 with the creation of an urban collective of 50 cities, referred to as COURLY (Communauté Urbaine de Lyon), which was then expanded to consist of 55 cities and towns. ${ }^{39}$ Soon after, in 1974, the communities of COURLY also decided to organize their public transit provision, and Transports en Commun Lyonnais (TCL) was formed by a ministerial decree..$^{40}$

In 2014 , a national law created an entity called the métropole, or metropolis. Similar to the Metropolitan Cities of Italy, the métropole is a form of regional government for an area that used to be part of a province. In the case of Lyon, cities and towns were essentially extracted from the province (department) of Rhône to become a separate entity called La Métropole de Lyon, the metropolis, or metropoli$\tan$ area, of Lyon; this change became effective on January 1, 2015. There are 59 municipalities in the métropole of Lyon and a total population of over 1.3 million; the City of Lyon is the largest city with over 500,000 inhabitants. The department of Rhône still exists with fewer municipalities than before. Also, in 2015, French parliament passed a law reducing the number of states (régions, in French) from 22 to 13, effective January 1, 2016. The région of Auvergne and the région of Rhône-Alpes were combined to become the région of Auvergne-Rhône-Alps. The new région consists of 12 different departments with a total population of some 7.5 million.

\section{Description of SYTRAL, the Regional Transit Coordinator}

The Syndicat des Transports de l'Agglomération Lyonnaise (SYTRAL) was created in 1985 as the overall body that organizes and links together multiple public transit networks and services in several urban areas. According to their website, SYTRAL is currently the only structure, authority, or institution in France to organize all the urban and interurban public transit services on this scale. ${ }^{41}$ Prior to 1985 , there was another agency whose purview was only the COURLY, i.e., greater Lyon. Since its creation in 1985, SYTRAL's geographic area as well as its duties have expanded. SYTRAL's current geographical area reach extends beyond the Lyon metropolitan area to the entire province of Rhône (Figure 10 and Figure 11). As such, it organizes all public transport in Greater Lyon and the province of Rhône, that is, the transit system of TCL (Lyon and its metropolitan area), the Cars du Rhône network (Rhône province), and the Libellule network (Villefranche sur Saône in Rhône province). 
Regional Transit Coordination, Institutional Climate, \& Governance Setting 37

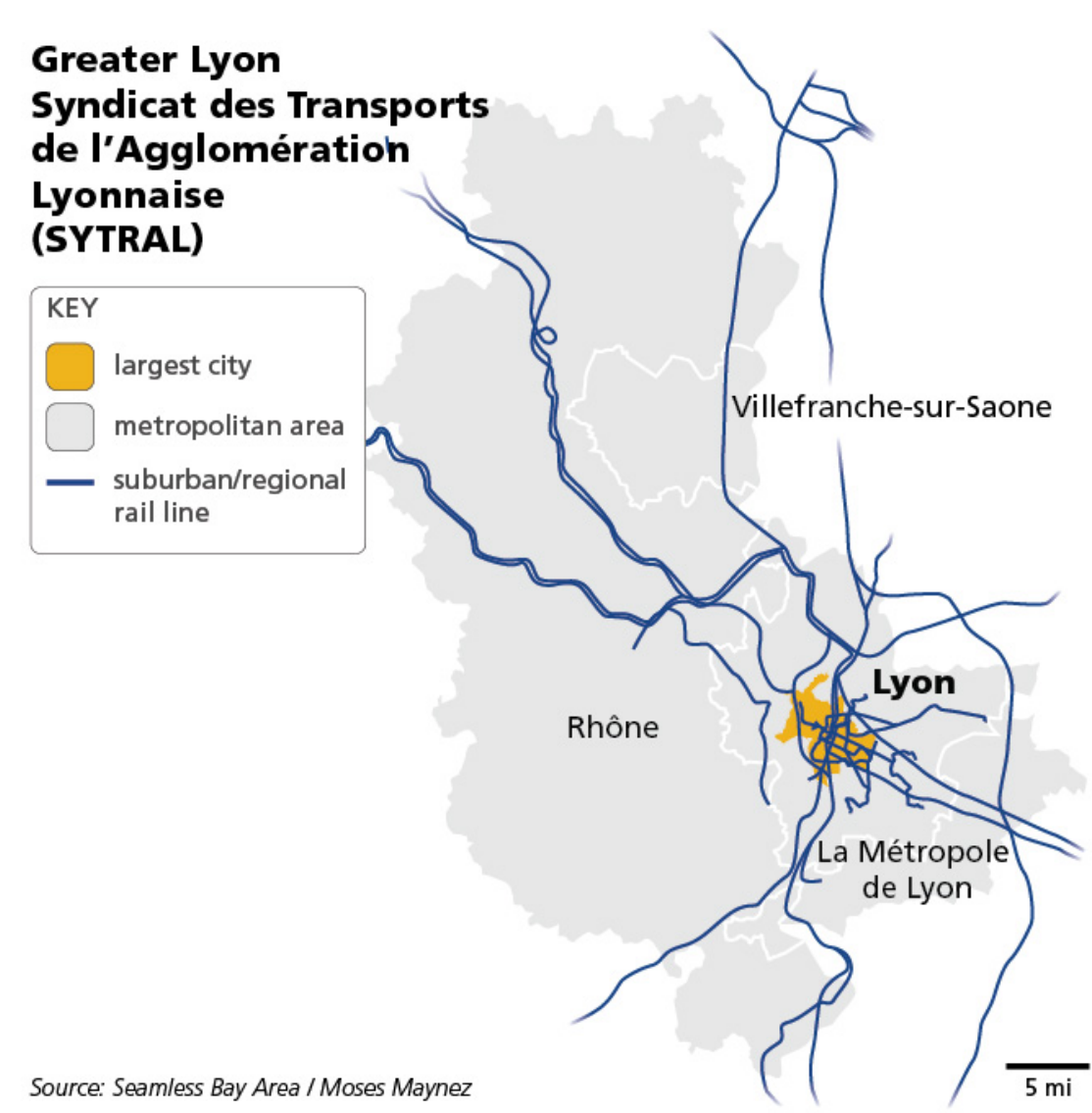

Figure 10. SYTRAL Service Area of Lyon and Rhône

SYTRAL is governed by a supervisory board. In 2017, the composition of the board was changed; there are now 31 members, as follows.

- 23 chosen from among elected representatives of the Lyon metropolis

- Four chosen from among elected representatives of the State of Auvergne-Rhône-Alps region

- Four chosen from among elected representatives of the other communities in the area 


\section{SYTRAL SYTRAL's operating area}

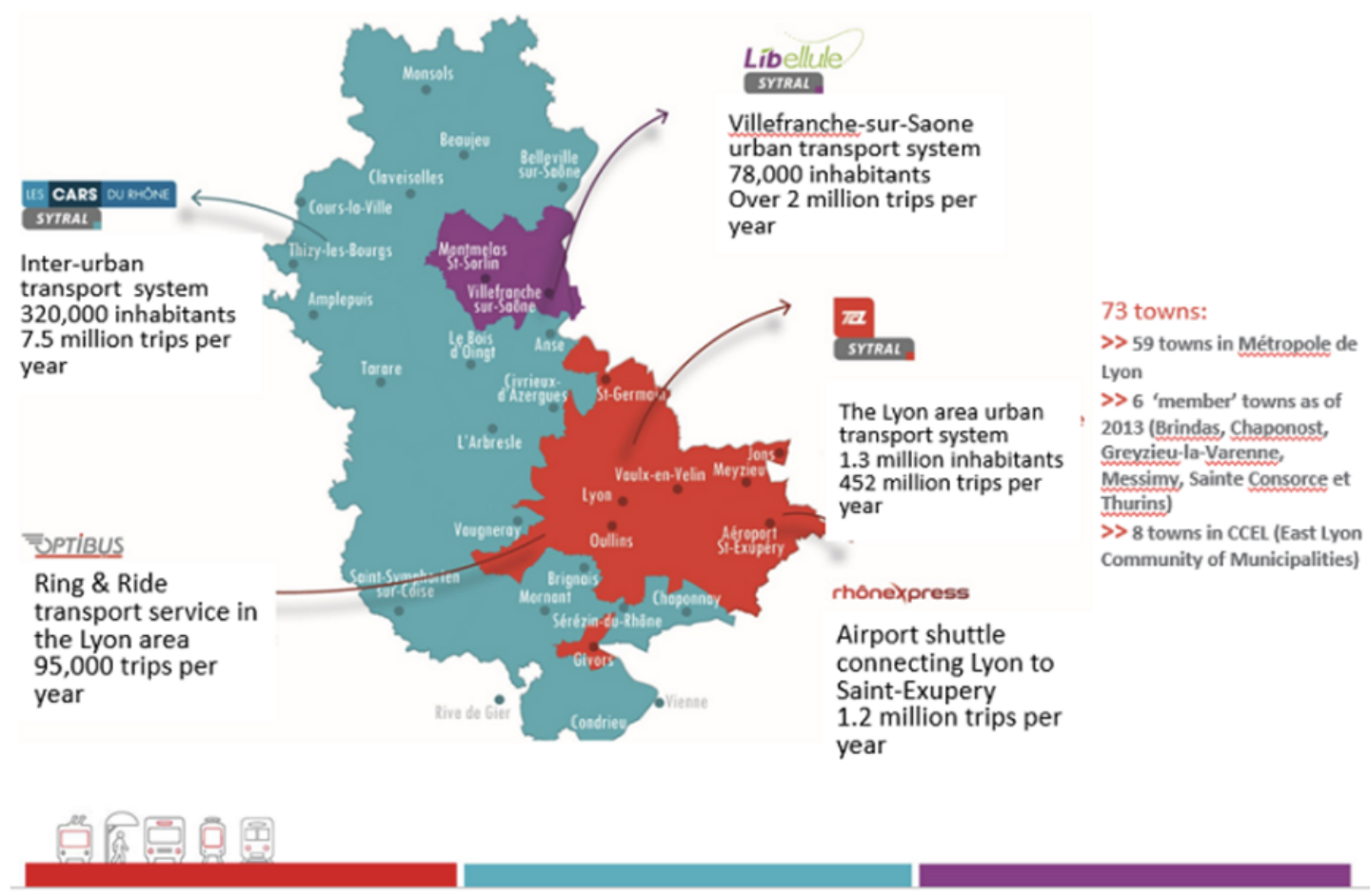

Figure 11. Operation Area of SYTRAL, Lyon and Rhône ${ }^{42}$

Role of SYTRAL as the Regional Transit Coordinator ${ }^{43}$

Specific duties of SYTRAL are as follows.

- Delegate the operation of the TCL network and the Optibus service.

- Define the strategic goals and make the necessary investments: metro, tram, trolley bus and bus, or on-demand transport.

- Decide on the transport offered: routes and frequency of the lines, location of stations and stops, etc.

- Define and inspect the standards of quality of service: punctuality, availability, cleanness, safety, fraud prevention and response, and so on.

- Define a suitable and equitable fare policy.

- Develop and implement the Urban Transport Plan, as well as conducting surveys among local households.

SYTRAL coordinates the following public transit agencies. ${ }^{44}$ 
- TCL (Transports en Commun Lyonnais), which operates all the public transport serving the City of Lyon as well that of 72 adjacent municipalities; this includes four subway lines, five tramway lines, 100+ bus and trolley bus lines, and two funiculars.

- Rhône Express train line to the airport.

- Public transport in Villefranche/Beaujolais/Sone with 18 municipalities and 78,000 inhabitants.

- Public transport serving Les Cars du Rhône with 228 municipalities and 340,000 inhabitants.

- Optibus for disabled persons.

\section{STUTTGART, GERMANY}

The Stuttgart metropolitan area is in southwest Germany in the state of BadenWürttemberg. There is a regional-level government entity called Verband Region Stuttgart (VRS) which was created in 1994 following legislation adopted by the federal state of Baden-Württemberg. It is the only such regional governmental body in Germany, a level of government in between the state (Land) ${ }^{45}$ and the large cities and the rural counties (Landkreis). ${ }^{46}$ VRS acts as the political entity for the Stuttgart region in the form of a public law corporation. Delegates to the VRS Regional Assembly are elected every five years by the local population. ${ }^{47}$ This "regional parliament" is unique in Baden-Württemberg and in Germany. Around 1996, soon after its creation, VRS became the authority responsible for the S-Bahn, the network of seven suburban train lines.

VRS is composed of five rural districts (Landkreis) of Böblingen, Esslingen, Ludwigsburg, Rems-Murr and Göppingen, and the City of Stuttgart (Figure 12). There are a total of 179 municipalities. Ninety percent of the VRS budget is allocated to public transportation. 


\section{Greater Stuttgart \\ Verband Region Stuttgart \\ (VRS)}

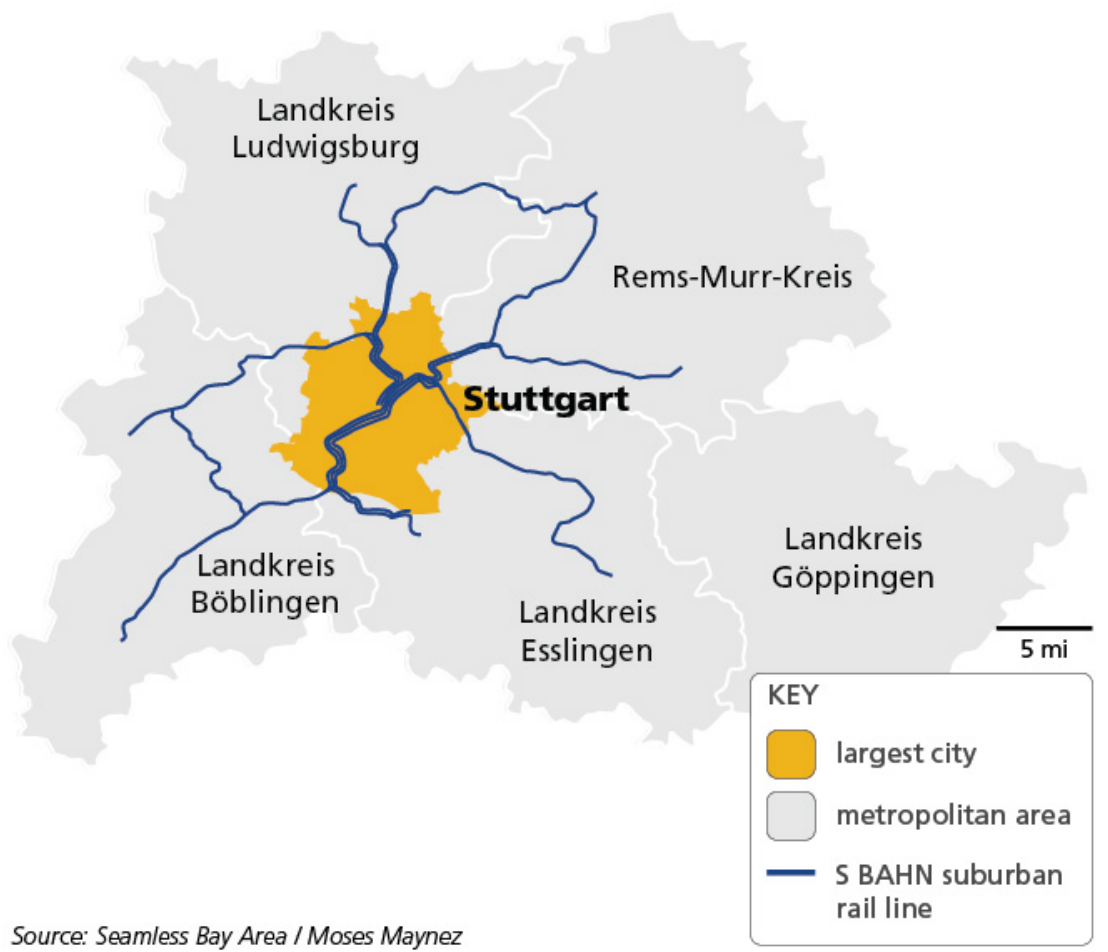

Figure 12. Stuttgart Metropolitan Area

\section{Description of VVS, the Regional Transit Coordinator}

The transit coordinator in the Stuttgart metropolitan region is called VVS (Verkehrsverbund Tarifverbund Stuttgart, literally translated as the Stuttgart Tariff/Fare and Transit Agency, but sometimes translated as the Stuttgart Integrated Public Transport Network).

The VVS was established in 1978-notably, before the regional government was created. This was the same year that three lines of the newly redesigned suburban trains, called S-Bahn, opened. The VVS coordinates all the transit systems and the 45 transit operators in the Stuttgart region in terms of conceptual planning, schedule coordination, uniform fares for all buses and trains, and revenue collection and distribution. While fare integration has been a key task since its founding, a truly unified single fare system was implemented only in April 2019.

The German word for the governing political body in its role with respect to public transportation is Aufgabenträger, ${ }^{48}$ what this report calls the transit system owner. The main transit system owners and their transit systems, all of which are coordinated by VVS, are as follows.

- VRS: S-Bahn, the electric commuter/suburban rail (seven lines). 
- Deutsch Bahn (DB): intercity rail.

- City of Stuttgart: SSB, Stuttgart Stadtbahn-Light Rail (16 lines); bus lines, a cog railway, and a funicular (vertical line).

- Esslingen and its transport company.

- Esslingen am Neckar and its transport company.

- 40 other bus companies serving segments of the other four counties, under their direction.

The VVS Governing Board is composed half of representatives of political jurisdictions and half of representatives of the transit companies/operators. ${ }^{49}$

\section{Role of the VVS as the Regional Transit Coordinator ${ }^{50}$}

The VVS is not responsible for operations, but it carries out the planning and coordination activities listed as follows.

- Conceptual planning

- Integration of operators

- Coordination of operations between companies

- Advertising

- Setting of common fares and transfer policies

- Demand analysis

- Collection and distribution of revenues (to the large transport companies or, in the case of smaller companies, to the Stuttgart Region Association)

- Uniform passenger information and coordinated timetables

- Comprehensive traffic surveys

- Marketing of fare and transport offers as well as cross-company press and public relations.

\section{FRANKFURT, GERMANY}

The metropolitan area of Frankfurt-Rhine-Main is considered to be polycentric, with three cities each having a population of 200,000 or more. These are Frankfurt am Main, commonly referred to as Frankfurt, with 750,000 inhabitants; Wiesbaden, the capital of the state of Hesse, with 275,000 inhabitants; and Mainz, population 
200,000 . The major rivers Rhine and Main run through the area, giving it its name. The metropolitan region lies mostly within the state of Hesse but also includes the cities and rural districts of Mainz and Aschaffenburgt in the two adjoining states of Rhineland-Palatinate (Rheinland Pfalz) and Bavaria (Bayern), respectively (Figure 13).

The term "Metropolitan Area of Frankfurt Rhine-Main" is not a legal term, and there is no common political body. However, in 2011, the State of Hesse legislation created the Regionalverband (Regional Authority) Frankfurt-Rhein-Main, an association of about 75 local governments within the state of Hessen with the responsibility for preparing and updating the regional preparatory land use plan and the landscape plan, as well as conducting intensive regional monitoring. ${ }^{51}$ In essence, the Regionalverband is a voluntary cooperation of cities and counties working in close collaboration. ${ }^{52}$

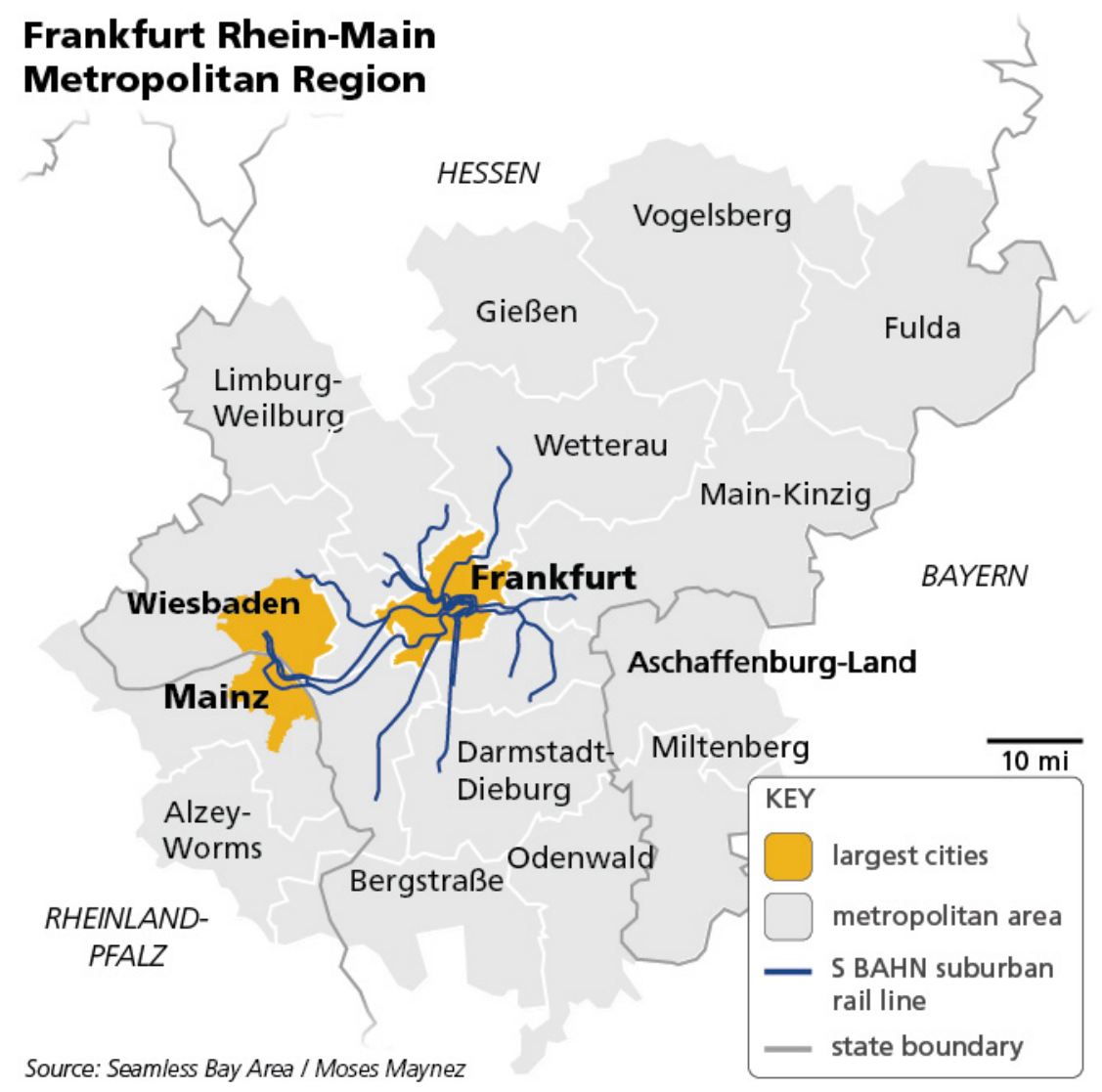

Figure 13. Frankfurt Metropolitan Area

\section{Description of RMV, the Regional Transit Coordinator ${ }^{53}$}

Rhein-Main-Verkehrsverbund (Rhine/Main Regional Transport Association or RMV) was established in 1995. It covers more or less the metropolitan area of Frankfurt Rhine-Main but has different members than the regional entity described above. 
The Rhein-Main-Verkehrsverbund is a consortium of 15 districts (Landkreis) and eleven municipalities (the eleven largest cities) as well as the state of Hesse. The responsibility as coordinator for all rail and bus transport services in the RMV network area has been assigned to RMV by state of Hesse law. But some of the transport services coordinated by RMV cross the state of Hesse's boundary into five adjoining states, which include Rhineland-Palatinate to the west, Bavaria in the south-east, and Baden-Württemberg in the south. The legal framework for local transport services in the state of Hesse provides that policy requirements and the planning and commissioning of service be separated from the delivery of transport services. Therefore, the role of RMV is to be a contractor of services and an intermediary between the policy makers (the municipalities and counties as represented by their elected representatives) who are the Aufgabenträger or transit system owners and the transit service operators.

Each of the 26 governmental political jurisdictions (11 cities and 15 Landkreis) are a shareholder of the RMV. RMV is governed by a supervisory board. Each shareholder appoints a representative to serve as a member of the RMV Supervisory Board, and each shareholder has one vote. The chair of the Supervisory Board is always held by the representative of the City of Frankfurt am Main.

\section{Role of RMV as the Regional Transit Coordinator}

The duties of RMV include coordinating and ordering transport services, as well as financing and marketing.

- This includes the planning of transport and mobility (planning new routes and service coverage). This division is responsible for the development of the regional public transport plan as well as updating the schedules for bus and train service. Furthermore, it is responsible for the expansion and improvement of the infrastructure.

- RMV duties additionally include contracting and procurement.

- RMV duties further require monitoring quality and infrastructure (setting standards, improving the quality for issues including punctuality, modern vehicles, cleanliness, and customer service).

- $\mathrm{RMV}$ is responsible for fares and fare structure including setting a single-ticket policy for the entire route on RMV and development of a range of ticket options,

- With respect to financing and accounting, RMV is responsible for all of the association's revenues and expenditures, as well as distribution of revenues to the members. 
- Finally, RMV duties include marketing and customer information through traditional print media, via electronic communications, and oneto-one in-person or telephone communications.

\section{STOCKHOLM, SWEDEN}

In Sweden, there is only one level of government between the municipality and the nation of Sweden: this governmental level is called the län. Thus, the län, or the region/county level, can also be considered to be the state level, i.e., the level immediately below the Swedish federal level of government (whose authority is contained in the Prime Minister/Parliament of Sweden). ${ }^{54}$ Although often translated as both "region" or "county", this discussion of Stockholm will use the word county to connote the fact that it is a governmental political jurisdiction.

Since 2005, the metropolitan area of Stockholm has been defined as all of Stockholm County (Stockholms län); it has 26 municipalities (Figure 14).

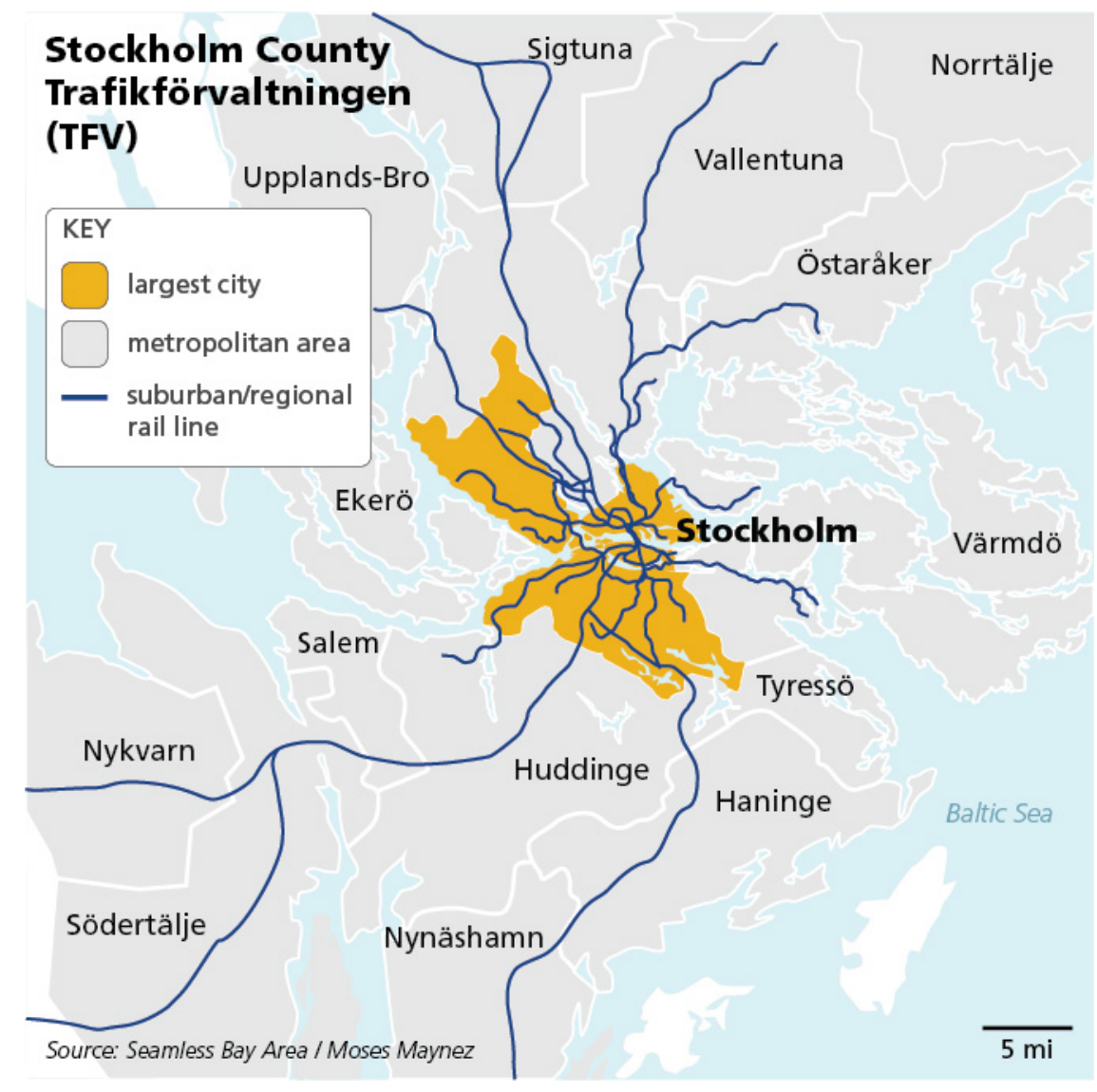

\section{Figure 14. Stockholm Metropolitan Area}

The County of Stockholm is governed by the County Assembly. County Assemblies are responsible for collective functions within the county, with a special 
emphasis on healthcare, public transport, regional development, and culture; they also have the right to levy taxes. The County Assembly is composed of $149 \mathrm{mem}-$ bers who are elected directly by the citizens in parliamentary fashion. Elections for the County Assembly are held every four years. ${ }^{55}$

\section{Description of TFV, the Regional Transit Coordinator}

Since 1967, all public transport in the metropolitan area of Stockholm has been the responsibility of the County of Stockholm. Since the metropolitan area of Stockholm is defined as the County of Stockholm, and it is also essentially a state, Stockholm County is the sole player in the delivery of public transit. Historically, there were many privately owned bus and tram agencies, but the City of Stockholm became an early agent in public transport when it bought two tram companies in 1915. The Stockholm Metro was opened in 1950. At the time, even though there was a Stockholm County Assembly level of government, it had no authority over public transport; moreover, at the time, the City of Stockholm was separate from the County, similar to German cities not being part of the Landkreis.

In January 1967, the City of Stockholm was brought into the County of Stockholm, and the County Assembly was given authority over all the metro, local train, bus, and ferry operations in the County. This change effectively merged all public transport into a single organization under the governance of the County of Stockholm. Up until this point, the different mass transit systems within the County had been run by different organizations, including the Swedish state railway, companies owned by the City of Stockholm and other local municipalities, and private companies.

The department within the County of Stockholm that is responsible for public transport is called Trafikförvaltningen (TFV), which translates as the County (or Regional) Public Transport Administration. It is responsible for the operations as well as the coordination and integration of all modes and areas of public transit. It provides public transport under three brand names:

- SL (AB Storstockholms Lokaltrafik, Stockholm public transport) governs all of the land-based public transport systems in Stockholm County.

- Waxholmsbolaget, which runs the 60 ferries.

- Färdtjänsten is responsible for transport for people with disabilities.

The County Assembly hires the director of Trafikförvaltningen. A special Transport Committee was created in January 2011, and members are appointed from among the members of the County Assembly. The Transport Committee has overall responsibility for public transport on land, at sea, and for people with disabilities. The Transport Committee is responsible for transport planning and for drawing up proposals for the Transport Provision Plan. The Committee also has overall responsibility for planning and procuring transport services and monitoring operations. ${ }^{56}$ 


\section{Role of TFV as the Regional Transit Coordinator and Transit Agency}

TFV is a government agency that functions as the single one-stop-shop for all public transportation in the County of Stockholm. Thus, TFV not only executes the coordinating function for all public transport in Stockholm County, but it also manages and tenders the operations of all public transit in the County. SL is the name best known to customers, but since SL is under TFV, ultimately, TFV is the responsible agency. ${ }^{57}$ TFV's duties with respect to public transport are as follows:

- planning, both short-term and long-term

- commissioning and procuring the operations

- setting schedules and operating headways

- ensuring schedule coordination between modes

- marketing

- customer service and ticketing

- setting fares and fare policies

- monitoring operations.

In Stockholm, all transit operations are contracted through tendered services.

\section{VANCOUVER, CANADA}

In the province of British Columbia, there is no equivalent of the county level of government, i.e., a governmental level between cities and the province. However, in 1965, provincial legislation created regional districts to address issues of a regional nature including water, waste water, solid waste/waste management/recycling, regional parks, and air quality. In the Vancouver area, this entity was the Greater Vancouver Regional District (GVRD) or simply Greater Vancouver, consisting of 21 municipalities, one Electoral Area, and one Treaty First Nation (Figure 15). In 2007, GVRD was rebranded for popular use as Metro Vancouver, which subsequently became its legal name. It collaboratively plans for and delivers regional-scale services.

Metro Vancouver, being a regional district, is a political body and corporate entity operating under provincial legislation but which has no directly elected politicians. The Board of Metro Vancouver is composed of 40 members who have been appointed by their respective municipal councils. Thus, while not directly elected to be on the Metro Vancouver Board, they are elected politicians from their own local municipalities. Directors are allowed one vote for every 20,000 people in their municipality. ${ }^{58}$ This level and type of government was identified as unique among the 
case studies. In order to distinguish it from what is defined in the preface as governmental political jurisdiction, it is referred to as a state-authorized regional district, since it is not a city or county nor does it have any elected politicians of its own. However, in many ways, it has many of the same duties as a governmental political jurisdiction.

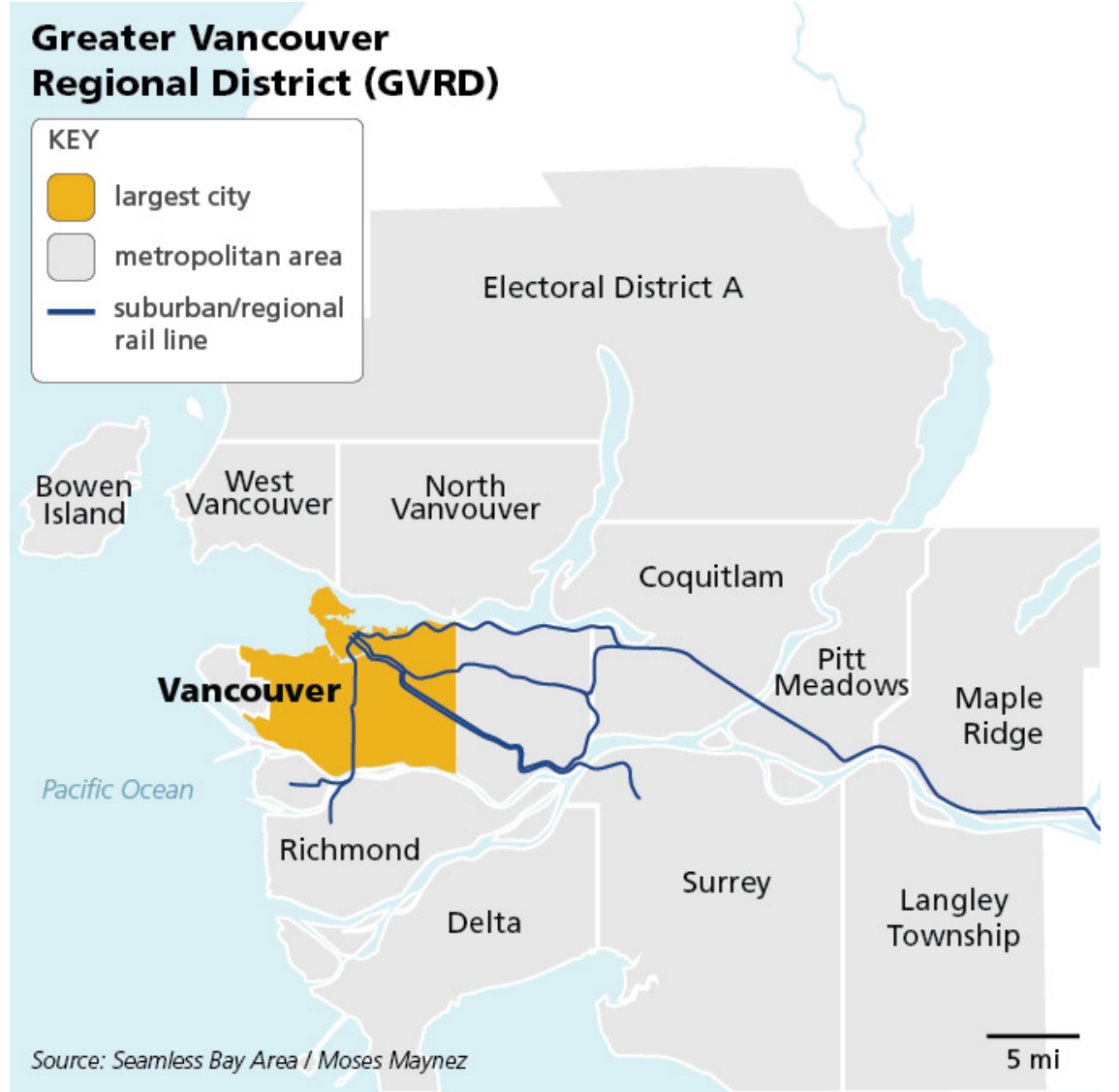

Figure 15. Vancouver Metropolitan Area

\section{Description of TransLink, the Regional Transit Coordinator}

In the 1970s, transit service in the Vancouver area had come under the management of the Province of British Columbia under the name of BC Transit. However, by the early 90s, the local municipalities, the GVRD, and the province all agreed on the need for a new regional authority that would focus on transportation. After years of study and negotiation, in 1998, the South Coast British Columbia Transportation Authority Act was passed by the province of British Columbia, creating the Greater Vancouver Transportation Authority 59 as a state-authorized regional district that is separate from Metro Vancouver. Called TransLink, it was officially launched on April 1, 1999. TransLink is responsible for planning, financing, and managing transportation modes and services in the Metro Vancouver region: i.e., planning the regional transit network as a strategic whole. Its responsibilities had three key new elements. 
Regional Transit Coordination, Institutional Climate, \& Governance Setting 48

1. Responsibility for creating and planning a regional transportation network,

2. Responsibility for both the public transit system and the major road network, and

3. Authority to raise its own funds through taxation.

In 2007, the province of British Columbia approved legislation changing the governance structure of TransLink and creating new revenue-generating measures. This law also created a new legal name, South Coast British Columbia Transportation Authority, opening the way for an expanded geographic mandate beyond Metro Vancouver and essentially increasing the areas under TransLink's jurisdiction.

TransLink has a two-tiered governance structure, including the Mayors' Council on Regional Transportation and TransLink's Board of Directors (Figure 16). ${ }^{60}$ 


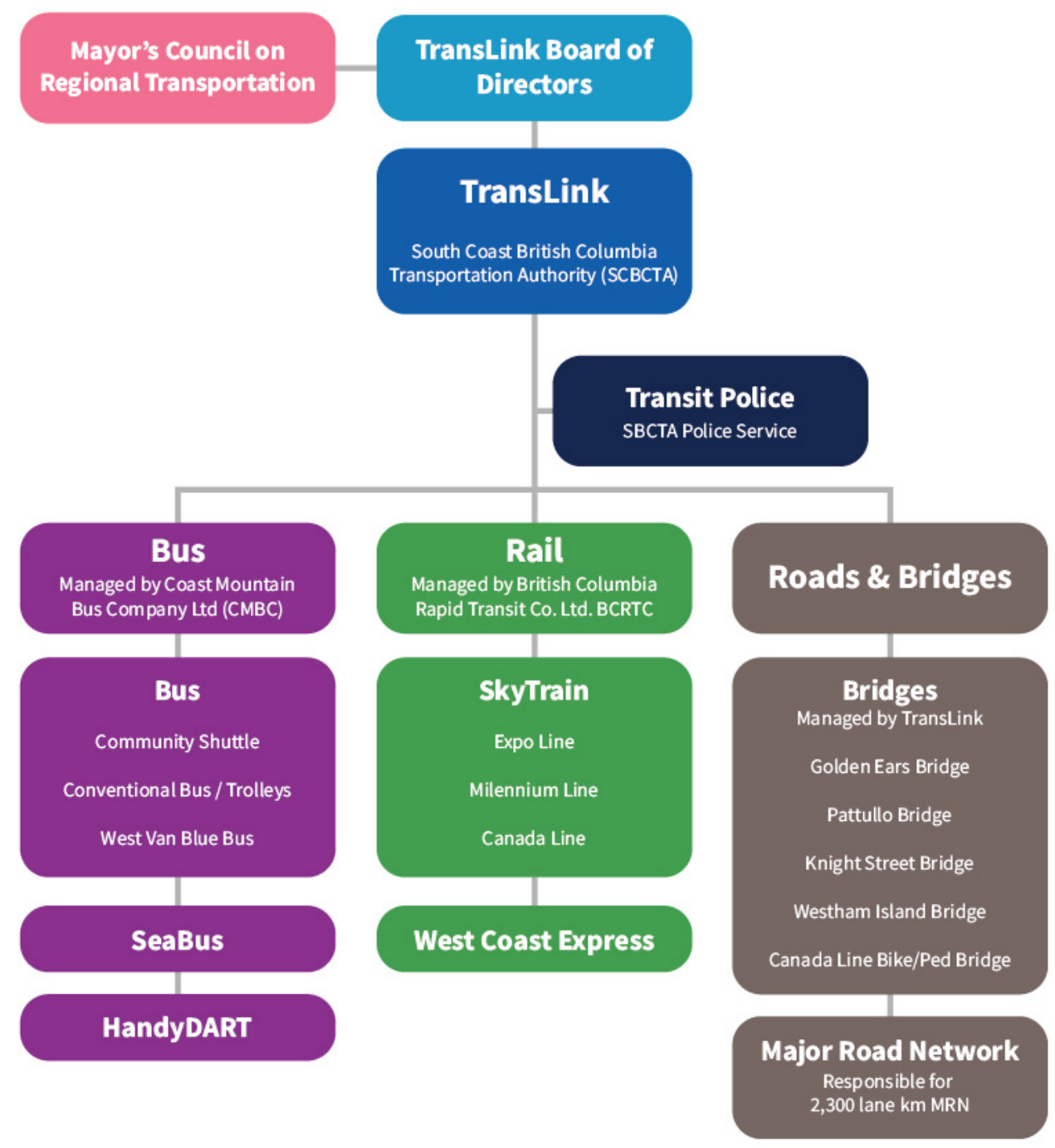

\section{Figure 16. Vancouver's TransLink Organization Chart ${ }^{61}$}

Given that a two-board structure is rather unique, the differences in the composition and duties of the two boards will be described below.

- The Mayors' Council comprises one member from each of the 21 local government agencies in Metro Vancouver. Its duties include:

$\circ$ appointing the Mayors' Council Chair and Vice Chair

- appointing seven TransLink Board members from a candidate list presented by the Screening Panel

$\circ$ approving long-term transportation strategies ( $\geq 30$ years)

○ approving 10-year transportation investment plans 
0 approving first-time short-term fares and short-term fare increases (increases in short-term fares, i.e., passes shorter than three days in duration, beyond two per cent per year, based on April 1, 2008 fares)

$\circ$ approving changes in customer satisfaction survey processes

$\circ$ approving changes in customer complaint processes

$\circ$ overseeing the sale of major facilities and assets

○ approving variations in TransLink director compensation levels

- approving TransLink's Executive Compensation Plan

- The TransLink Board of Directors has up to eleven members: seven individuals appointed by the Mayor's Council (from a candidate list presented by the Screening Panel), the Mayors' Council Chair and ViceChair (at their option), and up to two members appointed by the province. The appointed members do not represent any other interests or constituencies. The board is responsible for hiring, compensating, and monitoring the performance of the CEO and for providing oversight of TransLink's strategic planning, finances, major capital projects, and operations. While the Board conducts four public meetings a year, most of its deliberations are conducted in closed meetings. Its duties include:

○ appointing a TransLink CEO

- supervising the management of TransLink affairs

- submitting long-term transportation strategies to the Mayors' Council for approval

o submitting 10-year transportation investment plans to the Mayors' Council for approval

○ approving TransLink's annual operating budgets

- proposing to the Mayors' Council changes to customer satisfaction survey processes and conducting annual surveys

- proposing to Mayors' Council changes to customer complaint processes and implements approved processes

$\circ$ publishing annual reports

$\circ$ holding public annual general meetings 
- establishing subsidiaries and appointing Board Chairs and members

- An Independent Screening Panel was also established under TransLink's governing legislation. ${ }^{62}$ The Screening Panel's duties are to recruit candidates to replace TransLink directors whose terms are expiring. The Screening Panel provides the shortlist of candidates to the Mayors' Council on Regional Transportation, which then appoints individuals from the candidate list to fill upcoming director vacancies.

\section{Role of TransLink as the Regional Transit Coordinator and Transit Pro- vider}

TransLink is a state-authorized regional district that functions as the single point of contact for all public transportation operations in the Vancouver metropolitan area. As the sole entity responsible for public transportation, it is the transit system owner and transit operator, either directly or through contracted services, for all modes in the region. It is also the regional transit coordinator.

- As the RTC, TransLink is responsible for planning, financing, and managing transportation modes and services in the Metro Vancouver region of British Columbia. Its duties include:

$\circ$ managing the delivery of public transit

- reviewing the schedules of various modes of public transportation to ensure coordination

$\circ$ reviewing and providing fare structure and fare policies

- marketing public information and providing customer service

- long and short-term transit service planning

- developing TransLink's strategic transportation and financial plans

○ approving capital project

○ procuring capital purchases

- maintaining government relations and providing legal services

- As the transit agency for all modes of transit service in the region through its fully owned subsidiary companies, as well as a few contractors, its public transportation services involve all the tasks and duties involved in running the following: 63 
Regional Transit Coordination, Institutional Climate, \& Governance Setting 52

- Sky Train Rapid Transit

- West Coast Express regional commuter train

- SeaBus ferry

- local and regional buses

○ paratransit

As a quasi-government with the ability to impose and collect tax revenue, TransLink controls much of its own revenue planning. While it is not a governmental political jurisdiction with directly-elected representatives, it has taxation authority and directly receives revenue from a variety of sources, as described further in Chapter VI. ${ }^{64}$

\section{TORONTO, CANADA}

The boundaries of both the City of Toronto and the metropolitan area of Toronto have expanded in the last few decades. In 1998, the former area of Metropolitan Toronto, roughly equivalent to a county and comprising six municipalities (Figure 17), was amalgamated by provincial (Ontario) law to become a single municipality: the City of Toronto. It is not part of any county, so it is a single-tier municipality roughly equivalent to a U.S. city-county. The same is true for the City of Hamilton: the current City of Hamilton is an amalgamation of six smaller municipalities. 


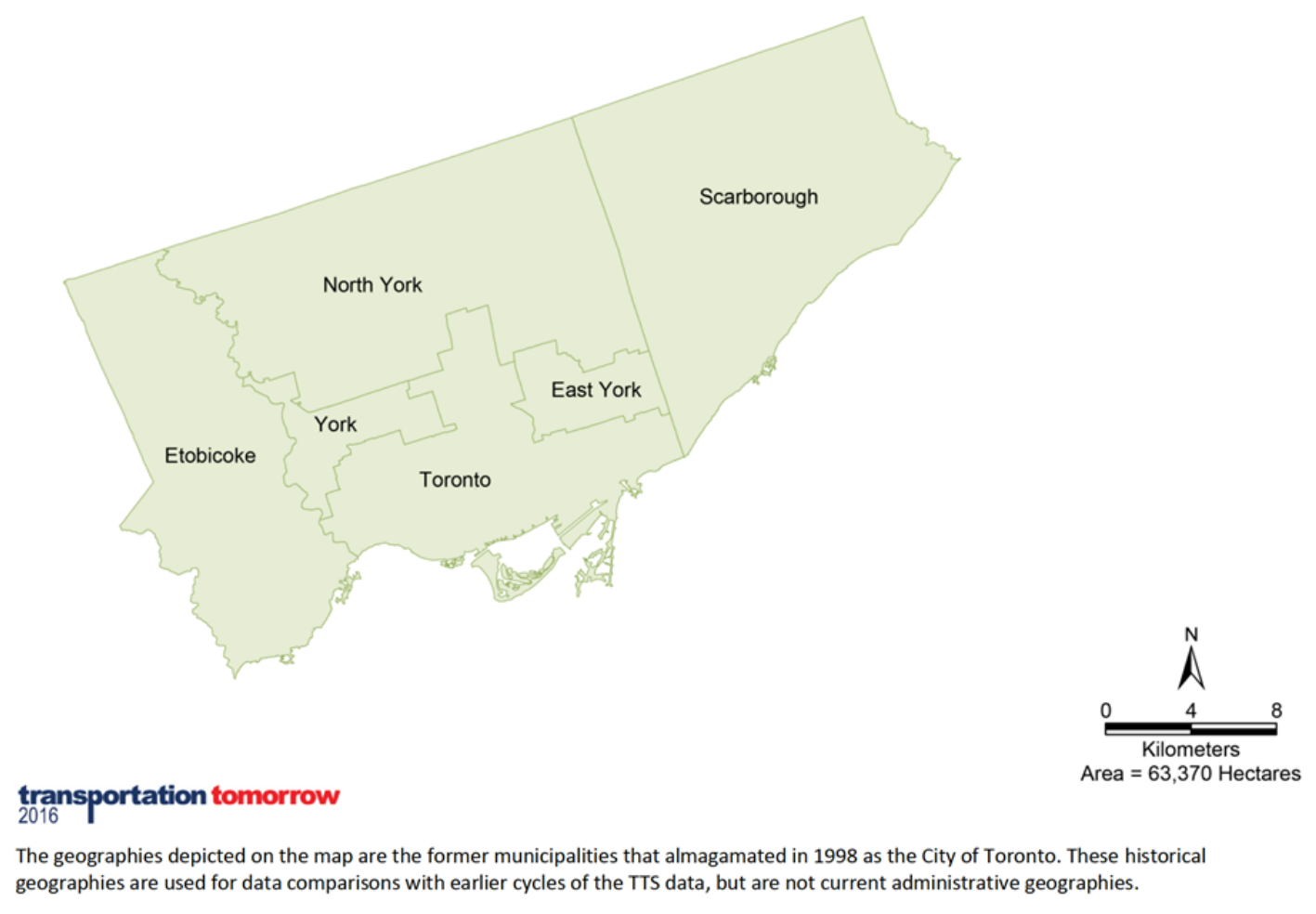

Figure 17. Current City of Toronto, a Single-Tier Municipality since $1998^{65}$

Previously, the metropolitan area of Toronto was considered to include the City of Toronto (as shown in Figure 17) and four other regions around the City of Toronto (Durham, York, Peel, and Halton), and it was referred to as Greater Toronto. During the first decade of this century, the term "Greater Toronto and Hamilton Area" (GTHA) was introduced to refer to the Greater Toronto Area and the City of Hamilton as a single metropolitan area. Thus, the GTHA is composed of these two cities plus four regions, as shown in Figure 18Figure 18. ${ }^{66}$ 
Regional Transit Coordination, Institutional Climate, \& Governance Setting 54

GREATER TORONTO AND HAMILTON AREA
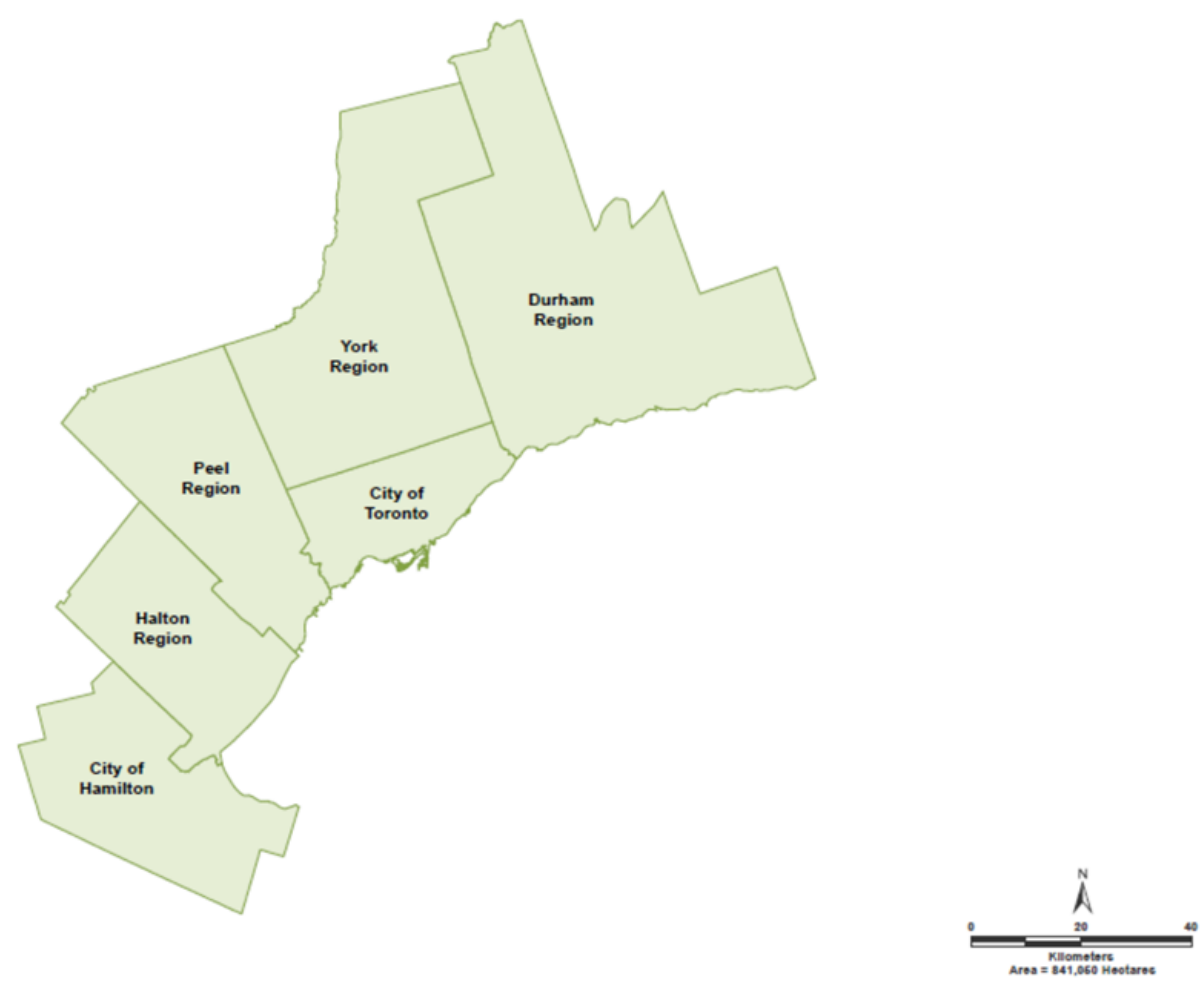

Figure 18. Communities in the Greater Toronto and Hamilton Area ${ }^{67}$

As the GTHA has grown, it has developed stronger ties to the rest of the Greater Golden Horseshoe (GGH) which encompasses all the lands bordering the shore of Lake Ontario from Niagara Falls in the south-west to Northumberland in the east. (Figure 19). 
Regional Transit Coordination, Institutional Climate, \& Governance Setting 55

Figure 1: Map of the Greater Golden Horseshoe, Including the GTHA and the GO Service Area

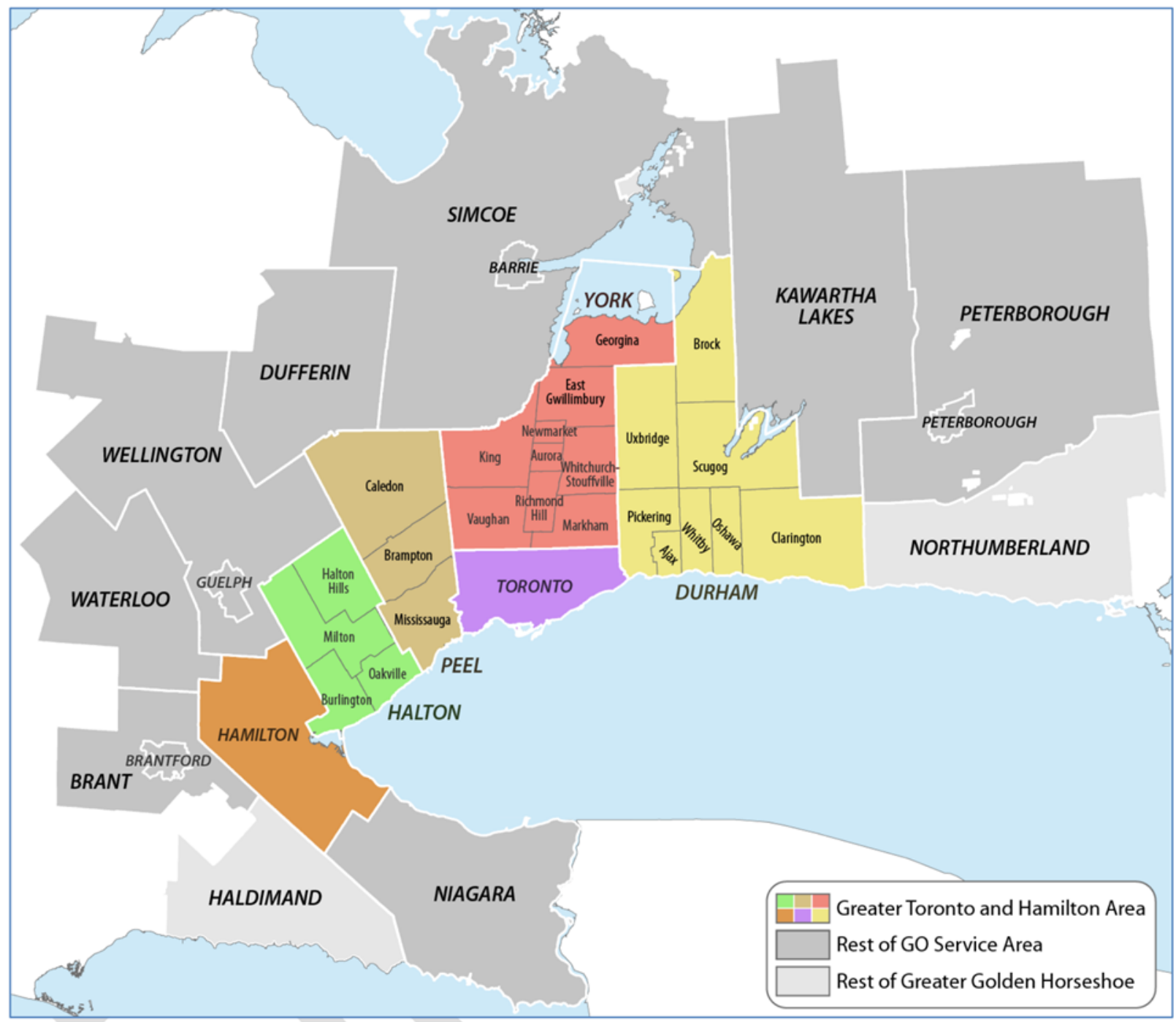

Figure 19. Communities in the Greater Golden Horseshoe Area ${ }^{68}$

There is no overarching governing body for the GTHA. The Province of Ontario takes on the role of developing regional land use plans both for the GTHA and the GGH. The local municipalities within the GHTA also collaborate on planning activities such as the areawide Transportation Travel Survey.

\section{Description of Metrolinx, the Regional Transit Coordinator of Toronto Metropolitan Area ${ }^{69}$}

Metrolinx was created by provincial (Ontario) law in 2006 as the Greater Toronto Transportation Authority. It is considered an agency of the Government of Ontario. It officially began service in 2007; it adopted Metrolinx as its brand name in 2007 and as its legal name in 2009. It was created to "ensure the region's transportation system would function as a whole-greater than just the sum of its parts-to meet current and future needs of the growing population." ${ }^{70}$ The purpose was to provide 
leadership in the coordination, planning, financing, development and implementation of an integrated, multimodal transportation network in the GTHA. The Minister sets Metrolinx's priorities through annual mandate letters and other letters of direction, as provided through the Metrolinx Act, 2006. Metrolinx has a mandate to develop and adopt a transportation plan that must comply with the prescribed provincial plans and policies and conform with the growth plans prepared and approved under the Places to Grow Act, 2005 within the GTHA ${ }^{71}$.

Subsequently, a few significant changes were made to the enabling legislation. ${ }^{72}$

1. Regional commuter train service in the area, called GO Transit, began in 1967 under the Ontario Ministry of Transportation; there are now seven lines. GO Transit also operates regional bus lines. In 2009, GO Transit was merged with Metrolinx to become a single entity. Thus, Metrolinx has two distinct roles: regional planner and coordinator, and transit system owner and operator.

2. The 2009 legislation also changed the board structure of Metrolinx. Previously, most members of the Board of Directors were appointed by the individual cities and regional municipalities (four for Toronto, one each for the other five municipalities, and two by the Lieutenant Governor). Interviews with local staff indicate that the change was likely made because, previously, the directors had no regional allegiance or sense of duty or obligation; ultimately, there was no accountability to make decisions that supported the good of the region instead of the good of their own municipality. The current board is now composed of not more than 15 private-sector persons appointed by the Lieutenant Governon on the recommendation of the Minister. Moreover, local and provincial politicians, as well as employees of any local municipalities or the province, or other boards, are specifically prohibited from serving.

3. In December 2018, the "regional transportation area" over which Metrolinx has planning and coordination authority was expanded beyond the GTHA to include the Greater Golden Horseshoe (see Figure 19). This was consistent with the fact that service area of GO Transit had already extended beyond the GHTA into several Greater Golden Horseshoe communities. However, no new funding or staffing was provided, so activities to further integrate with the rest of the region have been slow.

The City of Toronto is the largest city in Ontario, with the Toronto Transit Commission (TTC) being the largest transit agency coordinated by Metrolinx. The TTC is the third largest transit agency in North America after transit agencies in New York and Los Angeles. Its history represents the first wave of coordination in the Toronto area. 
In 1921, the City of Toronto created the Toronto Transportation Commission (TTC), which assumed control over all bus and streetcar routes in the city and eventually the metro system and the ferry routes (from 1927 to 1962). The opening of the metro in 1954 seemed to be the impetus for a number of key milestones. In 1954, a new local jurisdiction was created called Metropolitan Toronto, roughly equivalent to a county, which was composed of six cities shown in Figure 17. Also, in the 1950s, the TTC was renamed Toronto Transit Commission, and it greatly expanded its service area. It was at this point that the TTC acquired suburban routes from independent bus operators for the newly formed Metropolitan Toronto (which, as discussed previously, was amalgamated into a single city in 1998). Today, TTC operates all public transit in the City of Toronto (except for ferries) including bus, subway, streetcar, and paratransit services. Since the TTC is an agency of the City of Toronto, the City has full authority over the TTC's mandate and structure. The TTC, in turn, is overseen by the TTC Board of Directors, or Commission, which consists of ten members: six City Council members and four lay citizens. ${ }^{73}$

\section{Role of Metrolinx as the Regional Transit Coordinator and Transit Pro- vider}

Metrolinx serves as both the regional coordinator of public transportation in the GTHA and the owner-operator of regional transit. Metrolinx, in addition to operating GO Transit, also coordinates nine separately owned and operated transit agencies within the GTHA (Figure 20). ${ }^{74}$ They are as follows:

1. Toronto Transit Commission (TTC)

2. Hamilton Street Railway

3. York Region Transit and Viva Rapid Transit in York Region

4. Brampton Transit in Peel Region

5. Mississauga Transit in Peel Region

6. Durham Region Transit in Durham Region

7. Milton Transit in Halton Region

8. Oakville Transit in Halton Region

9. Burlington Transit in Halton Region 
Regional Transit Coordination, Institutional Climate, \& Governance Setting 58

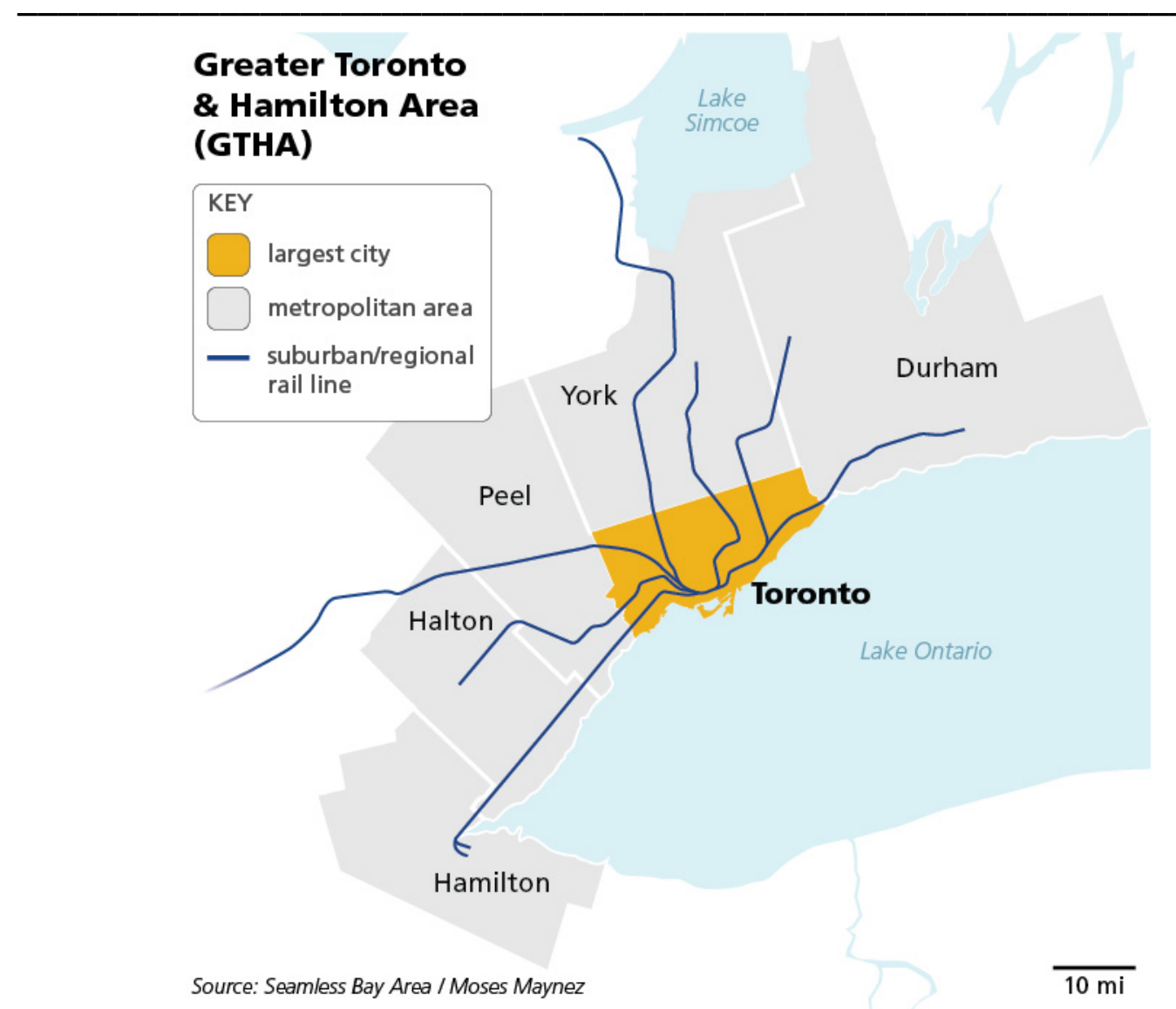

Figure 20. GTHA Metropolitan Area

As the Regional Transit Coordinator ${ }^{75}$

Provincial law created Metrolinx to provide leadership in the coordination, planning, financing, development, and implementation of an integrated transit network in the regional transportation area that is in line with growth plans prepared by the cities and with provincial transportation policies and plans applicable in the regional transportation area. Specific duties assigned to Metrolinx in this area are as follows. ${ }^{76}$

1. Regional Transportation Plan: Prepare a transportation plan for the regional transportation area that considers all modes of transportation and promotes the integration of local transit systems with each other and with the GO Transit system; and plan, co-ordinate, and set priorities for the implementation of the transportation plan.

2. Manage the funding of integrated transit network: Responsible for the funding (including arranging and/or managing the funding for), an integrated transit network for the entire region.

3. Foster coordinate decision making: Responsible for coordinated decision making and investment in the regional transportation area among 
the municipal governments in the region as well as the federal and provincial governments with the goal to ensure the efficient and cost-effective solutions to shared matters concerning public transportation, including:

a. the provision and the optimal use and location of transit infrastructure;

b. the integration and coordination of routes, fares, and schedules of the regional transit system and of local transit systems in the region.

4. Procurement: Assume responsibility for procuring transit vehicles, equipment, technologies, and related supplies and services on behalf of Ontario municipalities. This function entails establishing specifications and common standards for local transit system vehicles, equipment, technologies and facilities, and related supplies and services, as well as coordinating, negotiating, and managing the planning, design, development, and acquisition of said supplies and services.

5. Integrated Fares: Plan, design, develop, acquire, maintain, operate, and complete all other necessary tasks to implement all or any part of a unified fare system applicable to both the regional transit system and the local transit systems in the geographic areas of the City of Toronto, the City of Hamilton, and the Regional Municipalities of Durham, Halton, Peel, and York. However, as discussed in Chapter 4, its effectiveness integrating fares is hampered by lack of legal authority to force the other transit system owners to comply.

In sum, the Province of Ontario still retains quite a bit of authority; Metrolinx often needs supplemental legislation to fully implement its mandate. For example, while Metrolinx is responsible for the implementation and management of the "smart" Presto card, which is the tool behind the integrated fare policy, it is provincial legislation that names the transit agencies that are part of the fare card program. Indeed, much of Metrolinx's work is done in conjunction and with the agreement of its provincial and municipal partners.

\section{As the Transit System Owner-Operator}

As the transit system owner-operator, Metrolinx has the following duties:

- to maintain and operate the regional trains and buses under GO Transit

- manage and operate the airport rail link connecting Toronto Pearson International Airport to downtown Toronto's Union Station, UP (UnionPearson) Express 
- design, develop, and construct any alterations, extensions, and expansions to the regional transit system, subject to the approval of the provincial Minister of Transportation

- subject to the approval of the Minister of Transportation, operate local transit systems under agreements with municipalities within and outside the regional transportation area

- establish, construct, manage, and operate parking lots within or outside the regional transportation area in connection with the regional transit system

- conduct studies in respect of (i) the design, construction, maintenance, and operation of the regional transit system and any alterations, extensions, and expansions to it, (ii) the fare structure and service schedules of the regional transit system, and (iii) the operational integration of the regional transit system with local transit systems within and outside the regional transportation area

\section{SYDNEY, AUSTRALIA}

The City of Sydney has a population of about 246,000 . It is the largest city within the metropolitan area called Greater Sydney (Figure 21). ${ }^{77}$ (Greater Sydney is often referred to simply as Sydney, which leads to some confusion as to the size of the City of Sydney.) According to the Australian Bureau of Statistics, Greater Sydney covers $12,368 \mathrm{~km}^{2}$ and is made up of 35 local municipalities or councils, also known as Local Government Areas (LGAs). ${ }^{78}$ There is no formal regional level of government for the metropolitan area. Within an LGA, there are wards or neighborhoods, which are sometimes called suburbs, but they are not independent municipalities. 

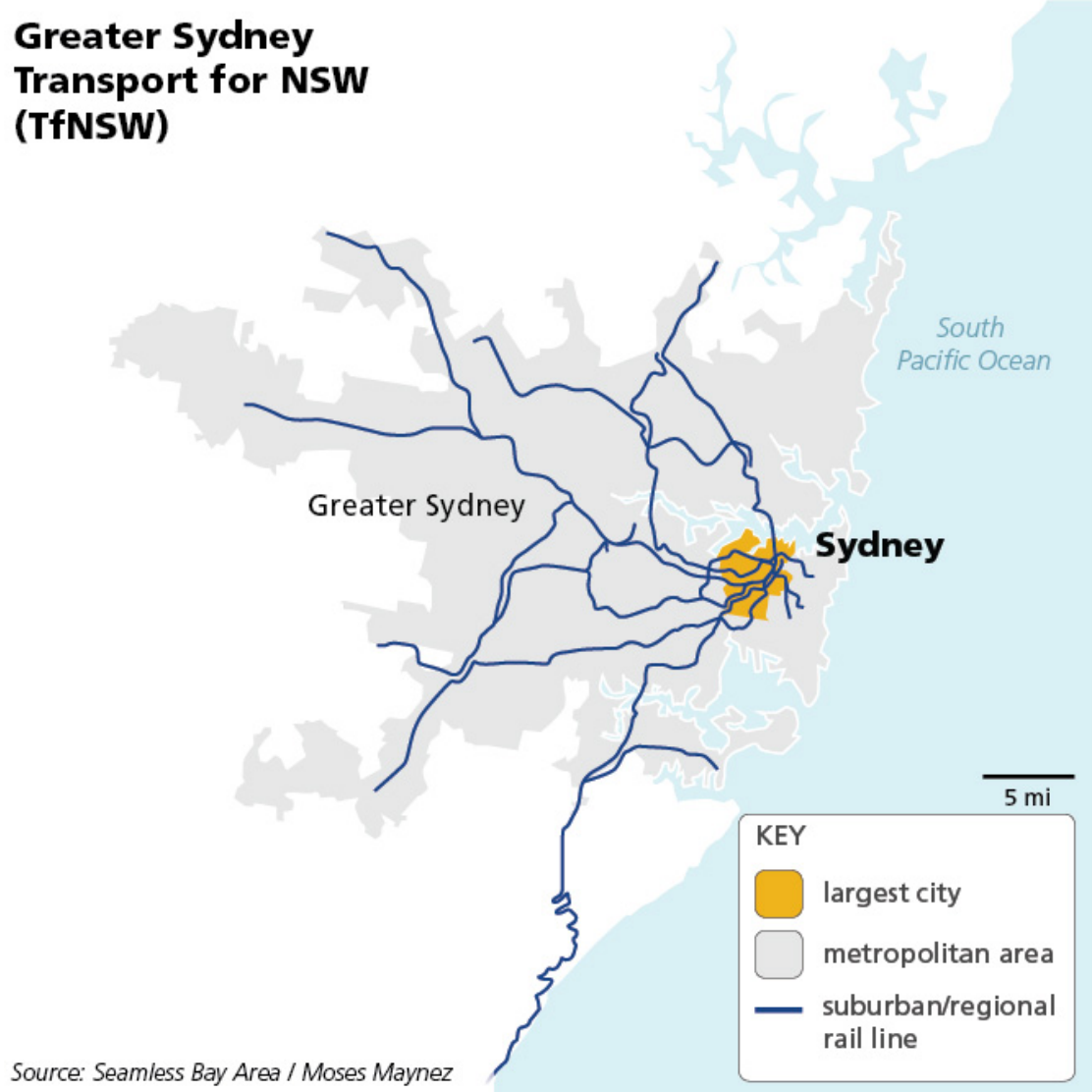

Figure 21. Greater Sydney Metropolitan Area

\section{Description of TfNSW, the Regional Transit Coordinator}

The agencies responsible for public transport in the state of New South Wales (NSW) have been frequently restructured over the past five decades, including major restructuring in 1972, 1980, and 1988 . The most recent and possibly the most significant change was introduced by State of NSW legislation of November 2011, which created the agency called Transport for NSW (TfNSW). ${ }^{79}$ Over the course of about a decade, between 2000 and 2010, all the public transit agencies, not only in Greater Sydney but in all of New South Wales, were merged under the single management of the newly created state agency: TfNSW. Since the 2011 legislation, things have continued to evolve; for example, at first, TfNSW was a separate entity from the New South Wales Department of Transport, but as of 2019, the two have merged to become a single agency. Thus, TfNSW manages public transportation as well as roads. ${ }^{80}$

Under Transport for NSW, separate government departments or agencies are responsible for providing public transit to the metropolitan area of Sydney as well as the rest of the State of New South Wales including Sydney Metro, Sydney Ferries, Sydney Light Rail, Sydney Trains, NSW Trains and an agency for the bus service (217 routes) in the Sydney metropolitan area. Thus, TfNSW functions as the 
overall coordinator of public transportation in Sydney as well as other areas in the State of NSW. Today, these agencies most often tender out the operations of the transit service to private companies. ${ }^{81}$

TfNSW is a state agency; there is no board. The chief executive officer of TfNSW is called the Secretary of the agency and is a public employee, not a political appointee. The TfNSW Secretary reports to two Ministers of the State of New South Wales: the Minister of Transport for Greater Sydney and the Minister of Transport for the rest of the state. ${ }^{82}$ The managers of the transit departments within TfNSW report to the Secretary and are hired by the Secretary; they are also state government employees. ${ }^{83}$

\section{Role of the TfNSW as the Regional Transit Coordinator and Transit Pro- vider $^{84}$}

The TfNSW has the responsibility within Greater Sydney to carry out the following activities.

- Build transport infrastructure and manage transport services in New South Wales

- Manage most train, bus, ferry, and light rail services in New South Wales

- Manage the route design, timetabling, and branding of these services

- Provide passenger information via printed material, a telephone service, and a website

- Procure the operation of the services contracted out to a mixture of other government-owned organizations and private enterprises (the trend is towards $100 \%$ private operators)

- Develop regulations, policies, and legislation to ensure that transport is delivered to a high standard

- Set fare policies and fares.

As the public transit provider, TfNWS is responsible for operating (or tendering out the operation of) the following transit services.

- Sydney Metro

- Sydney Ferries

- Sydney Light Rail

- Sydney Trains 
Regional Transit Coordination, Institutional Climate, \& Governance Setting 63

- All buses

- Paratransit

As already mentioned, TfNSW has other responsibilities besides public transport in Greater Sydney:

- The agency builds transport infrastructure and manages transport services in all of New South Wales, not just Greater Sydney.

- It directly manages most train, bus, ferry, and light rail services in all of New South Wales, not just Greater Sydney.

- Since 2019, the agency is also responsible for building and maintaining road infrastructure, managing day-to-day compliance and safety for roads and waterways, and vehicle and driving license registrations.

\section{PERTH, AUSTRALIA}

The metropolitan area of Perth, Australia is called Greater Perth. According to the Australian Bureau of Statistics, Greater Perth is made up of 32 Local Government Areas or LGAs with a total population of about 2 million (Figure 22). There is no formal regional level of government for the metropolitan, area nor is there any intermediate level of government between the LGA and the State of Western Australia. 85 
Regional Transit Coordination, Institutional Climate, \& Governance Setting 64

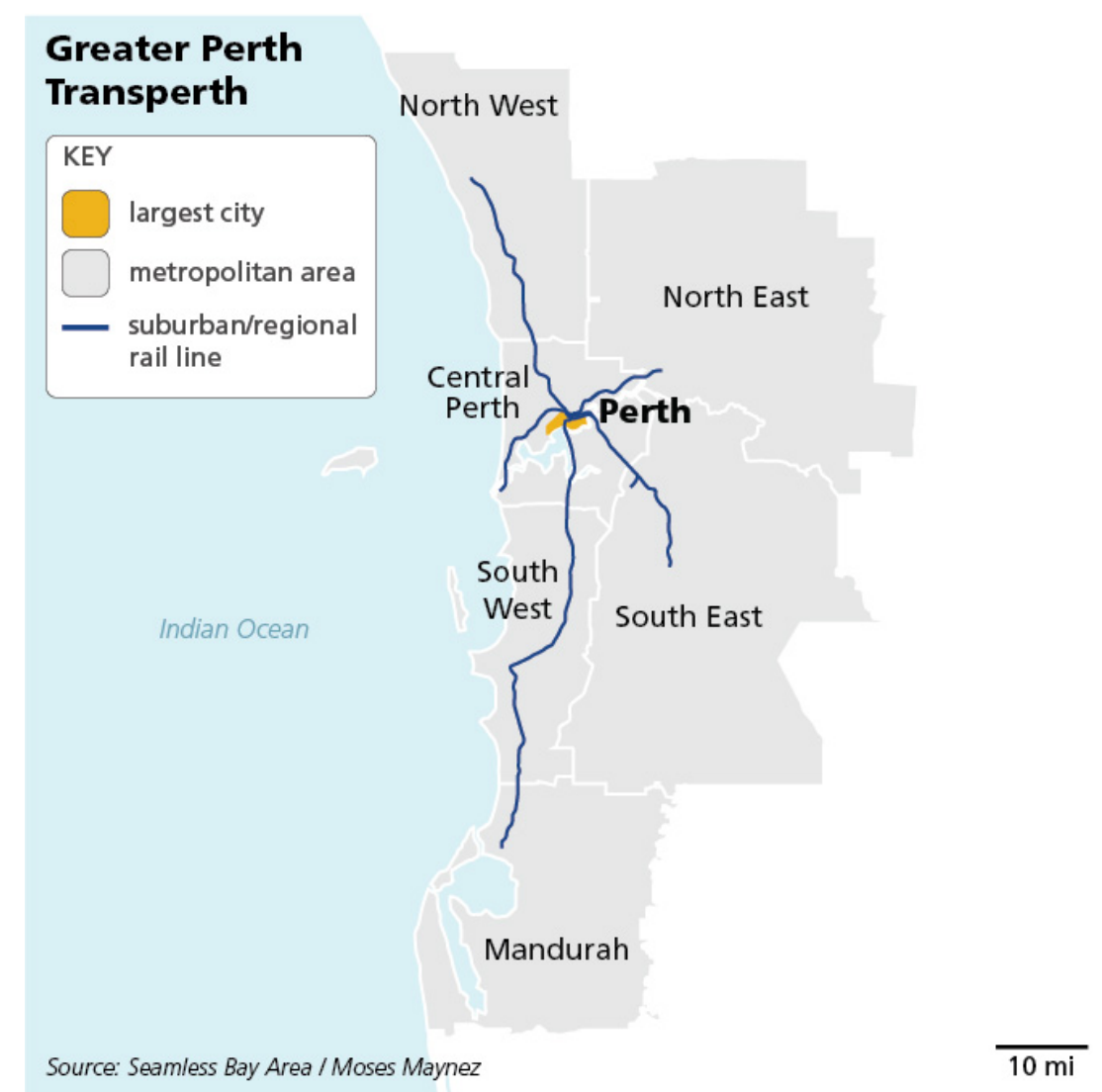

Figure 22. Greater Perth Metropolitan Area

\section{Description of Transperth, the Regional Transit Coordinator}

Transperth is the agency in charge of all public transportation in Greater Perth. Transit coordination-and indeed consolidation-in Perth has a long history. In 1958, the Metropolitan (Perth) Passenger Transport Trust took over the larger private bus companies, and trams were retired from service. In 1974, the management of urban rail services was placed with the Metropolitan (Perth) Passenger Transport Trust. In 1986, Transperth became the official name of this organization. In 1993, the planning, coordination, and policy functions for public transport were transferred from the Metropolitan (Perth) Passenger Transport Trust to the Department of Transport of the State of Western Australia. ${ }^{86}$ In 2003, Transperth and three other agencies were assumed under the newly created state agency called the Public Transport Authority (PTA) via the Public Transport Authority Bill 2003.87 Today, Transperth is now one of four main entities responsible for public transit under the purview of PTA. For the purposes of this study, it is difficult to tell whether Transperth or PTA would now be considered the RTC of Greater Perth; it appears that Transperth does all the needed coordination functions for the metropolitan area of Greater Perth, and PTA does any needed coordination beyond Greater Perth, i.e., for the rest of the state of Western Australia. In any case, they are both state agencies. 
Regional Transit Coordination, Institutional Climate, \& Governance Setting 65

As a state agency, Transperth has no board. The chief executive officer of Transperth is called the Executive Director. There is also a General Manager for Transperth Train Operations. Both report directly to the Chief Executive Officer of the PTA. The CEO of PTA reports to the Minister for Transport and Planning of the State of Western Australia. The Minister positions are cabinet positions appointed by the premier of the State from among the elected members of the state parliament. 88

\section{Table 4. Key Milestones in the Evolution of Transperth}

- $\quad$ 1958: Metropolitan (Perth) Passenger Transport Trust (forerunner of Transperth) took over the larger private bus companies, and trams were retired from service.

- $\quad$ 1974: Integration of Perth public transport took place when management of urban rail services was placed with the Metropolitan (Perth) Passenger Transport Trust (the forerunner to Transperth).

- $\quad$ 1986: Transperth became an official trading name.

- $\quad$ 1993: Planning, coordination, and policy functions for public transport were transferred from the Metropolitan (Perth) Passenger Transport Trust to the Department of Transport (State of Western Australia).

- 2003: The Public Transport Authority of Western Australia was formed through the amalgamation of Transperth, WAGR, school bus services, and regional town bus services. ${ }^{89}$

\section{Role of Transperth as the Regional Transit Coordinator and Transit Provider}

Transperth is both the transit operator and transit coordinator. It is most similar to Stockholm's TFV, given that it is a government (state) agency.

It is responsible for all aspects of public transportation, including:

- Short- and long-term planning

- Coordinating schedules

- Determining fare rates and appropriate ways to pay

- Marketing and branding

- Public information and customer service

- Procurement

- Building new rail lines 
Regional Transit Coordination, Institutional Climate, \& Governance Setting 66

As the public transit provider, Transperth is responsible for operating (or tendering out the operation of) the following transit services:

- Transperth trains (five lines, hybrid commuter/rapid transit electric trains)

- Transperth ferries

- Transperth buses

\section{SUMMARY}

All ten of the case study metropolitan areas have an RTC, but the path by which they got there varied considerably. Some created their RTC through a regional government lens, some through the state legislation, and some through local voluntary cooperation; the latter option, cooperation, was sometimes subsequently supplemented with state legislation.

Based on this review of ten metropolitan areas in seven countries, it is clear that there is no one model for transit coordination and the specific functions they carry out also vary (see Chapter 6 for a comparison table). Indeed, several models seem to work, with a wide variety of permutations occurring within each basic model. This review found that even within the same country there are different structures: for example, Toronto versus Vancouver.

A pattern did seem to emerge: the basic structure of the coordination agency identified in this research fits into one of three basic types.

- Coordination Only: Coordination agency is separate from the transit system owners and the transit operators. Typically, it is organized as an alliance of the separate local and regional transit system owners, but it has specific coordination responsibilities, which vary as shown in the Table 16 in Chapter 6. This coordination role as an alliance of other entities is the model seen in Frankfurt and Stuttgart (and indeed throughout Germany and Austria) and also in the case study areas of Milan, Lyon, and Barcelona. Board structure varies considerably, as does its mandate, which may either come from state or national legislation or a voluntary agreement among the many transit partners.

- Coordination Agency and Regional Transit Agency: In addition to coordination of all the separate transit system owners, the coordination agency also owns and manages the regional transit modes: that is, it is the owner and operator for regional transit (Metrolinx in Toronto, and researchers have detected one other agency like this: Transport for Greater Manchester, which owns and operates Metrolink, the UK's largest light rail network.) 
Regional Transit Coordination, Institutional Climate, \& Governance Setting 67

- Complete Consolidation: There is one metropolitan areawide agency for all public transportation modes that is responsible for all aspects of providing and coordinating transit service. This agency either operates under the state government (New South Wales for Sydney, Western Australia for Perth) or the county-state (Stockholm), or another government agency at a regional level (TransLink in Vancouver, the only agency of its kind found in this research-referred to here as a StateAuthorized Regional District [see preface]). 


\section{CUSTOMER-APPARENT CHARACTERISTICS}

World-class metropolitan transit systems appeal to riders-existing riders as well as potential riders. Owners of metropolitan transit systems have a vested interest in retaining current riders and turning potential riders into actual riders.

Customer-apparent characteristics are those features that directly affect riders and ridership. Many measures of quality and level of service are palpable to transit customers, affecting their decision to ride and their overall satisfaction. This section explores these customer-apparent features for the ten case study regions. Such factors include the following items.

- Average travel speeds of transit modes.

- Frequency of service for transit modes in commute periods as well as off-peak periods and weekends.

- Regional service provided in terms of area coverage.

- Coordinated scheduling (e.g., interagency and intermodal timed transfers).

- Coordination of fares between different transit operators and modes, including the following elements:

- Free transfers/single fares across systems in the region.

- The existence of single passes across systems in the regione.g., daily, multi-day, monthly, and yearly passes for the region.

- Regionwide incentives to use transit in off-peak times (bring a friend/child/family member for free, or other ridership incentives).

- Affordability compared to regional incomes or GDP per capita.

\section{TRAVEL SPEEDS}

Transit professionals and academic researchers both recognize the importance of speed of service. Speed may be defined as a combination of the running speed of a transit vehicle and the frequency of the service. Transit riders perceive time waiting with roughly double the weight compared to time spent in the transit vehicle..$^{90}$ It is origin-to-destination time, including waiting and transfer time, that most affects a rider's decision to ride; this emphasizes the importance of frequent service and timed transfers.

Transit speed also must be considered in context, that is, relative to other available modes of travel. In the early $20^{\text {th }}$ century, trams/streetcars were much faster than the only other mode available to most urban dwellers: walking. Today the chief competitor to transit is the automobile, and the relative speed of transit versus the 
auto is often the key factor deciding mode choice for riders with the option to drive, the other being the price of parking. While this study did not investigate these other two factors, the speeds of the case study transit modes were investigated to determine whether anything stood out.

Looking at the subset of European case study cities for which the EMTA Barometer report provides data, the research team found significant differences in in-service speeds across different modes, as expected. There were even some differences among the same modes between metropolitan areas. Bus, tram, metro, and commuter rail will each be examined in turn. ${ }^{91}$

Bus speed data were available only for three of the six European regions included in this study: Barcelona, Frankfurt, and Lyon. Barcelona's buses average $12 \mathrm{kph}$ (7.5 mph), while Frankfurt's buses average $15 \mathrm{kph}(9.5 \mathrm{mph})$, and Lyon's buses average $18 \mathrm{kph}(11 \mathrm{mph})$.

Thus, the scheduled speeds of buses in these three case studies from metropolitan areas are below that of the U.S. average $19 \mathrm{kph}(12 \mathrm{mph})$. However, they are within the range found for major U.S. cities: p.m. peak hour bus speeds in San Francisco range from 8-32 kph (5-20 mph), with most between 12-19 kph (8-12 $\mathrm{mph}$ ); New York City's average is $15 \mathrm{kph}(9.5 \mathrm{mph})$. It must be noted that bus speeds are dependent on a number of factors such as vehicle congestion, presence of bus-only lanes, fare payment method, intersection density, speed limit, and the number of boardings, some of which do not affect metro or commuter rail modes. A more meaningful comparison of bus speeds would control for these factors as well as ridership and population. But it does appear that the bus speeds achieved in these areas are not spectacular. A statistic that significantly affects bus speeds that is worthy of tracking but that was not readily available (not even on Wikipedia) is the presence and extent of bus-only lanes. EMTA had this data only for one of the case study cities, Barcelona $(119 \mathrm{~km})$.

Turning to rail modes, tram (in-street rail or streetcar) service speed data were only available for Lyon. Lyon trams average $21 \mathrm{kph}(13 \mathrm{mph})$. By comparison, U.S. streetcars average only $11 \mathrm{kph}(7 \mathrm{mph})$. This is about half the speed of Lyon's trams.

With respect to metros (urban rail operated within its own protected right of way, with underground or elevated stations), EMTA data were available for four systems. Frankfurt's metro operates at an average speed of $25 \mathrm{kph}(16 \mathrm{mph})$. The Barcelona (28 kph; $17.4 \mathrm{mph}$ ), Lyon (29 kph; $18 \mathrm{mph}$ ), and Milan (27-30 kph; $18 \mathrm{mph}$ ) metro systems are somewhat faster. The Stockholm metro is even faster at $34 \mathrm{kph}$ (21 $\mathrm{mph}$ ). In the U.S., APTA reports that heavy rail operates at an average speed of $31 \mathrm{kph}$ or $20 \mathrm{mph}$. (For reference, 15 U.S. transit systems are classified as heavy rail and are listed in Appendix A.) Given differences in station spacing and passenger loads between U.S. heavy rail and other countries' metro systems, it is impossible to draw many conclusions between these case studies and U.S. examples. For example, Bay Area Rapid Transit (BART) has station spacing similar to 
commuter rail for most of its network, which enables it to reach higher operating speeds. It can be said that the U.S. average speed for heavy rail modes is more or less the same as three of the case studies considered here, and it is faster than one (Frankfurt); only Stockholm's metro is faster than the U.S. average.

Commuter rail is the fastest rail mode owing to longer distances covered and greater distances between stations (and thus fewer stops per mile). EMTA reports data for three metropolitan areas. The Frankfurt and Barcelona commuter rail systems both average $47 \mathrm{kph}(29 \mathrm{mph})$. Stockholm's commuter rail is significantly faster at $59 \mathrm{kph}$ (37 mph). In the U.S., commuter rail speeds average $50 \mathrm{kph}$ (31 $\mathrm{mph}$ ). Again, the case study speeds are more or less the same as the U.S. average, and again, Stockholm exceeds the U.S. average speed.

In sum, the transit speeds in the case study areas did not seem out of the ordinary or remarkably better compared to U.S. averages. Again, it is not known how they compare to other options such as driving, nor is it known how they compare when considering frequency of service, time spent waiting for the bus in the first place, and time to transfers between modes or lines: that is, all the factors that would account for the full trip. This would be a good topic for future research.

\section{TRANSIT SUPPLY: COVERAGE AND FREQUENCY}

Transit supply is a factor of both network extent and how it is operated, that is, geographical reach of service and the frequency of service and temporal coverage throughout the day. These aspects of customer experience will now be explored.

\section{Service Levels as Measured by Transit Vehicle-Kilometers}

If the overall speeds of European systems do not seem remarkable, there is another measure on which they do: service frequency as measured by vehicle service-kilometers. Table 5 shows the number of transit vehicle-kilometers per capita (transit service area inhabitant) in five of the European case study metropolitan areas plus Toronto. ${ }^{92}$

In comparison, by one estimate, the U.S. has 28 vehicle-kilometers of transit service per capita (for urban residents). ${ }^{93}$ Each of these six metropolitan areas offers substantially more transit service, with Stockholm providing nearly four times the amount of service, compared to the average U.S. metropolitan transit system. 
Table 5. Number of Transit Vehicle Hours per Capita (Transit Service Area Inhabitant) in Five of the European Case Study Metropolitan Areas Plus Toronto: All Transit Modes and Rail Modes Only

\begin{tabular}{llc}
\hline & $\begin{array}{l}\text { All Transit Modes: } \\
\text { Vehicle-Kilome- } \\
\text { ters per Capita }\end{array}$ & $\begin{array}{l}\text { Rail Modes Only: Train-Kilometers } \\
\text { per Capita }\end{array}$ \\
\hline Greater Stuttgart & 37.4 & 14.0 \\
Frankfurt Rhein Main & 39.9 & 14.6 \\
Lyon & 41.6 & 9.0 \\
Greater Barcelona & 64.7 & 40.0 \\
Stockholm County & 109.4 & 54.0 \\
& & \\
Toronto & 48.0 & - \\
\hline
\end{tabular}

Note: Vehicle service-kilometers data for the other case study regions were not available. Rail modes include commuter/suburban rail, metro /heavy rail and light rail.

Source: EMTA Barometer 2019-Based on 2017 Data. EMTA, European Metropolitan Transport Authorities (June 2019), except Toronto from www.metrolink.com.

Even more stark is the difference between these case studies and the U.S. with respect to transit service for rail modes. The vehicle-kilometers per capita for only the rail modes (i.e., metro, tram/light rail and suburban rail) are also given in the EMTA Barometer 2019 and shown in Table 5.

Comparisons with U.S. rail mode data are difficult, because rail modes in the U.S. on the Federal Transit Administration's National Transit Database (NTD) summary sheets are reported as vehicle-miles whereas European data are reported as train-kilometers. One rail-heavy U.S. metropolitan area, Boston, using data on the NTD summary sheet, yields 17.8 vehicle-miles per capita (28.6 vehicle-kilometers per capita), but on further investigation it was found to have 3.7 train-miles per capita (6.0 train-kilometers per capita) ${ }^{94}$ This is two-thirds the service of Lyon, less than half as much service as the German case studies, and less than fifteen percent of the service in Barcelona and Stockholm.

There are many other metrics used to measure transit supply, service coverage, and frequency; below are just a few. 


\section{Route Miles of Rail Transit}

One simple comparison is the total length (kilometers or miles) of rail routes. Given that the focus of this research is the metropolitan area, the extent of the suburban commuter passenger rail network will be presented.

For the five European case studies whose data were available, all had between 80 and 290 kilometers of rail routes per million inhabitants, as shown in Table 6. Toronto was lower at 53 kilometers.

\section{Table 6. Suburban (Commuter) Rail Network Route-Kilometers per Million Inhabitants and Number of Suburban (Commuter) Rail Lines in the Six European Case Study Metropolitan Areas Plus Toronto and Chicago}

\begin{tabular}{lcc}
\hline Metropolitan Area & $\begin{array}{l}\text { Route-Kilometers } \\
\text { (miles) per Million }\end{array}$ & Number of Lines \\
Inhabitants & $290(180)$ & 6 \\
\hline Greater Stuttgart & $280(174)$ & -- \\
Frankfurt Rhein Main & -- & 14 \\
Lyon & $110(68)$ & 3 \\
Greater Barcelona & $100(62)$ & 12 \\
Stockholm County & $80(50)$ & 7 \\
Milano Basin & & \\
Greater Toronto and Hamilton & $53(33)$ & \\
Chicago Metropolitan Area (Metra) & $78(48)$ & \\
\hline
\end{tabular}

Note: Data for the other case study regions were not available. Suburban passenger rail miles only; subway lines and other rails not included.

Source: EMTA Barometer 2006. EMTA- European Metropolitan Transport Authorities (2007) except Chicago: https://metrarail.com/about-metra/reports-documents/operations-ridership-data; and Toronto: Metrolinx, The 2041 Regional Transportation Plan available at http://www.metrolinx.com/en/regionalplanning/rtp/ 
For comparison, the total length of 11 suburban commuter rail lines serving Chicago operated by Metra average close to $80 \mathrm{~km}$ (50 miles) per one million inhabitants, and Chicago has the second longest network in the U.S., boasting $784 \mathrm{~km}$ (487 miles ${ }^{95}$ ) with a metropolitan area population of about 10 million. It is second only to New Jersey Transit Railroad with 853 route-kilometers (530 route-miles).

\section{Headways}

Of course, having the tracks does not mean much if service is infrequent or operates only during the peak hour in the peak direction, as is the case for some U.S. suburban rail systems. A standard industry term to measure frequency is headway which is defined as "the time interval between vehicles moving in the same direction on a particular route." 96 This aspect of the rail transit supply is reflected in the vehicle-kilometers and train-kilometers discussed above. But with respect to headways, which a customer understands better than vehicle-kilometers, the 12 suburban lines of Milan are guaranteed to run at least every 30 minutes from 6 a.m. to midnight seven days a week, with more frequent service during the peak hours. These operational decisions are integral to achieving the high vehicle-kilometer or train-kilometer numbers shown above.

Metros and light rails are operated at even closer headways: Lyon's metro runs at headways of two minutes during the peak hour, whereas Stuttgart's U-Bahn (hybrid of heavy and light rail) runs peak hour headways of ten minutes.

When transit is operated at frequent headways, it reduces the passenger's overall travel time by reducing passenger wait time, as discussed above under Travel Time. Thus, short headways and timed transfers are an important component of the passenger experience. Indeed, if both services have short headways, timed transfers are moot.

\section{Percentage of Lines with Headways of Five Minutes or Less}

Another way of monitoring and comparing frequency is the share (percentage) of lines operating with headways under five minutes during the peak hour. For example, in Barcelona, 40 percent of bus lines, 70 percent of the tram lines, and 100 percent of the metro lines have headways under five minutes during the peak hour. ${ }^{97}$

\section{Coordinated Schedules}

In addition to greater overall service, a hallmark of all of the case study metropolitan areas is a high degree of schedule coordination across modes. In other words, not only is their service more frequent, but schedules are designed to facilitate transfers between transit modes and services. Schedule coordination greatly reduces transfer time and makes a transit system feel seamlessly integrated. 


\section{Late-Night Service}

Being able to take public transit after midnight is another measure of transit supply, and it makes a difference as to whether or not transit can be used as a substitute for a private vehicle. Of those who reported data to EMTA, Barcelona had the most night transit service of the case studies: 33 bus lines, five trams, and nine metro lines. Two other cases from EMTA operated night bus service but not trams or metros include Stuttgart (29 bus lines) and Stockholm (39 bus lines) ${ }^{98}$, while Toronto also operates night buses (24 lines). ${ }^{99}$

\section{Car Availability}

The availability and the attractiveness of automobiles represent a key element affecting transit travel. Table 7 reports the rates of car ownership per 1,000 inhabitants in the main cities of four case study metropolitan areas.

\section{Table 7. Car Availability in the Main Cities of Four European Case Study Metropolitan Areas}

\begin{tabular}{lc}
\hline Main City & $\begin{array}{c}\text { Car Ownership per } \\
1,000 \text { Inhabitants }\end{array}$ \\
\hline Stuttgart & 460 \\
Lyon & 250 \\
Barcelona & 360 \\
Stockholm & 370 \\
\hline
\end{tabular}

Notes: Data for the other case study regions' main cities were not available.

(a) EMTA Barometer 2019.

(b) VRS says 570 for the Stuttgart region, suggesting significantly higher car availability outside the main city.

By comparison, the U.S. had 838 private motor vehicles per 1,000 inhabitants in $2017^{100}$-more than twice the level of motor vehicle accessibility compared to a typical European city. This study cannot resolve whether car ownership is low in those cities because transit service is so good or whether transit service is so well used because car availability is low. 
FARES AND FARE POLICY

This section highlights key aspects in fares and fare policies in the case study metropolitan areas. Some key fare policies are summarized in Table 8 and general conclusions from the case studies' fare policies discussed in Chapter VI. These and other notable features of each metropolitan area's current fare system are described below. This chapter does not present a comprehensive evaluation of all fare policies across all case studies, but rather it is only meant to present the overall fare policies and illustrate that there are variations in the details and implementation. Except as noted, fare information was derived from the relevant regional transit coordinator's website in April 2020.

Table 8. Key Fare Policies of Metropolitan Case Studies

\begin{tabular}{|c|c|c|c|c|c|}
\hline & & Fare Policy & & & \\
\hline $\begin{array}{l}\text { Metropolitan Area/ } \\
\text { Regional Transit Coor- } \\
\text { dinating Agency }\end{array}$ & $\begin{array}{l}\text { Smart Elec- } \\
\text { tronic Fare } \\
\text { Card (1) }\end{array}$ & $\begin{array}{l}\text { Single Ticket/ } \\
\text { Single Fare } \\
\text { Across Modes } \\
\text { (i.e., free } \\
\text { transfers)? }\end{array}$ & $\begin{array}{l}\text { Passes Valid } \\
\text { Across All } \\
\text { Modes and } \\
\text { Systems? (2) }\end{array}$ & $\begin{array}{l}\text { Daily Cap? } \\
\text { (if there is } \\
\text { no daily } \\
\text { pass) }\end{array}$ & $\begin{array}{l}\text { Distance/ } \\
\text { Zone- } \\
\text { Based } \\
\text { Pricing? }\end{array}$ \\
\hline Greater Stuttgart/VVB & Yes (Polygo) & Yes & Yes & -- & Yes \\
\hline $\begin{array}{l}\text { Frankfurt Rhein Main/ } \\
\text { RMV }\end{array}$ & $\begin{array}{l}\text { Yes (e-ticket } \\
\text { Rhein-main) }\end{array}$ & Yes & Yes & -- & Yes \\
\hline $\begin{array}{l}\text { Lyon Metropolis/ } \\
\text { SYTRAL }\end{array}$ & Yes (Técély) & Yes & Yes & -- & No (3) \\
\hline $\begin{array}{l}\text { Greater Barcelona/ } \\
\text { ATM }\end{array}$ & $\begin{array}{l}\text { Planned ( } T \\
\text { Mobilitat) }\end{array}$ & Yes & Yes & -- & Yes \\
\hline Stockholm County/TFV & $\begin{array}{l}\text { Yes (SL Ac- } \\
\text { cess) }\end{array}$ & Yes & Yes & -- & No \\
\hline Milano Basin /TPL & Yes (Itinero) & Yes & Yes & -- & Yes \\
\hline $\begin{array}{l}\text { Greater Toronto and } \\
\text { Hamilton/Metrolinx }\end{array}$ & Yes (Presto) & No & No & No & $\begin{array}{l}\text { TTC: No } \\
\text { GO: Yes }\end{array}$ \\
\hline $\begin{array}{l}\text { Greater Vancouver/ } \\
\text { TransLink }\end{array}$ & $\begin{array}{l}\text { Yes (Com- } \\
\text { pass) }\end{array}$ & Yes & Yes & -- & Yes \\
\hline
\end{tabular}




\begin{tabular}{llllll}
\hline Greater Sydney/TfNSW & Yes (Opal) & No & No & Yes & Yes \\
$\begin{array}{l}\text { Greater Perth/ } \\
\begin{array}{l}\text { Transperth } \\
\text { Res (Smart }\end{array}\end{array}$ & Yes & No & No & Yes \\
\hline
\end{tabular}

TTC: Toronto Transit Commission

GO: Greater Ontario regional transit

Notes:

(1) Smart cards are a contactless electronic method of fare payment, which may or may not be tied to a specific person or to their bank account.

(2) Pass type varies by agency: typically, daily and monthly, but some also have weekly, annual, 48 hours, and/or 72 hours.

(3) The fare structure within the metropolitan area of Lyon is not zone based, but SYTRAL, which also manages the adjoining Rhône province has developed a fare policy to connect Lyon and all of Rhône with tickets structured effectively as a second zone.

\section{Frankfurt}

The public transit system in Frankfurt is coordinated by the Rhein-MainVerkehrsverbund (RMV). As noted earlier, the public transport network comprises several carriers, but all use the same fare system. One ticket is valid for a journey even if it includes several modes of transit or is run by different system owners or operators. Tickets can be bought in several ways: at the driver on board a bus, in advance of travel at a ticket vending machine, and online (whereby mobile tickets can be presented as proof of payment). For the monthly and annual passes there is the card based e-ticket system.

At stations, there are no turnstiles or similar barriers; instead, a proof-of-payment system is used. Plainclothes or uniformed fare inspectors are employed and carry out random checks to ensure passengers have paid. If found to be travelling without a ticket, passengers are required to pay a fine of $€ 60$ ( $\$ 66$ USD ${ }^{101}$ ).

A single, one-way trip within the city and inner suburbs of Frankfurt costs on average $€ 2.95$ ( $\$ 3.35$ USD), and a journey to the more distant suburbs outside Frankfurt costs on average $€ 10$ ( $\$ 11.30$ USD). There are also some discounts for children, as well as for group or day tickets. A day ticket for traveling within Frankfurt costs $€ 5.50$ (\$6.20 USD). ${ }^{102}$ Modes covered include rapid transit, trams, the underground, and buses.

\section{Stuttgart}

As described in Chapter III, the Verband Region Stuttgart (VRS) is the regional governmental political jurisdiction encompassing the City of Stuttgart and four surrounding counties, as well as being responsible for the operation of the suburban 
railway system (S-bahn), the new express bus services, the new Park \& Ride system, and regional traffic management.

VVS is the transit coordinating agency with the same geographic boundaries as VRS. It coordinates many system owners, the largest being Stuttgarter Straßenbahnen AG (SSB) in the City of Stuttgart. SSB owns and manages the Stuttgart Stadtbahn (light rail), bus lines, a rack railway, and a funicular (vertical) railway. All means of public transport in the VVS can be used with the new "Polygo" travel card which has extended its capabilities to include car sharing, e-mobility, and bike rentals.

As of April 1, 2019, the VVS reformed their fare structure, significantly simplifying the fare system. The 52 fare zones became five ring zones, as shown in Figure 23. VVS' uniform fares are valid throughout the City of Stuttgart as well as its neighboring counties, and a single ticket or pass can be used on all underground and commuter trains, trams, and buses, the rack railway, and the funicular railway. All of the City of Stuttgart is now within one fare zone. The new fare structure has made trips within Stuttgart and between Stuttgart and the surrounding areas much cheaper, with savings for commuters totaling as much as 25 to 30 percent. 


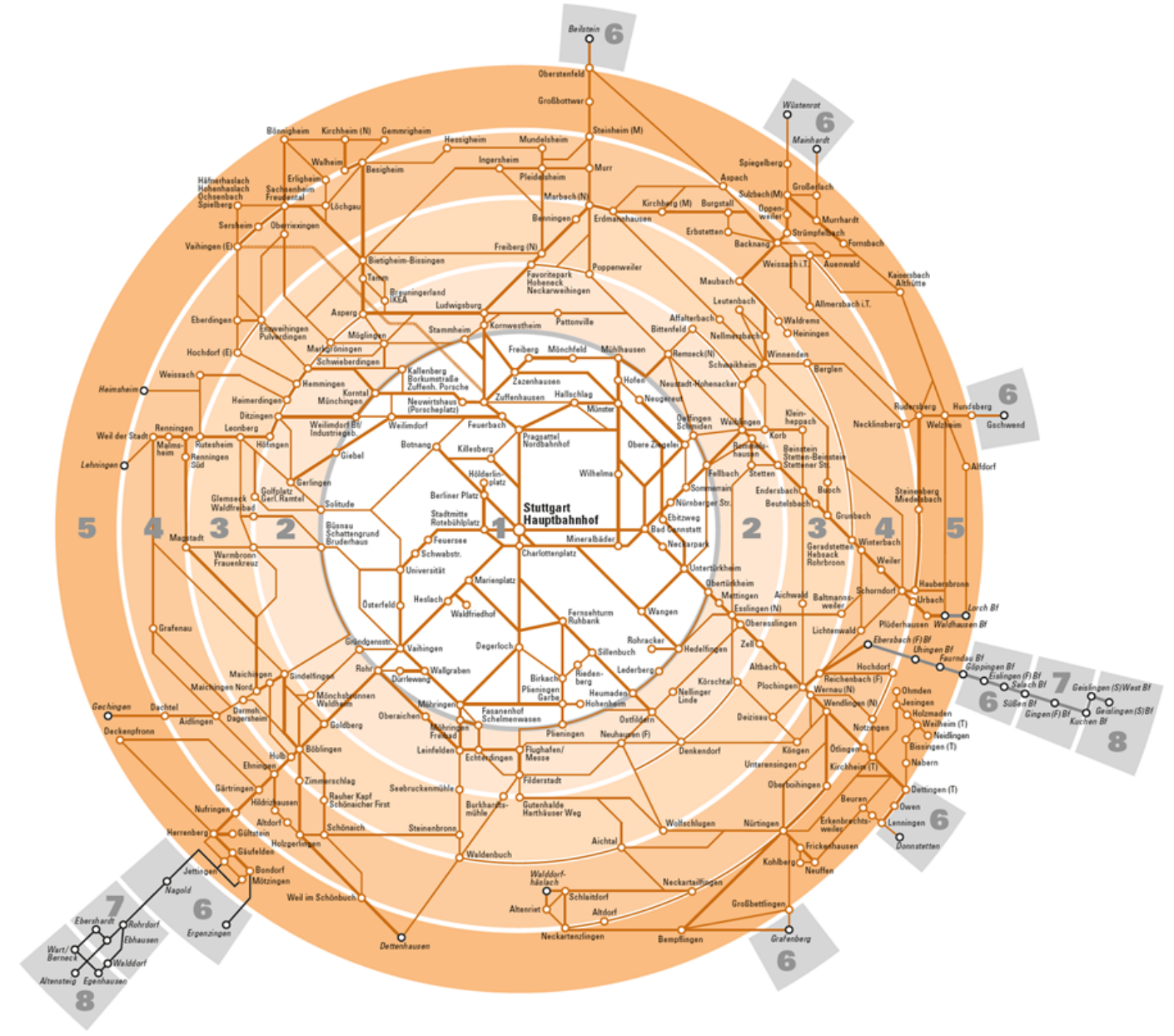

\section{Figure 23. Stuttgart's VVS Fare Zones ${ }^{103}$}

Since fare reform in April 2019, the number of people carried on the trains and buses in the VVS service area has increased by 3.2 percent. Considering only the tickets that were directly affected by the fare reform, the increase is higher: 4.8 percent. In particular, the number of pass subscribers has increased significantly as a result of the reform. This achieved an essential goal of the fare reform: the acquisition of additional regular customers.

\section{Barcelona}

As for six of the chosen case studies, public transport in Barcelona metropolitan area is operated by several companies, most of which are part of the RTC for the metropolitan area of Barcelona called Metropolitan Transport Authority (ATM). An important aspect of ATM's mission is to foster cooperation among the agencies that belong to the consortium. As such, fares have been developed on a zonal basis without regard to who owns or operates the transit service. 
There are seven zones, with Zone 1 comprising central Barcelona and the airport. A variety of single-integrated tickets are offered alongside a variety of discount options.

- T-casual (10 journeys)

- T-usual (unlimited journeys for 30 days)

- $\quad$-grup (70 journeys for 30 days)

- T-familiar (8 journeys for 30 days)

- T-dia (unlimited journeys for 24 hours)

As an example of the discount, base fare for one zone costs $€ 2.40$ (\$2.66 USD); the ten-journey $T$-casual ticket is priced at $€ 11.35$ ( $\$ 12.58$ USD), a more than $50 \%$ discount per journey. ATM also offers tourist passes valid for $2-5$ days of unlimited daytime travel. One pass also includes discounts on many attractions of interest to visitors.

\section{Milan}

Beginning in July 2019, a new fare system was implemented for the metropolitan City of Milan and the Province of Monza-Brianza. The fares vary by number of zones crossed, and there are nine zones. The City of Milan and its 21 adjacent communities constitute the first three fare zones, M1-M3 (see Figure 24). The new fare system now includes the province of Monza-Brianza. See Table 9 for a summary of the Milan metropolitan area's transit fares, which shows fares that are significantly more attractive than they were previously. 


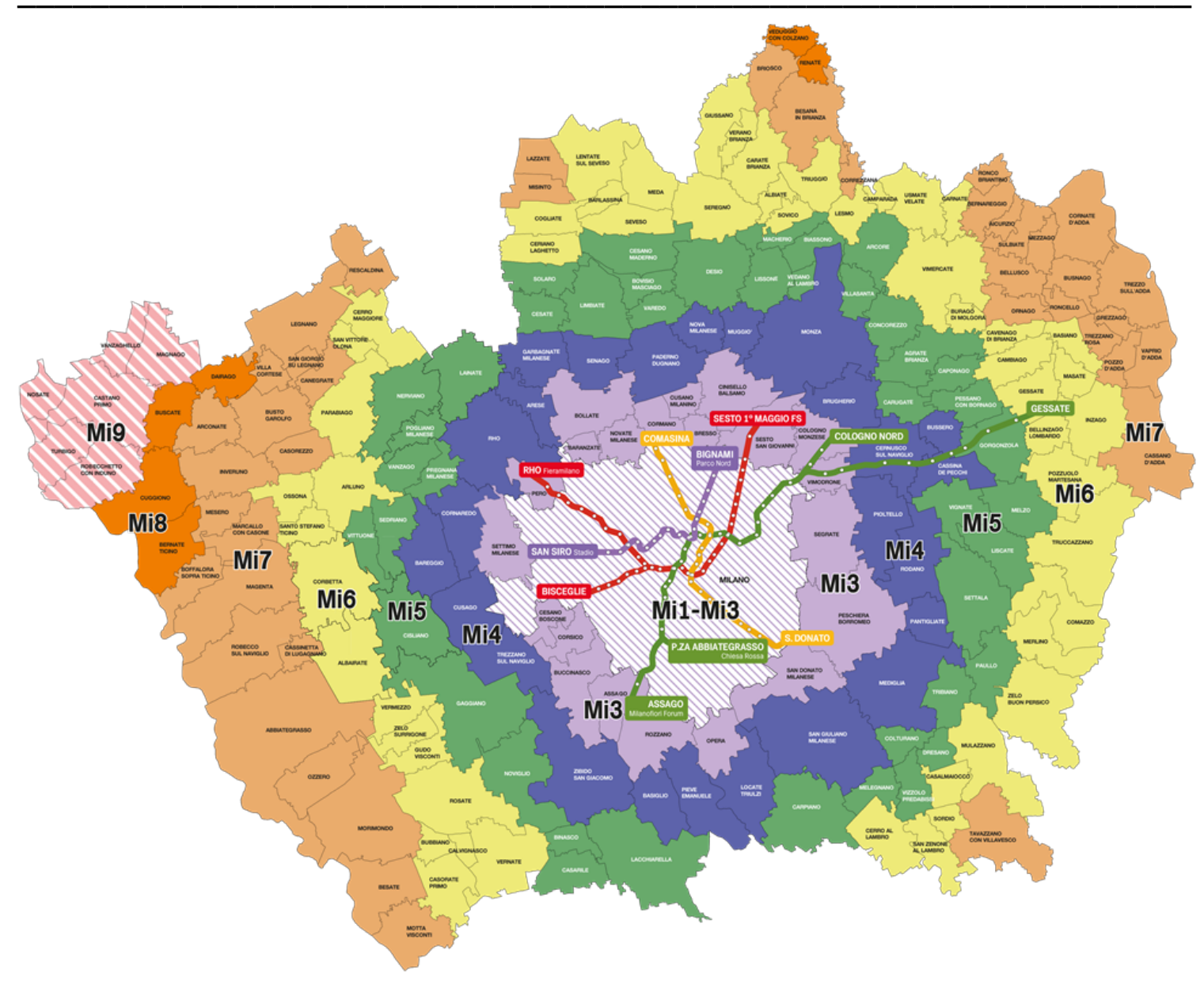

Figure 24. Fare Zones in the Milan Area ${ }^{104}$

The new fare system considers the City of Milan as the center of the Mobility Basin, from which the surrounding area is divided into concentric "crowns," each approximately five kilometers wide. Each crown represents a fare zone to which an identification code has been assigned.

The City of Milan is included in a larger area that includes the 21 municipalities bordering it and the Rho Fiera Milano station of Metro Line 1. This area corresponds to three fare zones and is identified by the codes Mi1-Mi3. Each municipality of the Basin, with all its stops and stations, is entirely assigned to a single fare zone. 
Table 9. Milan's Fare Structure

\begin{tabular}{lllll}
\hline Milan Fares as of 2019 & 2-Zone & $\begin{array}{l}\text { 3-Zone (Milan } \\
\text { Mi1-Mi3) }\end{array}$ & All 9 Zones & $\begin{array}{l}\text { Lombardy-Wide } \\
\text { Pass }\end{array}$ \\
\hline $\begin{array}{l}\text { Single ride good for } 75 \\
\text { to } 90 \text { to } 255^{*} \text { minutes }\end{array}$ & $\$ 1.77$ & $\$ 2.22$ & $\$ 4.87$ & $\mathrm{~N} / \mathrm{A}$ \\
Daily & $\$ 6.20$ & $\$ 7.76$ & $\$ 17.17$ & $\mathrm{~N} / \mathrm{A}$ \\
Monthly & $\$ 44.32$ & $\$ 55.40$ & $\$ 96.39$ & $\$ 119.65$ \\
Annual & $\$ 407.71$ & $\$ 509.63$ & $\$ 843.11$ & $\$ 1151.11$ \\
\hline
\end{tabular}

Notes: Special fare within City of Milan only is $€ 39$ (\$43.21 USD) monthly, $€ 330$ (\$365.61 USD) annually.

*Extra 15-30 min of valid time for each additional zone.

Passes available: daily, three days, weekly, monthly, and annually. Ten-ride ticket available.

Single tickets are valid for 75-90 minutes (or more, depending on how many zones are traversed), and they are valid regardless of how many mode or system transfers the rider makes. Ten-ride tickets are also available. Alternatively, there are also passes available for many time frames including daily, three days, weekly, monthly, and annually. In addition to the fare structural reforms that improved affordability as well as ease of use, there are several fare categories that provide significant discounts to certain users. Those riders purchasing fare categories based on age need to show proof of age when purchasing and using the passes, and/or a photograph is embedded on the pass itself. The fare price categories include the following:

- ordinary

- free for ages 14 and under

- $25 \%$ discount for those 65 and older

- $25 \%$ discount for those under 26

- family passes

\section{Lombardy Regionwide (Statewide) Fare Integration}

In February 2011, a fare system was initiated that created a single pass to move within the entire regione (state) of Lombardy (which consists of 12 provinces, 10 million people). The pass is valid on all modes of public transportation, both urban 
and interurban as well as suburban in any community in Lombardy. This includes buses, light rail, the Milan and Brescia metros, aerial cable cars (funivie), funiculars, regional intercity trains, and ferries on the lakes which are run by local governments (not tourist operators). The pass is available on a weekly, monthly, and yearly basis.

\section{Lyon}

SYTRAL, the RTC of the Lyon Rhône area of France, is somewhat unique, since it oversees the transit system of the metropolitan area of Lyon, which is run by TCL, as well as those of two other noncontiguous smaller urban areas in the province of Rhône. Thus, SYTRAL is responsible for more than just the metropolitan area of Lyon.

The RTC SYTRAL is responsible for fares and fare structure in its entire region, and it uses both passes and a paper ticket system. Since 2008, the pricing system for TCL was simplified. TCL introduced a single price fare system and discarded zone pricing. The other transit systems, which have simpler networks, also have a "single ticket single fare" policy. To travel on all the systems served by SYTRAL, SYTRAL created the Rhônepass, which allows use of all the networks managed by SYTRAL: TCL and the other two local networks, as well as SNCF regional rail. The Rhônepass is also available on an electronic card called "Oura." An adult fare is $€ 3.50$ ( $\$ 3.88$ USD) per trip, $€ 8.50$ ( $\$ 9.42$ USD) per day, $€ 80.00$ ( $\$ 86.63$ USD) per month, and $€ 800$ ( $\$ 886$ USD) per year.

TCL's service area, serving over 70 municipalities, consists of multiple modes including four metro lines with 42 stations, five tram lines, a trolleybus system, motorbuses, and longer distance coaches. There are also two funicular (vertical) lines that emanate from the old Lyon city center.

On the TCL system, a single ticket costs $€ 1.90$ ( $\$ 2.11$ USD) purchased in advance, or $€ 2.20$ ( $\$ 2.44$ USD) purchased on the bus, and it is valid for 60 minutes regardless of transfers and number of modes used; even round trips are allowed, as long as the last validation/connection was made within 60 minutes. There are passes available for a variety of timeframes: 24-hour, 48-hour, 72-hour, and weekly and monthly passes, which are of course valid on all modes of the TCL network. The TCL pass is called "Técély."

\section{Stockholm}

The Trafikförvaltningen (TFV, Stockholm County Public Transport Administration) is the county department behind Stockholm Public Transport (SL), Waxholmsbolaget (ferries), and disability transportation in Stockholm County. SL is the umbrella brand for all land-based public transport services in the Greater Stockholm area.

Stockholm's fare zone system was abolished in 2016. Fares are now flat over the entire county, and a single-ride fare is valid for 75 minutes. As is common, SL has 
two main forms of tickets: the pass and the single ticket. Both may be used for all SL public transport within Stockholm County.

Passes via travel card: valid during a specified period of time, from 24 hours up to a year, depending on the card.

Single-journey ticket: valid for 75 minutes from activation, within Stockholm County. Single-journey tickets are mainly purchased with credits loaded onto an SL Access card.

In either case, the ticket is loaded onto an SL Access RFID card that is scanned at the start of the first journey.

To travel outside the Stockholm metropolitan area, there are supplemental fares, for example to take the Stockholm Commuter Rail (Pendeltåg) to Arlanda Airport or to cross the county border to Uppsala and Knivsta. As mentioned above, the additional cost for using the railway station at Arlanda Airport is 120 SEK ( $\$ 12.55$ USD ${ }^{105}$ ) and can be paid upon arrival. Travelling to Uppsala or Knivsta with SL from Stockholm County requires a valid Uppsala County (UL) ticket in addition to the usual SL ticket.

The use of the SL Access card is almost universal for all ticket and travel card types. There are also single-use travel cards suitable for visitors.

\section{SL's Ticket Prices}

As of January 2019, the prices for the most common tickets are shown in Table 10. 
Table 10. SL's Single Journey Ticket Prices

\begin{tabular}{lcc}
\hline Purchase Method & $\begin{array}{l}\text { Adult Fare } \\
\text { (USD) }\end{array}$ & $\begin{array}{l}\text { Discounted Fare } \\
(<20 \text { or }>65) \\
\text { (USD) }\end{array}$ \\
\hline SL Credits ("Reskassa”) & $\$ 3.19$ & $\$ 2.19$ \\
$\begin{array}{l}\text { Mobile App, Ticket Machines, } \\
\text { Ticket Booths, or Ticket } \\
\text { Agent }\end{array}$ & $\$ 4.49$ & $\$ 3.09$ \\
& $\$ 6.38$ & $\$ 4.19$ \\
\hline Bought from Conductor & & \\
\hline
\end{tabular}

Notes: This fare structure strongly discourages buying from conductors on-board vehicles.

Source: Storstockholms Lokaltrafik website: $\underline{\text { https://sl.se/en/. }}$

\section{Table 11. SL's Travel Card Prices}

\begin{tabular}{llc}
\hline Card Type & Adult Fare (USD) & $\begin{array}{l}\text { Discounted Fare } \\
(<20 \text { or }>65)\end{array}$ \\
\hline 24-Hour Card & $\$ 15.45$ & $\$ 10.47$ USD \\
72-Hour Card & $\$ 30.90$ & $\$ 20.93$ USD \\
7-Day Card & $\$ 40.37$ & $\$ 26.92$ USD \\
30-Day Card & $\$ 92.71$ & $\$ 61.81$ USD \\
90-Day Card & $\$ 276.14$ & $\$ 180.44$ USD \\
365-Day Card & $\$ 973.96$ & $\$ 852.96$ USD \\
30-Day Card including & $\$ 118.63$ & \\
Arlanda Passage & & \\
\hline
\end{tabular}

Source: Storstockholms Lokaltrafik website: https://sl.se/en/. 
In addition, there are tickets available for school students under 20 years old, as well as tickets valid both for SL and UL.

Prepaid tickets are discounted: the longer the period of validity of the ticket, the greater the discount. Tickets and travel cards are sold at many shops as well as at metro and commuter railway stations. There are also ticket machines at most metro and commuter railway stations, as well as in a number of other locations. It is also possible to purchase a single-journey ticket, a 24-hour travel card, and a 72-hour travel card via a smartphone app.

\section{Stockholm Congestion Charge: A Modal "Equalizer"?}

For more than a decade, Stockholm has had a congestion tax levied on most vehicles entering and exiting central Stockholm. The congestion tax was first given a trial run in 2006 and implemented on a permanent basis on August 1, 2007. ${ }^{106}$

The primary purpose of the congestion tax is to reduce traffic congestion and improve the environment in central Stockholm. The funds collected are used for new transportation infrastructure in Greater Stockholm. The presence of the congestion charge has likely increased the attractiveness of public transit for travel to central Stockholm.

\section{Toronto}

The Toronto Transit Commission (TTC) is by far the largest system in the Greater Toronto and Hamilton Area (GTHA) region. The TTC operates a system of subways, buses, and streetcars, covering approximately $1,200 \mathrm{~km}(750 \mathrm{mi})$ of routes. Regional commuter rail and bus service is provided by GO Transit the GTHA, with operations extending to several communities in the larger (Greater Golden Horseshoe) region. Smaller communities in the region typically have their own bus systems. Metrolinx is the agency charged with coordinating fares and services in the Greater Golden Horseshoe (GGH) region.

Within the TTC system, transfers are free and valid for two hours, but unlike fares in Europe, no return trips or backtracking is permitted ${ }^{107}$. The price of fares varies according to the age or student status of riders. Children 12 years of age or under can ride on the TTC free of fare-a boon for families with children.

An electronic fare ("smart") card called Presto is available: it can be used in various ways (multiple-use, stored-value, electronic fare cards). Presto tickets (single-use, electronic paper tickets) are also available. Both use Presto readers to charge fares and validate transfers. Presto cards can be used on all TTC modes, GO Transit commuter rail lines and buses, as well as on the vehicles of approximately ten smaller operators in the GTHA region.

In 2018, Toronto and its surrounding municipalities signed a number of fare integration agreements, leading to discounted transfers for trips using the GO system (commuter rail and buses) and TTC (Toronto subways, buses, streetcars, and 
Scarborough light rail) as well as free transfers between key transit operators outside of Toronto. This was largely facilitated through the use of Presto cards. According to Metrolinx staff, the discount between the TTC and GO rail services was terminated in March 2020. The TTC believed the cost of the discounts was negatively affecting their revenue and that they were "subsidizing suburbanites"' travel. Nevertheless, the discount program has resulted in a 20 percent increase in interline ridership before it was ended, suggesting that it was at least partially successful at increasing transit ridership overall. ${ }^{108}$

One recent innovation promoted by Metrolinx is a $\$ 10 \mathrm{CAD}\left(\$ 7.51\right.$ USD $\left.{ }^{109}\right)$ Sunday pass aimed at encouraging travel on a day that typically sees the lowest ridership and most available transit capacity. ${ }^{110}$

\section{Vancouver}

As a single (consolidated) agency that manages and operates all modes, TransLink allows free transfers between modes. The metro area is divided in a three-zone system with fares depending on the number of zones (see Figure 25). TransLink uses a smart card electronic payment system called Compass Card. It is intended to replace existing paper monthly and daily passes, tickets, and cash. TransLink has been slowly phasing in use of the Compass Card. Summer 2015 saw the greatest number of post-secondary school students begin using the fare cards. TransLink rolled out the card to the general population in November 2015. To encourage its use, the fare is discounted, as shown in Table 12.

Table 12. Vancouver TransLink's Fare Discounts System

\begin{tabular}{lccc}
\hline Zone Travel Category & $\begin{array}{l}\text { Adults } \\
\text { (USD) }\end{array}$ & $\begin{array}{l}\text { Compass Card } \\
\text { (USD) }\end{array}$ & $\begin{array}{l}\text { Concession } \\
\text { (USD) }\end{array}$ \\
\hline Travel Within One Zone & $\$ 2.25$ & $\$ 1.80$ & $\$ 1.47$ \\
$\begin{array}{l}\text { Travel Between Two } \\
\text { Zones }\end{array}$ & $\$ 3.19$ & $\$ 2.59$ & $\$ 2.22$ \\
$\begin{array}{l}\text { Travel Between Three } \\
\text { Zones }\end{array}$ & $\$ 4.32$ & $\$ 3.38$ & $\$ 2.97$ \\
\hline
\end{tabular}

All TransLink buses are designated "fare paid" zones, where a rider is required to be in possession of a valid fare (transfer or transit pass) while on board the bus and to produce it upon request by a transit official. 


\section{Fare Zone Map}

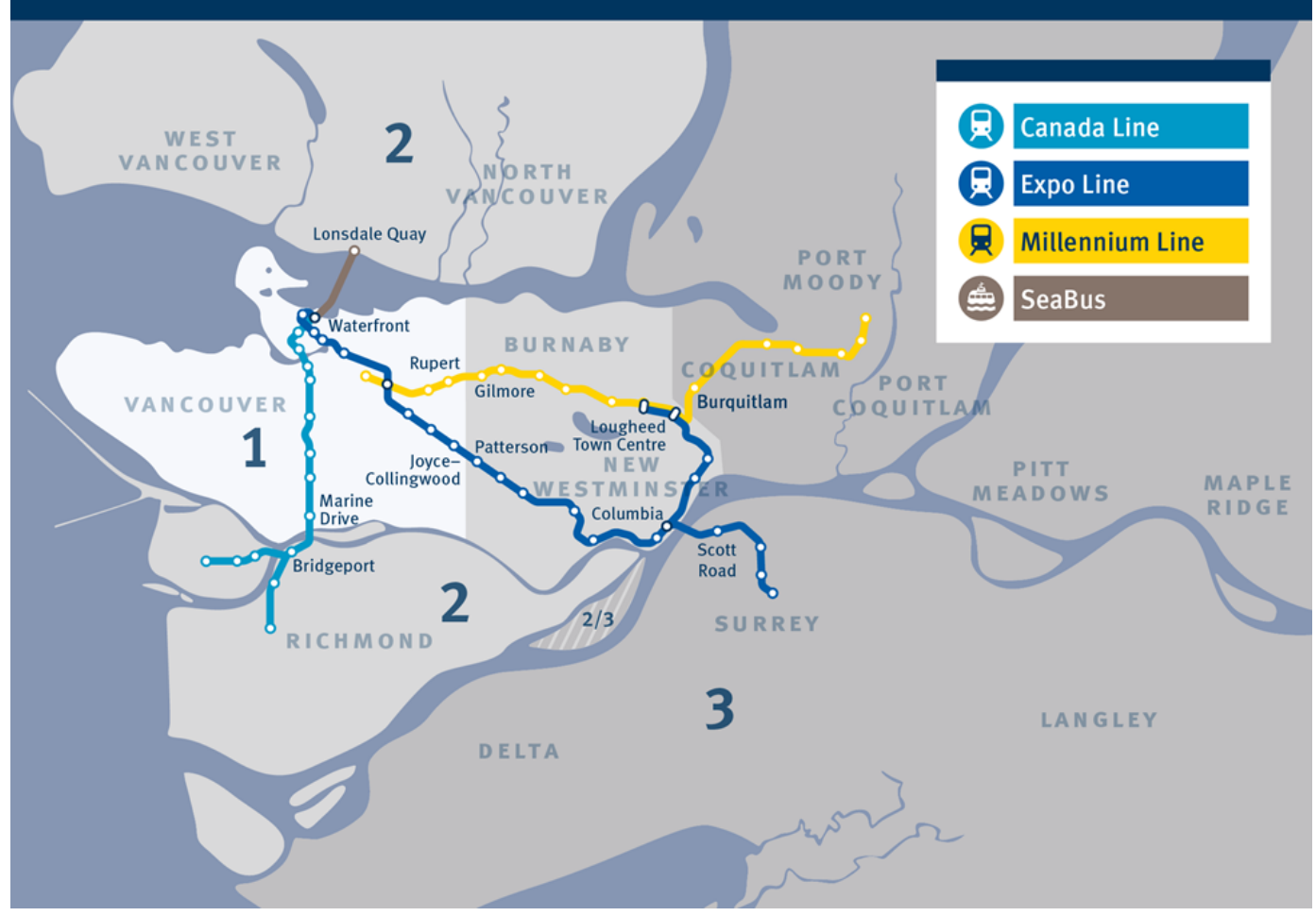

Figure 25. TransLink Fare Zones, Vancouver ${ }^{111}$

\section{Sydney}

As described previously, Sydney's public transport network is owned and managed by Transport for NSW (TFNSW). Modes include:

- Sydney metro

- Sydney trains

- Sydney light rail

- Sydney ferries

- State Transit Authority (buses)

- Rail Corporation of New South Wales (RailCorp)

Compared to other agencies, TfNSW has a somewhat complicated fare system. It is distance-based with a different formula used for travel by bus and light rail versus metro and commuter trains. In addition, while free transfers are permitted between Sydney metro, Sydney trains, and/or NSW TrainLink Intercity, there are no free transfers between the trains and the light rail system or buses. TfNSW also lacks 
monthly or daily passes. Instead, Sydney has a system of daily and weekly "caps." If one uses the electronic Opal (smart) card, the adult fare cap, which includes unlimited travel on metro, train, bus, ferry, and light rail services within the Opal network, is $\$ 16.10$ AUD ( $\$ 10.92$ USD $^{112}$ ) a day or $\$ 50$ AUD ( $\$ 33.93$ USD) a week. On Sunday, the fare is capped at $\$ 2.80$ AUD (\$1.90 USD).

TfNSW encourages the use of the Opal smart card system through its pricing policy. The fare is less if the card is used as shown in Table 13. The Opal card can be used to pay for travel on public transport within Greater Sydney as well as all of New South Wales. Fares are calculated based on the following items:

- distance traveled

- method of payment (cash versus prepayment or Opal card)

- mode of transport

- eligibility for a concession fare or free travel

- other Opal benefits, e.g., discounts and capped fares that may apply

Table 13. Sydney's Distance-Based Fare System

\begin{tabular}{ccc}
\hline Distance & $\begin{array}{l}\text { Adult Opal Card } \\
\text { Fare (USD) }\end{array}$ & $\begin{array}{l}\text { Adult Opal Sin- } \\
\text { gle Trip Ticket } \\
\text { Fare (USD) }\end{array}$ \\
\hline 0-3 Kilometers & $\$ 1.52$ & $\$ 1.97$ \\
3-8 Kilometers & $\$ 2.53$ & $\$ 3.12$ \\
8+ Kilometers & $\$ 3.26$ & $\$ 4.07$ \\
\hline
\end{tabular}

Source: https://transportnsw.info/tickets-opal/opal/fares-payments/adult-fares

The metro also has a dual fare system for peak versus nonpeak travel. Discounts (called concessions) are available for the following user groups.

- Children and students

- Seniors

- Pensioners

- Centrelink customers 
- Asylum seekers

- Apprentices or trainees

- People with disabilities

- Veterans and war widow/ers

Though these concessions make the fare system complex, the Opal card system instantly calculates the discounted fare applicable.

\section{Perth}

As a single agency that manages and operates all modes, Transperth allows free transfers between all modes. As in Sydney, fares are distance-based, so one can change buses or transfer between bus and rail, all for the price of one ticket. Given that the backbone of the network is the six commuter rail lines serving mostly suburban areas, easy and free transfers between buses were considered essential. Thus, one ticket (one fare) is used from origin to destination, regardless of how many times the rider transfers vehicles or modes. Greater Perth is divided into nine fare zones according to distance from the city center.

Cash tickets have an expiration time printed on them: two hours for a journey of one to four zones, and three hours for a journey of five or more zones. Any number of bus, train, or ferry rides are allowed, provided boarding occurs before the expiration time.

Transperth does not have monthly or weekly passes. They have a daily pass valid after 9 a.m. and all day on weekends and holidays. They also offer a family ticket that gives a group of up to seven people unlimited travel on the day of purchase, provided that no more than two of them normally pay full fare. It can be used during the following times.

- Weekends and public holidays: any time.

- Monday to Thursday outside school holidays: after 6:00 p.m.

- Fridays outside school holidays: after 3:00 p.m.

- Monday to Friday during school holidays in Zones 1 to 4: after 9:00 a.m.

- Monday to Friday during school holidays in Zones 5 to 9: after 8:30 a.m.

- Electronic fare card: SmartRider cards.

Though single-journey cash tickets are still offered, Transperth's SmartRider card is promoted as the cheapest and most convenient way to ride on all Transperth services. 
Using SmartRider, the system detects a rider's location, completes the time calculations, and deducts the correct fare from their card balance. Zones are circular bands, each between eight and ten kilometers wide, with the City of Perth in the center. Card users get a 10 percent discount compared to the cash fare (20 percent if set up to auto load from a bank account).

Transperth's system includes a commuter rail network consisting of 70 railway stations on six narrow-gauge lines to Midland, Armadale, Fremantle, Butler, and Mandurah, complemented by an extensive bus network that is fully integrated with the core rail services. While Perth has far lower ridership and development density compared to the European case study regions, Perth is something of a low-density success story. Transperth had 131.6 million boardings in the 2009-10 fiscal year. By comparison, the Orlando, Florida metropolitan area, with a similar population, had under 25 million annual transit riders-less than a fifth of Perth's ridership. ${ }^{113}$ While Figure 6 shows that the Perth metropolitan area's 69 annual transit trips per capita ranks as the lowest of this study's ten regions, their performance is roughly equal to the San Francisco Bay Area's level of riders per capita. ${ }^{114}$ Since the Bay Area's population is almost four times Perth's, Perth's performance in capturing ridership is admirable.

Haber, in a detailed comparative analysis of Perth and Orlando, attributes Perth's relative success to four factors.

- Bus and rail integration in terms of both schedules and fares

- Effective regional planning for physical coordination as well as funding, revenue, and fare technology integration

- Strategically located stations, including freeway intercept stations in lower density areas

- Outreach and educational programs, e.g., in suburban areas. ${ }^{115}$

\section{RELATIVE TRANSIT AFFORDABILITY IN EUROPE}

Table 14 shows fares for both the main city and the RTC area for five case study areas that are EMTA members as of 2017, plus Milan. Stockholm charges the most for a single-ticket fare within the main city due to a flat fare structure. Lyon offers the least expensive main city and regional single ticket. The German case study cities have the highest single-ticket regional prices: $€ 8.60$ (\$9.53 USD) in Stuttgart and $€ 15.50$ ( $\$ 17.70$ USD) in Frankfurt.

Looking at monthly passes, the pattern largely holds, with the German metros being the most expensive by a considerable degree. Barcelona's main city pass is the least expensive, with Lyon's city pass being the second least expensive; Lyon also has the cheapest monthly regional pass. Adjusting for gross domestic product (GDP), Barcelona's monthly passes are mid-range, and Milan, Lyon, and Stockholm offer the most affordable citywide monthly passes. 
Table 14. Comparison of European Metropolitan Area Fare System Prices

\begin{tabular}{|c|c|c|c|c|c|c|c|c|}
\hline \multirow[b]{3}{*}{ Metropolitan Area } & \multicolumn{4}{|c|}{ Single-Ticket Price } & \multicolumn{4}{|c|}{ Monthly Pass Price } \\
\hline & & & $\begin{array}{l}\text { Main } \\
\text { City }\end{array}$ & $\begin{array}{l}\text { RTC } \\
\text { Area }\end{array}$ & & & $\begin{array}{l}\text { Main } \\
\text { City }\end{array}$ & $\begin{array}{l}\text { RTC } \\
\text { Area }\end{array}$ \\
\hline & $\begin{array}{l}\text { Main } \\
\text { City } \\
\text { (USD) }\end{array}$ & $\begin{array}{l}\text { RTC } \\
\text { Area } \\
\text { (USD) }\end{array}$ & $\begin{array}{l}\text { Share } \\
\text { of Per } \\
\text { Capita } \\
\text { GDP }\end{array}$ & $\begin{array}{l}\text { Share } \\
\text { of Per } \\
\text { Capita } \\
\text { GDP }\end{array}$ & $\begin{array}{l}\text { Main } \\
\text { City } \\
\text { (USD) }\end{array}$ & $\begin{array}{l}\text { RTC } \\
\text { Area } \\
\text { (USD) }\end{array}$ & $\begin{array}{l}\text { Share } \\
\text { of Per } \\
\text { Capita } \\
\text { GDP }\end{array}$ & $\begin{array}{l}\text { Share } \\
\text { of Per } \\
\text { Capita } \\
\text { GDP }\end{array}$ \\
\hline Greater Stuttgart & $\$ 2.77$ & $\$ 9.53$ & $0.04 \%$ & $0.10 \%$ & $\$ 74.89$ & $\$ 244.85$ & -- & $4.99 \%$ \\
\hline $\begin{array}{l}\text { Frankfurt Rhein } \\
\text { Main }\end{array}$ & $\$ 3.21$ & $\$ 17.17$ & $0.04 \%$ & $0.19 \%$ & $\$ 96.83$ & $\$ 299.69$ & -- & $7.24 \%$ \\
\hline Lyon & $\$ 1.99$ & $\$ 1.99$ & $0.22 \%$ & $0.22 \%$ & $\$ 70.02$ & $\$ 70.02$ & $1.10 \%$ & $1.32 \%$ \\
\hline Greater Barcelona & $\$ 2.38$ & $\$ 3.32$ & $0.06 \%$ & $0.08 \%$ & $\$ 58.44$ & $\$ 78.66$ & $1.58 \%$ & $2.87 \%$ \\
\hline Stockholm County & $\$ 4.99$ & $\$ 4.99$ & $0.06 \%$ & $0.06 \%$ & $\$ 95.50$ & $\$ 95.50$ & $1.15 \%$ & $1.44 \%$ \\
\hline Milano Basin & $\$ 1.77$ & $\$ 4.87$ & -- & -- & $\$ 43.21$ & $\$ 96.39$ & -- & -- \\
\hline
\end{tabular}

Source: EMTA Barometer, p. 42 (2017 data). Milan data: ATM website (2020 data).

\section{Summary of Fare Policies}

Without exception, the ten case studies from metropolitan areas have moved towards a regionally integrated fare policy. This complete integration was often preceded with steps outlined below.

- Using electronic fare payment cards for all transit systems and modes have allowed for an integrated fare policy. This makes it easier to pay and to track usage across modes so that revenue can be allocated (if needed). However, the existence of a card does not mean there is a single-ticket policy with free transfers.

- Discounted fares are provided when transferring between vehicles or modes within same city or operator. 
- Discounted fares are provided when transferring between operators within the inner suburbs of the urban area.

- Discounted fares are provided when transferring between systems or modes within the entire metropolitan area.

- Free transfers: there is a single-ticket for buses/trains and for different modes within the same city.

- Free transfers: there is a single ticket for all modes and systems in the entire metropolitan area, i.e., regional fare integration.

- In larger metropolitan areas, variable fares by distance are accomplished by establishing zones. Travel within a certain number of zones costs a certain fare. There is still a single ticket, i.e., free transfers between modes and systems.

- For single-ride tickets there is often a time limit (e.g., 90 minutes), and round trips are often permitted within that time limit. This is not necessary with day ride or longer passes.

It should also be noted than many passes (and now smart cards) are or can be tied to a specific individual (i.e., who is named on the pass or card). This is fairly common in France and Italy especially for age-related passes available to seniors and youth. For regular adult passes, there may be a different price structure, i.e., cheaper for one specific person versus an open pass; for the reduced fare, one specific person is named on the pass, usually accompanied with a photo.

Most of our case studies experienced fare simplification (particularly Milan, Stuttgart, Lyon, and Vancouver). A 2016 EMTA study of fare policy among European transit agencies found contrasting trends in planned fare structure changes. Whereas some cities aim for more price differentiation aided by technological advances in fare collection (i.e., smart cards) others aim for simplicity, citing issues such as social welfare or customer satisfaction. Whether or not fare structures are simplified, the existence of a uniform, regional fare structure and medium (a smart card) increases customer satisfaction. ${ }^{116}$ Moreover, EMTA notes that smart cards facilitate "pricing journeys, not trips." 117 Customers do not want to be charged according to how many transfers they make. This appears to be a common and important feature implemented by most European cities. As integrated fare areas increase in size, distance-based fares will likely become more important. However not all regions have one primary city, so that ring zones such as those used in Milan and Stuttgart may not be applicable in all cases. 


\section{TRANSIT FINANCE DATA AND ANALYSIS}

Information describing and comparing the key financial characteristics of the ten selected case study metropolitan areas and their primary cities were gathered, calculated, and evaluated. These characteristics include:

- Transit Expenditures (annual operational budget)

- Transit Expenditures per Capita

- Transit Expenditures per Rider

- Transit Farebox Recovery

- Transit Subsidy per Capita

- Transit Subsidy per Rider

\section{TRANSIT EXPENDITURES}

The total expenditures made by a metropolitan area every year for transit services provide an indication of the commitment each region has made to providing their traveling population with a viable alternative to the automobile. Figure 26 presents the annual transit expenditures (operational budgets) ${ }^{118}$ of each case study region for comparison.

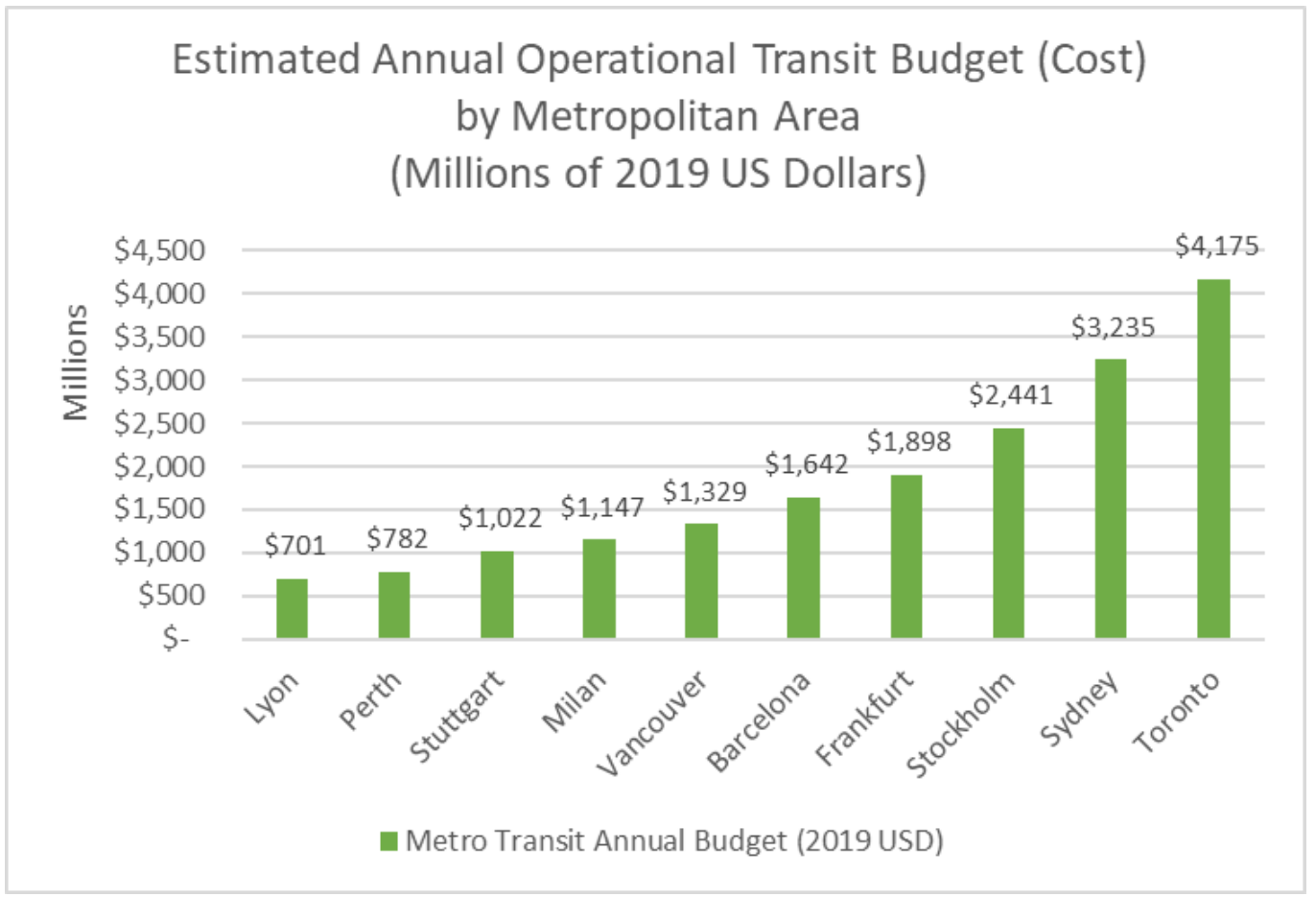

Figure 26. Annual Metropolitan Area Transit Budget (Operations) ${ }^{119}$ 
Annual transit operational expenditures for the case study regions range from a low of $\$ 652$ million for Lyon to a high of $\$ 4.175$ billion for Toronto. A comparison of Figure 26 with Figure 2 (Population) confirms the hypothesis that the total amount spent on transit depends in part on a region's size, since Lyon is the smallest in terms of population and cost, just as Toronto is the largest.

However, political commitment to transit also seems to play a role, since Stockholm, the third lowest region in terms of population (2.3 million), is the third highest in terms of total expenditures on transit ( $\$ 2.4$ billion).

\section{TRANSIT EXPENDITURES PER CAPITA}

Annual transit expenditures per capita estimates (see Figure 27) provide a more level playing field for comparing the relative commitment each region has made to transit by controlling for the effects of population size.

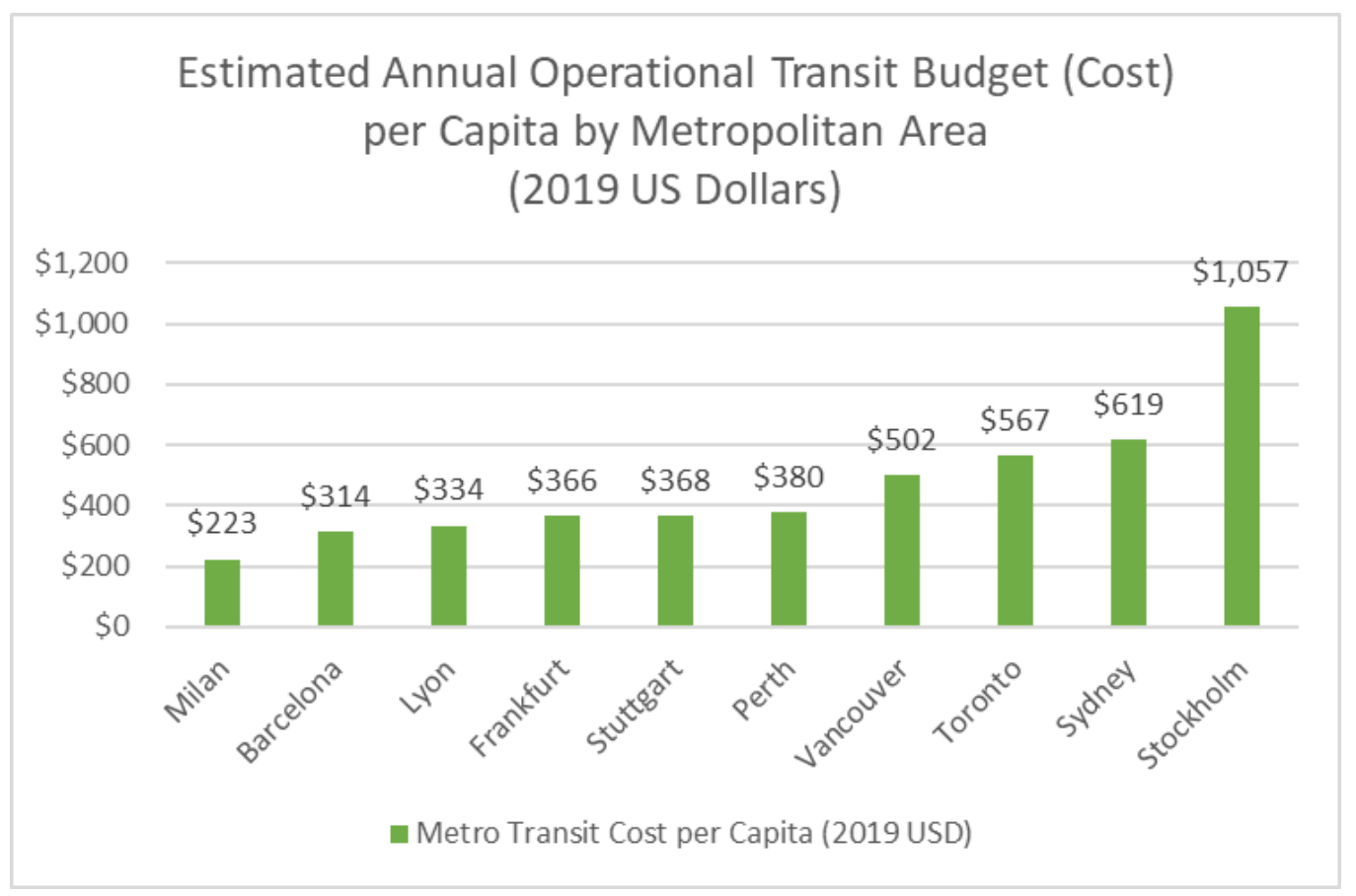

\section{Figure 27. Annual Metropolitan Area Transit Operations Budget (Cost) per Capita ${ }^{120}$}

Annual transit expenditures per capita for the case study regions range from a low of $\$ 223$ USD for Milan to a high of $\$ 1,057$ USD for Stockholm. As noted previously, Stockholm is an intriguing outlier. While all the other top five expenditures per capita regions are located in British Commonwealth countries (Canada and Australia), Stockholm is not only the highest in per capita spending, but it is also markedly so, spending 64 percent more than Sydney, which occupies the number two spot on Figure 27. The five other European case study regions occupy the bottom five spots in Figure 27, suggesting that Stockholm is going its own way when setting spending priorities for transportation; it is decidedly pro-transit. 
Lyon, on the other hand, is on the low end of the scale when it comes to their regional commitment to spending on transit. Lyon's \$334 USD per capita spent on transit operations per year places them at third from the bottom, just above Milan and Barcelona. Therefore, despite Lyon's high level of primacy (see Figure 3), high central city density, and very high level of riders per capita (the second highest for this study), Lyon does not appear to have produced these ridership successes through unusual spending on transit (or unusually low fares) compared to our case studies. Further analysis of Lyon's riders per capita success will follow in Chapter VI using subsidy data which may suggest that regional transit coordination (i.e., the efficiency and effectiveness of their transit system) could be a main reason for their success.

\section{TRANSIT EXPENDITURES PER RIDER}

Higher values of a region's transit expenditures per capita reflect a region's relative commitment to transit. In contrast, transit expenditures per rider (see Figure 28) reflect the relative cost-and therefore the system's level of efficiency-of providing that service.

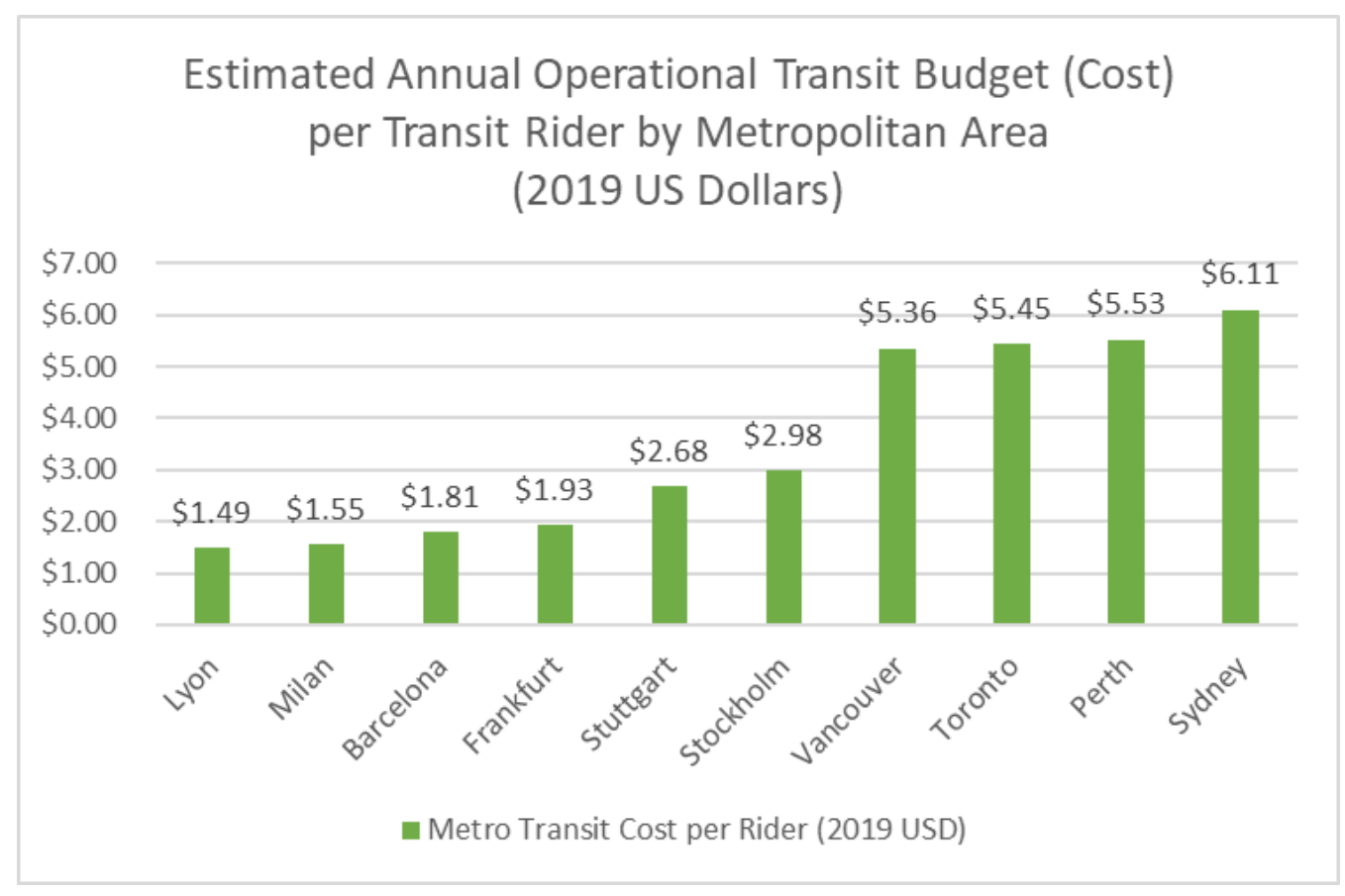

\section{Figure 28. Annual Metropolitan Area Transit Operations Budget (Cost) per Transit Rider ${ }^{121}$}

The regional cost of providing transit services (as indicated by the transit expenditures per rider) range from a low of $\$ 1.49$ USD per rider in Lyon to a high of $\$ 6.11$ USD in Sydney. As seen previously, the case study regions are grouped by geography, with European cases occupying the low end of the cost per rider scale in Figure 28 and the Commonwealth regions occupying the higher end of the scale. Indeed, the priciest European case (Stockholm at \$2.98 USD per rider) has roughly 
55 percent the cost of the Commonwealth region with the lowest cost (Vancouver at $\$ 5.36$ USD per rider), suggesting the Commonwealth countries operate at a structural disadvantage compared to Europe that translates into higher costs for providing transit services.

However, in contrast to the rankings seen in Figure 27, where Stockholm spent the most on a per capita basis, here (in terms of cost per rider) Stockholm is in the middle of the pack, with a cost per rider of \$2.98 USD. This suggests that the reason why Stockholm is spending so much on a per capita basis is not because it costs so much to provide transit (i.e., transit is not significantly more expensive there than in the rest of Europe), but rather, they are intentionally prioritizing transit spending. This also explains, in part, why Stockholm has the third highest total annual ridership (see Figure 5) and the highest per capita transit ridership (see Figure 6); they spend a lot by choice, further suggesting that the main city's high degree of regional primacy (see Figure 3 ) helps to influence regional and national spending priorities to favor transit.

Lyon's lowest ranking of the case study group in terms of spending per rider, suggests that their transit system is very cost-effective and efficient. When considering their similarly low spending on a per capita basis (see Figure 27), it seems likely that their ranking in terms of riders per capita (second highest place, see Figure 6) may be the result of a highly effective, efficient, regionally coordinated transit system.

\section{TRANSIT FAREBOX RECOVERY}

Farebox ${ }^{122}$ recovery ratio (FRR) is a standard metric in the transit industry that measures the share of the operational costs of transit service that riders pay for with their fare payments. By implication, the inverse of the FRR percentage value is the share of the operational costs that are subsidized by alternative (non-rider) revenue sources. In other words, since Perth's FRR is 30 percent, that means they subsidize 70 percent of the cost of each transit trip.

Typically, since transit systems tend to be publicly owned and operated, these subsidies often come from public coffers. Figure 29 presents the FRR of each case study region for comparison. 


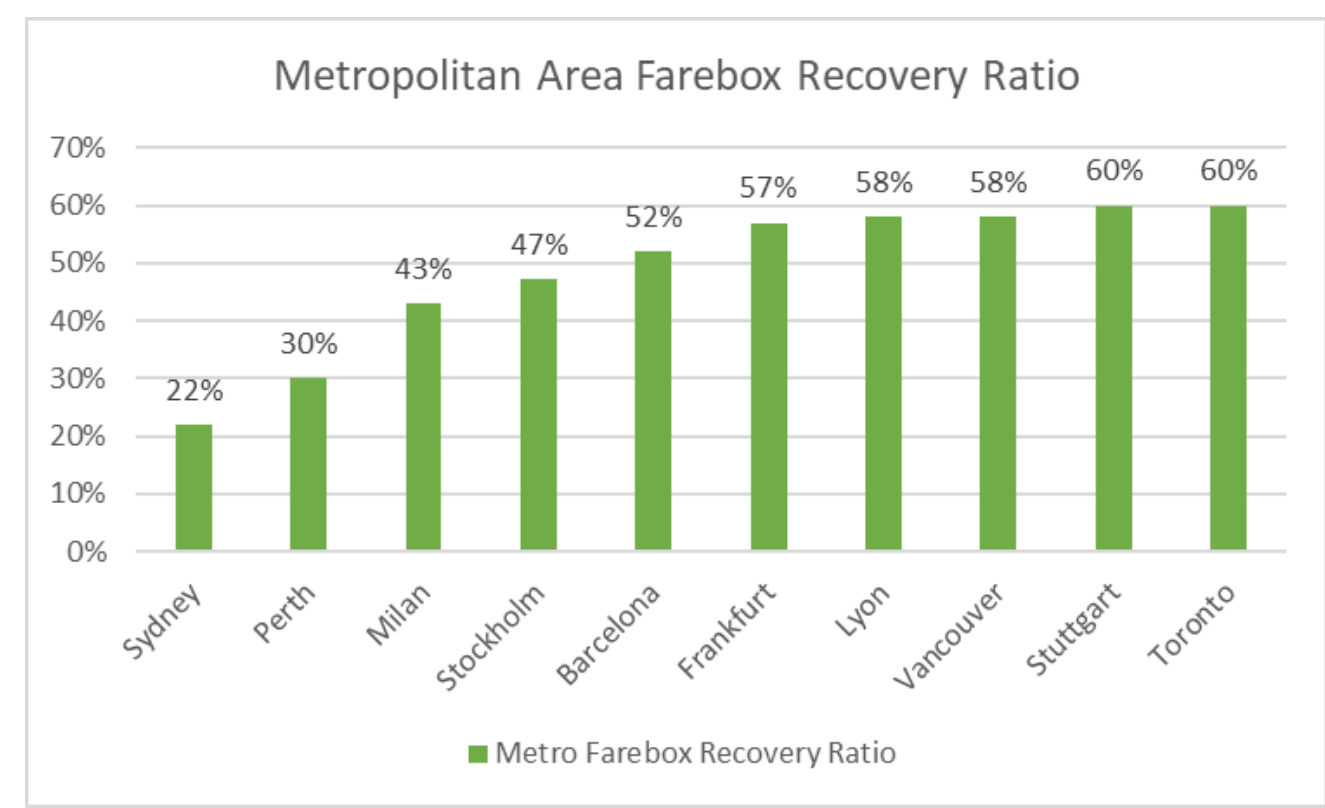

Figure 29. Share of Total Metropolitan Budget from Farebox Revenues (Farebox Recovery Ratio) ${ }^{123}$

FRR shares in the case study regions range from a low of 22 percent for Sydney to a high of 60 percent for both Stuttgart and Toronto. In general, Canadian metropolitan regions have some of the highest FRRs, suggesting that their transit systems are run with an eye towards minimizing subsidies, while Australian metropolitan regions have the lowest FRR values, indicating their transit systems are highly subsidized and also suggesting priority may be placed on maximizing service levels and ridership.

Vancouver is ranked second highest (tied with Lyon) among the study cases with an FRR of 58 percent. It is also interesting to note that Vancouver ranked second lowest among Commonwealth regions (just above Perth) in terms of expenditures per capita (see Figure 27) and lowest among Commonwealth case study regions in terms of cost per rider (see Figure 28), suggesting they have an efficient metropolitan-level transit system that successfully keeps their per rider costs low (compared to other Commonwealth regions) and allows them to spend less at the regionwide level on a per capita basis.

The reasons for Vancouver's success at keeping their costs and expenditures relatively low may be found by examining the previous data presented. In terms of population (see Figure 2), Vancouver ranks roughly in the middle of the case study range, with 2.8 million people, but since this is only about 700,000 higher than the smallest case study region (Perth), its size, as well as any resulting economies of scale that may accrue to larger regions, does not seem to explain how their costs per rider are so low.

In terms of primacy, Vancouver is also in the middle of the case study range (see Figure 3), suggesting their central city does not wield an unusual amount of political 
clout in its region compared to the other case study metropolitan areas. Likewise, Vancouver occupies a middle-of-the-pack position in terms of metropolitan density (see Figure 4), which undoubtedly makes it less expensive to provide effective and attractive transit services there-but this does not seem to explain why it is ranked second-highest in terms of FRR.

As to total annual transit riders (see Figure 5) and riders per capita (see Figure 6), Vancouver is second lowest on both scales compared to the other regions. This suggests the operational cost efficiencies that Vancouver enjoys (suggested by their high FRR ranking and low expenditures per rider compared to other Commonwealth case study regions) are not used to expand service and capture more riders, but rather, are used to keep operational costs per rider levels low, thereby enabling them to maintain a high FRR with low subsidies. The data analysis to follow addresses whether this low subsidy share of ticket costs translate into low subsidies on a per capita and per rider basis as well.

\section{TRANSIT SUBSIDY PER CAPITA}

The transit subsidy per capita metric suggests how committed a region is to attracting riders. Therefore, the more a region spends on subsidies per capita, the more politically committed to increasing transit ridership that region may be. Conversely, the less a region spends in terms of subsidies per capita, the less committed they may be to growing ridership and the more they may be committed to keeping subsidies low (and FRRs high).

Transit subsidy per capita data for each case study are presented in Figure 30.

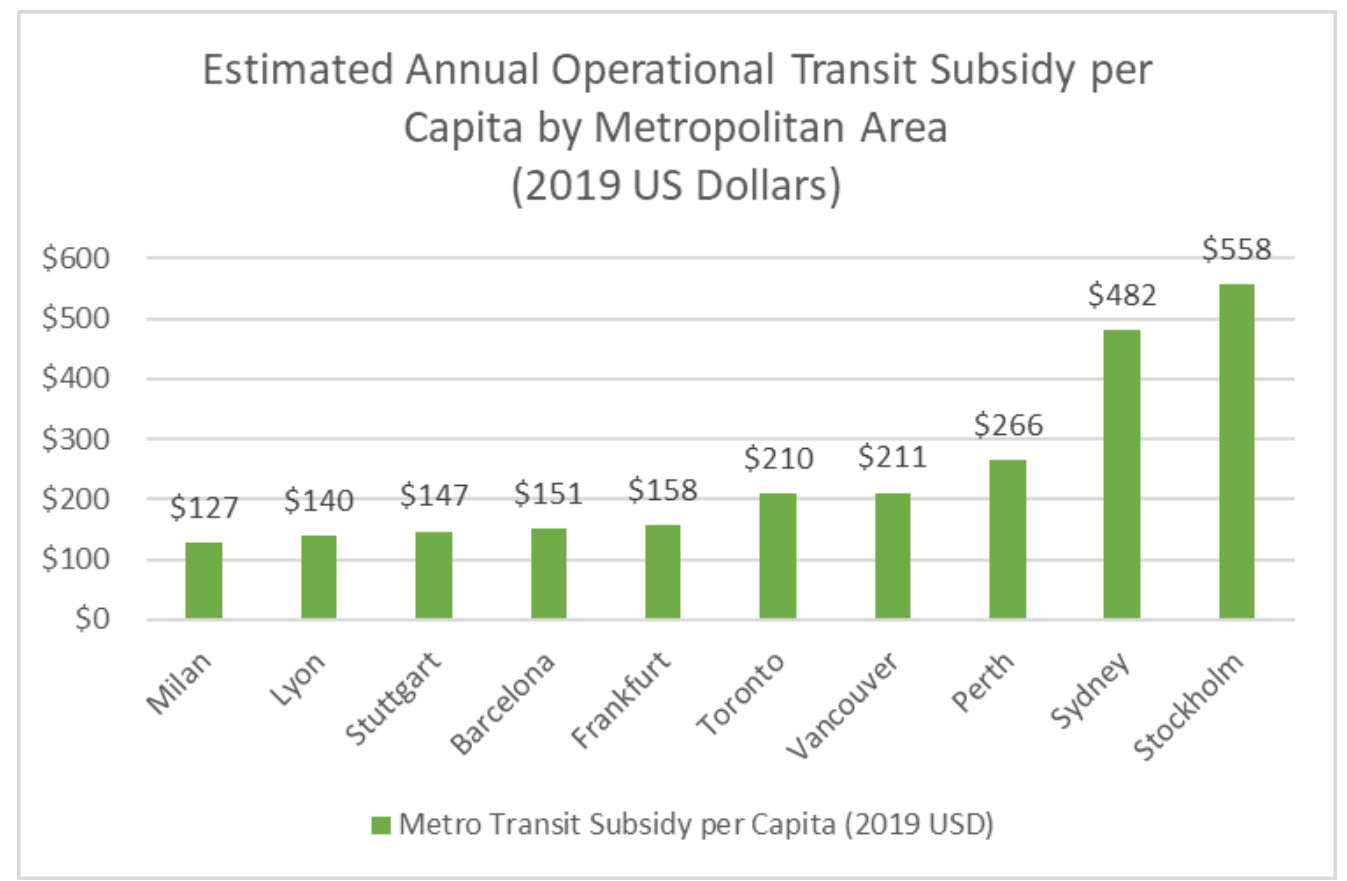

Figure 30. Metropolitan Area Transit Subsidy per Capita ${ }^{124}$ 
Transit subsidy per capita levels range from a low of \$127 USD for Milan to a high of $\$ 558$ USD for Stockholm. The fact that Stockholm is spending more than four times as much on a per capita basis subsidizing transit than Milan, reinforces the earlier point that Stockholm has intentionally made a large commitment to providing regional transit and maximizing ridership.

Vancouver and Toronto subsidize transit at a high level compared to the European regions (except Stockholm) but at the lowest levels compared to the other Commonwealth regions. Therefore, since Canadian metropolitan areas' subsidy per capita and expenditure per capita (see Figure 27) levels are on the low side for Commonwealth regions, their moderate subsidy per capita level and relatively low riders per capita level (see Figure 6) suggest that they have prioritized keeping FRRs high.

Lyon's second-lowest subsidy per capita ranking adds support to the hypothesis noted earlier: that their success at attracting high levels of per capita ridership may be the result of effective regional coordination.

\section{TRANSIT SUBSIDY PER RIDER}

The transit subsidy per rider metric suggests how effective a region's subsidy is at attracting riders. Therefore, the less a region spends on subsidies per rider, the more effective those subsidies are at attracting those riders. Conversely, the more a region spends on subsidies to attract riders, the less effective their subsidies are for attracting riders.

Transit subsidy per rider data for each case study region are presented in Figure 31.

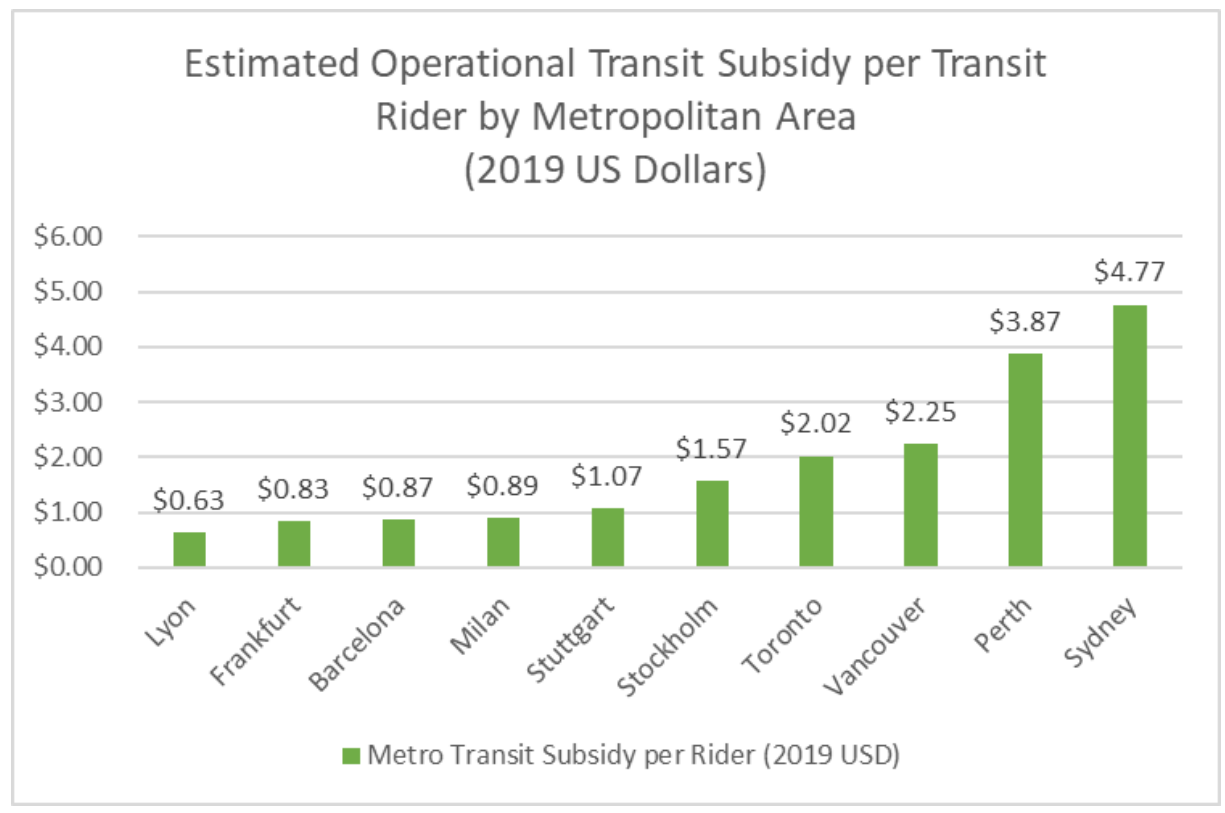

Figure 31. Metropolitan Area Transit Subsidy per Transit Rider ${ }^{125}$ 
Transit subsidy per rider levels range from a low of $\$ 0.63$ USD for Lyon to a high of \$4.77 USD for Sydney. As seen with previous metrics, the Commonwealth areas are grouped together, in this case with high subsidy per rider values, and the European regions occupy the lower end of the scale.

While Stockholm showed great commitment to maximizing their ridership by committing the highest subsidy per capita, here they show a moderate level of effectiveness with those subsidies, as indicated by their fourth-ranking place in terms of subsidy per rider. Nevertheless, they still subsidize at the highest level compared to other European case study regions.

Lyon's ranking as the region with the lowest subsidy per rider out of the group of cases studied here suggests their level of transit subsidization is highly effective at attracting riders at a low cost. As noted previously, this may be due in part to a highly effective coordination of transit at the regional level. 


\section{SUMMARY AND DISCUSSION}

The ten case studies of metropolitan areawide transit were selected because all had high transit ridership among cities in developed countries: at least $15 \%$ for regional transit mode share (except for the Greater Perth area with regional modal shares of $10.3 \%$ and $23-40 \%$ for the major city's transit mode share). These high mode shares were achieved even though the areas are all in western economies with high car ownership rates.

This study has aimed to find the commonalities behind these ten metropolitan area transit systems from a regional perspective that may have led to this high transit mode share. While a case study methodology does not yield statistically significant findings, the findings may be useful to identify patterns and characteristics and to direct future research about what other metropolitan areas can do to improve their transit mode share. It must be acknowledged that since this was not an analysis of agencies with both low and high transit mode share, we cannot say definitively that those areas with low ridership do not have some or all of these characteristics. But we can say that these ten do, and that to our knowledge, most metropolitan areas in the U.S. do not. Further research is needed to corroborate this hypothesis with respect to specific U.S. metropolitan areas.

One of the common factors behind this outcome of high transit use was the presence of a regional coordination agency which has ensured that schedules between modes are coordinated and that there is a single regionwide fare structure. This fare structure is mode- and operator-blind and can be referred to as seamless in this study.

While the research team for this study knew ahead of time that the two German metropolitan areas had an RTC, it was not known that this was the case for all ten areas. Similarly, while it was known that Perth, for example, had a form of fare affordability - free transfers between the regional trains and the local bus serviceit was not known that seven of the ten areas had complete fare integration.

From a transit system design perspective, in all metropolitan areas there is a regionwide trunk rail network supplemented by a citywide metro/subway and/or light rail (see Figure 32). Some areas have five overlapping layers of rail transit: trams/light rail, metro/subway system, suburban commuter trains, regional intercity rail, and the national railway (and if funiculars and aerial gondolas are included, there could be six). Overall, public transit is reliable, affordable, and abundant. Furthermore, there is a financial commitment, both past and present, to building and maintaining the infrastructure and operations to support the transit systems. 


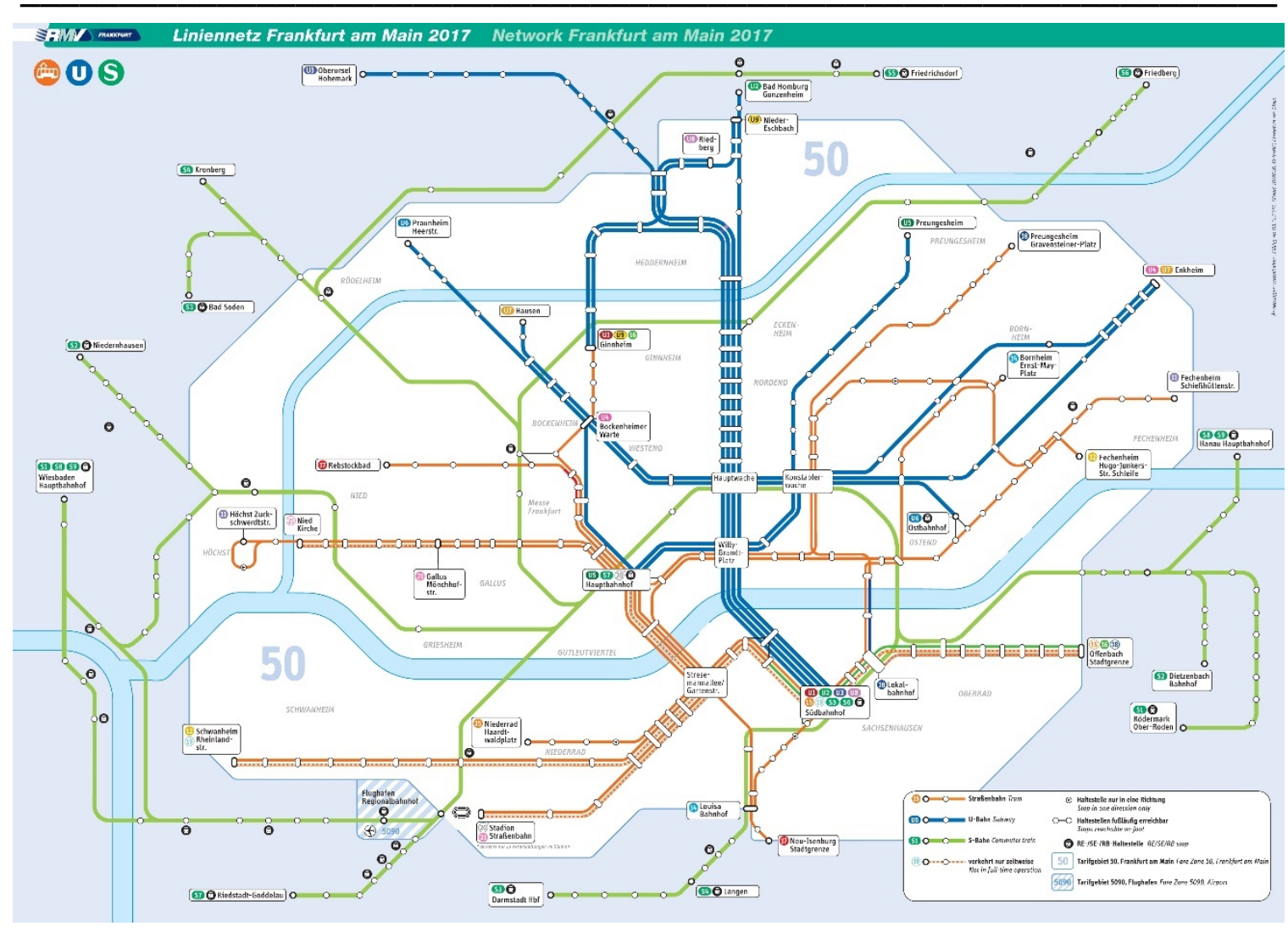

Figure 32. Frankfurt Urban Rail Transit System Map ${ }^{126}$

Further analysis of the data reveals some interesting findings and shows that while customer-apparent outcomes are similar (such as seamless fare structures and frequent service), the path to achieve such outcomes varied considerably. The following sections discuss in turn the following features: institutional set-up; customer-apparent features; and issues pertaining to funding, subsidies, and investments.

\section{FINDINGS ON INSTITUTIONS AND GOVERNANCE}

Across all case studies, in reading the history of their public transit systems, a pattern similar to the U.S. experience seemed to emerge. In the early days of public transit, before and after the First World War, public transportation was provided by a mix of public and private entities. Then, approximately after the Second World War, private transit companies began to be bought out or assimilated by public governmental bodies. The last stage of this evolution, which has occurred in all the case studies, is the development of regional coordination. But here the path splits into two as illustrated in Figure 33; one branch is the model that this report has called coordination and the second branch has been called consolidation. Both seem to work equally well. 
Phase 1

Transit is provided by both private and public entities, even within the same jursdication
Phase 2

Public governing bodies (cities, counties, states*) assume responsibility to provide transit
Phase 3

Coordinating entity manages the many modes \& transit systems for entire metropolitan area

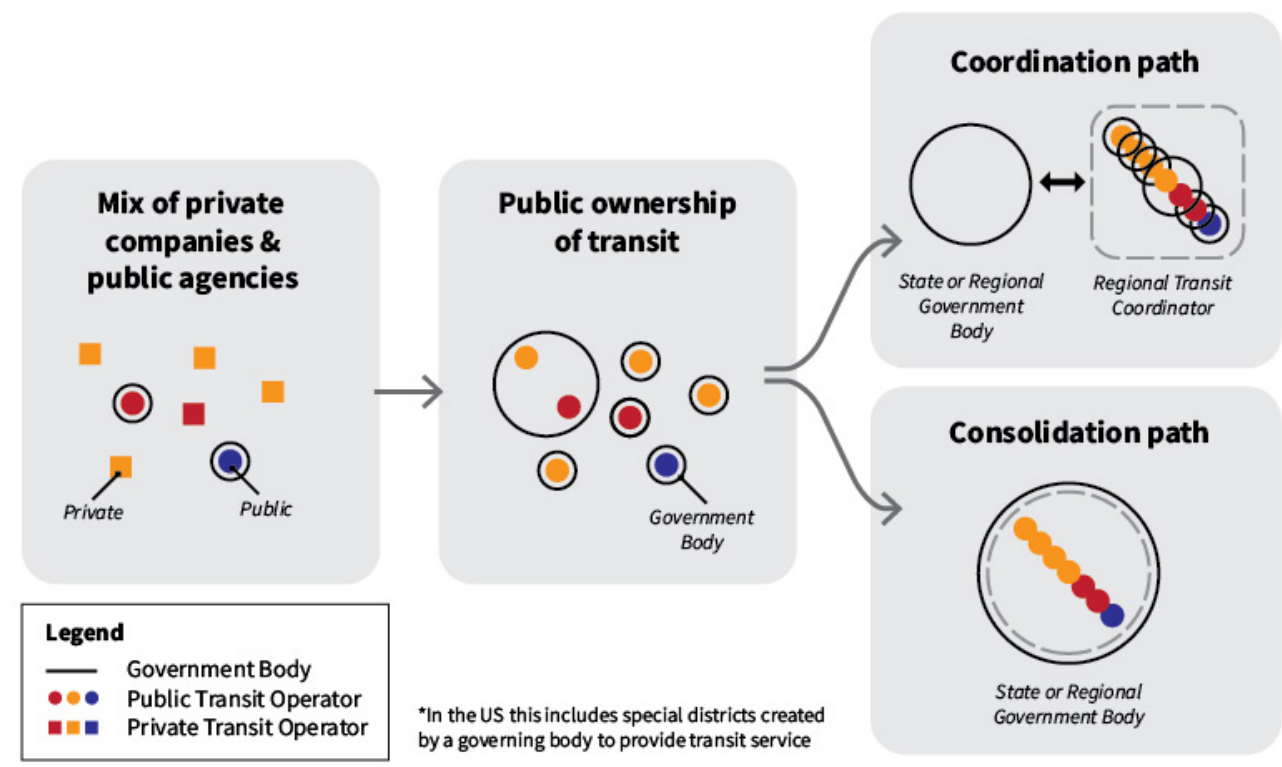

\section{Figure 33. Phases of Public Transit Ownership and Management ${ }^{127}$}

As noted above, the presence of a regional transit coordination body was a common factor in all ten case studies. Some commonalities as well as differences in this regional coordination between the case studies were noted in the following areas, discussed in order below.

- Regional transit coordination structure

- Roles of regional transit coordinator

- Governance of the regional transit coordinator

- Geographic area of the regional transit coordinator

- Regional political consolidation

- Regional transit coordination structure

\section{Regional Transit Coordination Structure}

The review of the ten case studies in seven countries revealed that even though all had a regionwide public transit coordinator, there was no single best practice 
for how this was accomplished. Many models appear to work. In fact, there were different models within the same country, particularly Toronto versus Vancouver. The underlying commonality is the fact that there is an entity with the authority to coordinate the many pieces of the regional transit network puzzle, especially fares and schedules.

The RTCs discussed in this research fall into three categories.

- Coordination Only: The Regional Transit Coordination agency is the coordinating body of many individual transit systems owned and operated by different governmental political jurisdiction at different levels of government: cities, provinces, regions, and/or the state.

- Coordination and Regional Transit Provider: The Regional Transit Coordination agency also owns and manages the regional transit system. For example, Metrolinx in Toronto runs the regional transit (rail and buses) branded as GO Transit.

- Complete Consolidation: All public transportation in the metropolitan area is run by one agency, and this single agency is by default the Regional Transit Coordinator.

Furthermore, even within these three basic models there was wide variation between them, as follows.

\section{Model 1: Coordination Only}

In this model, a governing board is needed for the RTC, since it is a consortium of different political jurisdictions. There are many models for their governance, and the board structure varies from having a mix of representatives from political bodies (e.g., city council members) to having politicians specifically prohibited from serving on the board. Some RTCs have two layers of governance.

The composition of the board is often related to the geographic area that is served by the RTC and how many transit system owner jurisdictions there are. The German model typically has both political representatives and transit operator representatives. While some boards have only government representatives and no representatives from the transit operators, it must be kept in mind that in these case studies, the transit operators are either owned or hired by the governmental political jurisdiction (see the preface of this report) so that the transit systems are represented on the board through the government representatives. Alternatively, some boards are composed entirely of private citizens.

TPL of Milano is interesting in that elected political representatives are on the board but are prohibited from receiving any compensation for this role. Metrolinx is interesting in that politicians are outright prohibited from serving on the board. 
As concluded by Buehler et al., "The [Verkehrsverbund] model has spread quickly because it is adaptable to the different degrees and types of integration needed in different situations." ${ }^{28}$ Mees found that the coordination-only model of regional transit coordination is ideal for the rapidly growing suburban development around cities. ${ }^{129}$

The RTC also varies in how it relates to the borders of governmental political jurisdictions it serves.

- Stuttgart: Geographic area of the RTC is the same as the regional political body, but there is a separate board.

- Milan: Geographic area of the RTC is four independent provinces (technically one metropolitan city and three provinces).

- Lyon: Geographic area of the RTC is two provinces (technically one metropolis and one province).

- Barcelona: Geographic area of the RTC is the AMB of Barcelona (36 cities plus an additional 100 smaller suburbs in the second and third rings).

Model 2: Coordination plus Regional Transit System Owner-Operator ( $\mathrm{Hy}$ brid)

Only one of the case studies fits this model, Metrolinx of Toronto, but this research discovered that this also seems to be the case for Transport for Greater Manchester (TfGM), which is the RTC for Greater Manchester in the United Kingdom. There appears to be variation between Toronto and Manchester in how this model was adopted, which may be useful to explain. In Toronto, Metrolinx was established as the coordinating body in 2006 (effective 2007), and only later (in 2009) was given responsibility for the regional transit GO Transit (established in 1967), taking it over from the Province of Ontario.

In Manchester, transit coordination began much earlier than Toronto, in 1969, with changes in 1974 and 1986. Ultimately, in 2008, the Greater Manchester Integrated Transport Authority (GMITA) was created. Three years later in 2011, the Greater Manchester Combined Authority was created, essentially a regional governmental body with an elected mayor. At this time, the transport functions of GMITA were transferred to GMCA and became Transport for Greater Manchester. TfGM now owns the light rail system called Metrolink-the UK's largest light rail network-as well as Greater Manchester's bus stations, stops, and shelters. ${ }^{130}$

\section{Model 3: Complete Consolidation}

In the two Australian case studies, all public transit is owned and coordinated by a department of the state: the State of New South Wales (TfNSW for Greater 
Sydney) and the State of Western Australia (Transperth for Greater Perth). In fact, TfNSW also runs and manages the public transportation for the area outside Greater Sydney.

In Stockholm, all public transit is owned and coordinated by a department of the County of Stockholm (where the County is considered to be the metropolitan area).

In Vancouver, all public transit is owned and coordinated by a specially created quasi-government agency for the metropolitan area of Greater Vancouver. It is a separate governmental body from the pre-existing regional government of Greater Vancouver known as Metro Vancouver.

\section{Role of Regional Transit Coordinator}

Even though the case study RTCs have the same overall role of coordination, some have more duties and authority than others, as shown in Table 15. Almost all ensure schedule coordination, and most have adopted full fare integration. In some cases, the RTC procures and tenders the operations, and in others, that responsibility is retained by the system owner. Most, but not all, take on marketing duties and a one-stop website, but some are in different phases of implementing such single points of information.

Table 15. Roles and Responsibilities of Regional Coordinators

\begin{tabular}{|l|l|l|l|l|l|l|l|l|}
\hline $\begin{array}{l}\text { Name of } \\
\text { RTC (Major } \\
\text { City) }\end{array}$ & $\begin{array}{l}\text { Plan- } \\
\text { ning }\end{array}$ & $\begin{array}{l}\text { Single- } \\
\text { Ticket } \\
\text { Policy }\end{array}$ & $\begin{array}{l}\text { Schedule } \\
\text { Coordi- } \\
\text { nation }\end{array}$ & $\begin{array}{l}\text { Market- } \\
\text { ing/ Pub- } \\
\text { lic Info } \\
\text { Services }\end{array}$ & $\begin{array}{l}\text { Pro- } \\
\text { cure- } \\
\text { ment/ } \\
\text { Con- } \\
\text { tracting }\end{array}$ & $\begin{array}{l}\text { Monitoring } \\
\text { (e.g., punc- } \\
\text { tuality, rid- } \\
\text { ership) }\end{array}$ & $\begin{array}{l}\text { Transit Op- } \\
\text { erations as } \\
\text { well as Co- } \\
\text { ordination? }\end{array}$ & $\begin{array}{l}\text { Other } \\
\text { Transpor- } \\
\text { tation Re- } \\
\text { sponsibil- } \\
\text { ities? }\end{array}$ \\
\hline $\begin{array}{l}\text { TransLink } \\
\text { (Vancou- } \\
\text { ver) }\end{array}$ & Yes & Yes & Yes & Yes & Yes & Yes & $\begin{array}{l}\text { Yes, all } \\
\text { public } \\
\text { transit in } \\
\text { Greater } \\
\text { Vancouver }\end{array}$ & Yes (3) \\
\hline $\begin{array}{l}\text { Metrolinx } \\
\text { (Toronto) }\end{array}$ & Yes & No (1) & Yes & No & Yes & No & $\begin{array}{l}\text { Yes, } \\
\text { owner-op- } \\
\text { erator of } \\
\text { GO Transit- } \\
\text { regional rail } \\
\text { b buses }\end{array}$ & No \\
\hline $\begin{array}{l}\text { TPL (Mi- } \\
\text { lan) }\end{array}$ & Yes & Yes & Yes & $\begin{array}{l}\text { Yes * (In } \\
\text { pro- } \\
\text { gress) }\end{array}$ & No & Yes & No & No \\
\hline
\end{tabular}


Summary and Discussion

\begin{tabular}{|c|c|c|c|c|c|c|c|c|}
\hline $\begin{array}{l}\text { SYTRAL } \\
\text { (Lyon) }\end{array}$ & Yes & $\begin{array}{l}\text { Yes } \\
(2)\end{array}$ & Yes & No & Yes & Yes & No & No \\
\hline $\begin{array}{l}\text { TFV } \\
\text { (Stock- } \\
\text { holm) }\end{array}$ & Yes & Yes & Yes & Yes & Yes & Yes & Yes & $\begin{array}{l}\text { No, but } \\
\text { part of } \\
\text { county } \\
\text { responsi- } \\
\text { bilities (3) }\end{array}$ \\
\hline $\begin{array}{l}\text { RMV } \\
\text { (Frank- } \\
\text { furt) }\end{array}$ & Yes & Yes & Yes & Yes & Yes & Yes & No & No \\
\hline $\begin{array}{l}\text { VVS } \\
\text { (Stuttgart) }\end{array}$ & Yes & Yes & Yes & Yes & No & Yes & No & No \\
\hline $\begin{array}{l}\text { ATM (Bar- } \\
\text { celona) }\end{array}$ & Yes & Yes & Yes & Yes & Yes & Yes & No & No \\
\hline $\begin{array}{l}\text { Transperth } \\
\text { (Perth) }\end{array}$ & Yes & Yes & Yes & Yes & Yes & Yes & $\begin{array}{l}\text { Yes, all } \\
\text { public } \\
\text { transit in } \\
\text { the Greater } \\
\text { Perth }\end{array}$ & No \\
\hline $\begin{array}{l}\text { TfNSW } \\
\text { (Sydney) }\end{array}$ & Yes & No & Yes & Yes & Yes & Yes & $\begin{array}{l}\text { Yes, all } \\
\text { public } \\
\text { transit in } \\
\text { Greater } \\
\text { Sydney and } \\
\text { New South } \\
\text { Wales (4) }\end{array}$ & Yes (5) \\
\hline
\end{tabular}

(1) Enabling legislation gives Metrolinx the task of fare integration but not the authority to successfully do so. TTC has a single fare policy for all of its modes. However, there is no single fare or ticket type that includes both GO Transit and TTC.

(2) Single fare applies to the entire metropolitan which is served by TCL (73 communities). To include all the areas managed by SYTRAL (TCL plus the two rural areas), there is a daily pass, a monthly pass, and a yearly pass. So, although Greater Lyon has only one zone, in practice there are two zones for the area coordinated by SYTRAL.

(3) Major roads and bridges.

(3) Has separate oversight committee which is under the County Council Assembly.

(4) The transit agencies are separate government agencies under this government agency.

(5) Since 2019, the agency has also been responsible for building and maintaining road infrastructure, managing dayto-day compliance and safety for roads and waterways, and vehicle and driving license registrations. 


\section{Governance of the Regional Transit Coordinator}

In terms of the governance of the coordination agency, it was found that many areas tried one overall organizational structure and modified it subsequently, either soon after or years later. Some current RTCs are the result of decades of incremental coordination. Some eventually became fully subsumed into a state agency (as in Perth and Sydney). Those that are not part of a state government have their own boards (that is, all but Perth, Sydney, and Stockholm) and the composition of the board varies widely. It is interesting to note that some RTCs changed how the board was composed, including two who changed it within two to ten years of its formation: TransLink (Vancouver), founded in 1999, adopted a new board composition 2007; Metrolinx (Toronto), founded in 2006, adopted a new board composition in 2009. Further, SYTRAL (Lyon), founded in 1985, changed its board composition in 2017. In Europe in particular, the boards of the RTC are often composed of half or even mostly elected politicians from cities and counties; however, it is important to keep in mind that even in those cases where public transit operators do not have a representative on the board, the individual cities and provinces are the owners of their own public transit systems, so the transit system owner is on the board and public transportation does have representation.

\section{Geographic Area of the RTC Coordinator}

In general, the geographic area that is overseen by each RTC is at least as large as the defined boundaries of the metropolitan area (i.e., Stockholm, Stuttgart, Frankfurt). In some cases, it is larger (i.e., Barcelona, Lyon, Milan, Toronto, Perth, and Sydney). This observation accentuates the fact that there are various ways to define a metropolitan area, from the nation's census statistical areas to the functional urban area to using existing defined political boundaries such as provincial boundaries. Some definitions of metropolitan areas incorporate only whole counties or provinces. Some incorporate only the urbanized areas, while other definitions include the rural hinterlands.

Also, in countries with growing populations, the definition of urban and metropolitan areas has grown over time. For example, the Toronto metropolitan area has grown from the Greater Toronto Area to the Greater Toronto and Hamilton Area to the still-larger Greater Golden Horseshoe area. For RTCs that have been around for more than ten years, their areas have grown as well. The general trend in the ten case studies was an expansion of the geographic area within the purview of the RTC. In no cases did it shrink; the cases where it has expanded include Milan, Lyon, Barcelona, Toronto, and Vancouver.

From the perspective of the RTC, all case study RTCs encompass entire political boundaries (e.g., whole rather than partial provinces in Italy and France). Therefore, they encompass low-density and even rural areas. Even these low-density areas have public transportation that connects to the main city (or cities) via regional trains or buses or both. 
Indeed, another distinctive finding about the case study countries compared to the U.S. may be the fact that these countries do not abandon their rural and low-density suburbs to the car but still strive to provide them with a base level of public transportation. To be sure, bus or rail is not provided to every rural community, but there is transit service into many rural communities or to nearby ones, making transit a viable option for rural and ex-urban residents.

\section{Regional Political Consolidation}

It is interesting to note that in some of the case study metropolitan areas, there was also regional political consolidation. Sometimes regional transit coordination came first (Stuttgart), whereas sometimes regional political consolidation/coordination came first (Vancouver): see Table 3. In most cases, there was a continuum of increasing cooperation between local municipalities that culminated in consolidation or coordination (Sydney, Lyon). Most often, state legislation was involved either to initiate the creation of an RTC (Sydney, Perth, Vancouver) or to improve an existing RTC (Milan). Similarly, in areas with a more cohesive regional political structure, state or national legislation was involved (as in British Columbia, Canada; Baden-Württemberg, Germany; Stockholm, Sweden).

\section{FINDINGS ON CUSTOMER-APPARENT FEATURES}

\section{Regionally Integrated Seamless Fare Policies}

Without exception, the ten case studies from metropolitan areas have moved towards a regionally integrated fare policy, most having fully embraced it. A regional fully-integrated fare policy means the following.

- In regions with multiple systems, owners, and modes, each system owner does not set its own fares; there is only one fare structure for the whole region that is used by all transit systems.

- The key feature is that there is a single ticket regardless of transfers between modes or systems. The fare strategy is to price the whole journey (from origin to destination) not individual trips, thus it is mode- and operator-blind, and seamless.

- This single fare structure applies to the single-ride/single-journey fare as well as passes (in most cases, there are passes).

- Any and all applicable discounts are uniform throughout the region, such as those for students, seniors, weekend travel, families, etc.

- The pricing structure could be a flat fare for the whole region (e.g. in Stockholm) or distance-based with higher fares for traveling longer distances within the region (e.g. in Milan and Vancouver). This said, there is only one ticket fare, with no additional fare payments for transferring. 
This is true even if a passenger wishes to change busses or trains or between systems. It is seamless, with a fare perspective in mind, to change vehicles, modes, and operators.

- Most but not all integrated fare structures also have an option for daily, weekly, and/ or monthly passes, which again are valid for all modes and all systems.

\section{Consolidation Not Necessary for Fare Integration}

It is easy to understand how a single consolidated entity like that of Vancouver or Stockholm, which owns and operates all the transit in the region, can have a single integrated fare policy across all modes (although TfNSW does not). But this is also the case in Frankfurt, Stuttgart, Milan, Lyon, and Barcelona. This essentially means that transfers are free regardless of mode or system owner-operator. When there is a pass (monthly, daily, or weekly), there is only one pass, and it is good for all modes regardless of owner-operator. It is necessary that the RTC has the legal authority or agreement from all the system owners to set the fare policy.

\section{Smart Cards Do Not Necessarily Mean Fare Integration}

Smart cards make using multiple systems easy and greatly facilitate the purchase of tickets and passes. All case study areas have embraced smart card technology. For some areas, including Barcelona, the introduction of the smart card was the "trigger" to examine their fare structures. ${ }^{131}$ For customers, the result is an easyto-understand and easy-to-use system, since transferring between modes and systems is straightforward and unencumbered by the need to carry proof of payment, which is embedded in the card. For areas with single-ticket policies, no additional payment is required: the smart card knows the fare has been paid and keeps track of the time validity. For other areas without single-ticket policies, the smart card makes paying multiple fares easier, although it is not necessarily cheaper.

The single-ticket policy - the policy of having one ticket across all operators and modes-is surely facilitated by an electronic smart card. But such a card is not essential to the concept of a regionally integrated single-ticket policy. Free transfers and day (and longer) passes do exist and have existed without smart cards. Furthermore, the existence of a smart card does not mean that there is a single pass good for one mode, let alone all modes and systems (e.g., Sydney, Perth, Toronto). Indeed, many areas have smart cards but do not have "single fare single ticket policies" (including two of the case study metropolitan areas, Toronto and Sydney, and indeed most U.S. metropolitan areas including Chicago and the San Francisco Bay Area). Thus, a smart card can be considered a complementary but not a necessary step towards a "single ticket single pass" system, i.e., full fare integration. 
Fare Integration and Coordination Benefits Ridership

Since a regionally integrated fare policy was found to be common to all of the case studies, it is worth noting that research has generally substantiated that fare inte-gration leads to higher transit ridership. One review of the impacts of several fare integration schemes by Sharaby and Shiftan (2012) showed that in each case, ridership increased, as presented in Figure 27.

Table 16. Sample Fare Integration Programs and Ridership Impact

\begin{tabular}{lll}
\hline Metropolitan Area & $\begin{array}{l}\text { Year of } \\
\text { Implementation }\end{array}$ & $\begin{array}{l}\text { Ridership } \\
\text { Increase }\end{array}$ \\
\hline Greater Manchester, England & $1999-2001$ & $4 \%$ \\
New York, USA & $1994-1999$ & $\begin{array}{l}12 \% \text { subway } \\
40 \% \text { bus }\end{array}$ \\
Vienna, Austria & $1988-2001$ & $24 \%$ \\
Madrid, Spain & 1987 & $15 \%$ \\
Paris, France & 1975 & $33 \%$ \\
Stockholm, Sweden & 1973 & $25 \%$ \\
Hamburg, Germany & 1967 & $19 \%$
\end{tabular}

Source: N. Sharaby and Y. Shiftan, "The Impact of Fare Integration on Travel Behavior and Transit Ridership," Transport Policy 21 (2012): 63-70.

A 2018 study by Buehler et al. ${ }^{132}$ examined how metropolitan regions in Germany, Austria, and Switzerland have successfully implemented regional public transport (PT) coordination through organizations called Verkehrsverbunde (VVB). The VVB typically include dozens of public and private transit entities but provide "one time-table, one fare, and one ticket." This study focused on six case studies represent-ing the largest VVB: Hamburg (opened in 1967), Munich (1971), Rhine-Ruhr (1980), Vienna (1984), Zurich (1990), and Berlin-Brandenburg (1999). Buehler and colleagues found substantial and diverse benefits from VVB. Since 1990, all six of these VVB have increased the quality and quantity of service, attracted more pas-sengers, and reduced both the percentage of costs covered by subsidies and car mode share in the six metropolitan areas studied. 


\section{Travel Time}

As noted in Chapter IV, overall travel time is important, but this does not directly equate to transit vehicle speeds. The frequency of service and the ease of transferring between complementary services-that is, the factors that affect the whole trip and that reduce transfer time and wait time-is what is important to riders.

With respect to transfers: transfers per se do not inhibit ridership, but rather the time involved and the additional cost incurred do. Coordination of those two key components fixes this issue. U.S. research also corroborates this claim: Pratt and Evans found that "bus re-restructuring in the Seattle area that moved from a relatively infrequent one-seat ride from suburbs to downtown Seattle to more-frequent service requiring a timed transfer at a transit center resulted in a $23 \%$ ridership gain over 2 years." 133 The Green Bus Line from Queens (New York) experienced a 30 percent increase in ridership when "one city, one fare" policy was instituted in the mid-1990s, which allowed, among other things, free transfers to the subways. ${ }^{134}$

\section{REGIONAL COORDINATION AND SUBSIDIES}

\section{Coordination Can Yield High Ridership Without Heavy Spending}

Focused analysis of four case study regions-Stockholm, Vancouver, Lyon, and Barcelona-suggests that regional coordination can increase ridership on its own, without high levels of spending and subsidies. It might seem intuitively obvious that the fastest route to a high-ridership region would occur through a combination of regional consolidation and heavy subsidies. Stockholm clearly illustrates this approach. However, Vancouver has been successful at generating relatively high ridership by consolidating their transit providers without heavy subsidies. Even more interesting are the cases of Lyon and Barcelona, where ridership is high, subsidies are low, and they have avoided the heavy handed approach of consolidation, focusing instead on regional coordination using an RTC.

\section{Stockholm: High Spending and Service Consolidation}

Stockholm is identified in previous sections as an intriguing example of how a high level of transit spending (with the highest transit subsidy per capita level of any case study region at \$558 USD) yields high transit ridership and mode share. However, Stockholm's subsidies appear to yield an even greater "bang for the buck," because the region has consolidated its transit system under one under one owner/operator.

Therefore, on closer inspection, Stockholm combines their high levels of spending with the efficiencies that come with regional consolidation to yield a very high level of annual regional transit riders per capita, 355 . However, Stockholm's high service and per capita ridership may come at the cost of a relatively low farebox recovery ratio $(47 \%)$, the second-lowest of any European case study region. This suggests 
that as a metropolitan area, Stockholm is intentionally subsidizing transit at a high level with the goal of providing high levels of service and maximizing ridership. This very high level of subsidy also suggests there is political consensus in the region that supports keeping fares low (leading to a low FRR relative to other European case study regions and higher ridership), keeping transit-supportive taxes high, and centralizing the administrative and operational control of regional transit under one consolidated agency: the County of Stockholm.

Stockholm's success is clear, but does it represent the only way forward? Closer investigation of Vancouver, Lyon, and Barcelona suggests that there are other paths available to building a world-class regional transit system.

\section{Vancouver: Consolidation with a Focus on the "Bottom Line"}

In contrast to Stockholm, where consolidation and high subsidy levels have produced a high-service, high-ridership regional transit system, Vancouver's ridership performance suggests that the benefits of consolidation can be used to achieve other goals as well. While Vancouver has the second-lowest level of annual transit riders per capita among the case study regions (94), the region compares well to U.S. metropolitan areas, indicating relative success in the North American context.

However, their low subsidy per capita level (\$211 USD) compared to other Commonwealth case study regions (Perth $=\$ 266$ USD and Sydney $=\$ 482$ USD), and their high FRR (tied for third place among all case studies with an FRR of 58\%), suggest Vancouver residents value cost-effectiveness in their regional transit sys-tem. This insight is illustrated in the public debate over a 2015 regional sales tax measure to increase transit funding, in which several transit researchers contrib-uted evidence that, despite tax opponents' claims to the contrary, Vancouver's consolidated regional transit system (TransLink) is cost-effective (on aver-age) compared to other Canadian metropolitan areas, and extremely cost-effective compared to U.S. regions. ${ }^{135}$

Vancouver's ridership performance compared to other North American regions, their high FRR, and their low subsidy per capita level indicate that there is some political tension among voters and decision makers between those who are focused on keeping FRR levels high (and subsidy taxes low) and those who wish to spend more on transit with the aim of boosting transit ridership and mode share. Therefore, it is intriguing to hypothesize what Vancouver's ridership would be like with their current, consolidated regional transit system and a Stockholm-level transit subsidy.

\section{Lyon: Cost-Effective Coordination}

Lyon illustrates that consolidation and high subsidies are not the only way to generate high ridership. With a less heavy-handed approach, Lyon has coordinated their region's transit providers through the establishment of an RTC. As a result, 
Lyon holds the second-place showing in terms of annual transit riders per capita (224) among case study regions.

With this high ridership per capita ranking, it would seem reasonable to assume that Lyon also heavily subsidizes its transit system, thereby allowing it to provide a very high level of regional transit service. Surprisingly, Lyon provides the secondlowest subsidy per capita level (\$140 USD) among its case study peers, suggesting the benefits they generate compared to other case study metropolitan areas come from something other than high spending on (and heavy subsidies towards) transit services.

While their high FRR level (58\%) is partially attributable to their very low subsidy level, Lyon's very high annual level of riders per capita suggests their RTC may be successful to such a high degree that it yields highly effective regional transit services, that in turn, attract very high ridership—all without heavy subsidies. Further investigation of this case may yield additional insights that could prove useful for designing effective and efficient RTCs.

\section{Barcelona: "The Middle Road"}

While Barcelona's subsidy per capita level (\$151 USD) is technically a middle-ofthe-road case study region, it is near the top of the range for European cases (excluding Stockholm, which is generally an outlier), and at the top of the range compared to other regions with a coordination rather than a consolidation approach to regional transit. Therefore, this study ranks Barcelona's subsidy per capita spending as high.

Despite its moderately high subsidies, Barcelona has a respectable, middle-of-theroad FRR ratio of 52 percent, suggesting some of the benefits of its RTC are being channeled towards keeping their service cost-effective, even as they attract high levels of ridership.

\section{Regional Goals: Coordination and Consolidation Can Both Yield Major Benefits at a Low Price}

One important takeaway from this analysis is that all ten case studies regions finance their transit systems to an adequate extent to provide fast, frequent, reliable, and affordable service. Furthermore, the four case studies discussed immediately above (Stockholm, Vancouver, Lyon, and Barcelona) illustrate that high ridership levels can be achieved by regional coordination (i.e., using an RTC), and if wellmanaged, can also be done without heavy subsidies.

Although consolidation paired with heavy subsidies can be highly effective (as in Stockholm), regional coordination at a low cost can also achieve similar objectives (as in Lyon). Therefore, regional consolidation and high subsidies are not prerequisites for a high-ridership regional transit system, but some form of effective regional coordination is a must. 
The presence of an RTC reduces the need for each system owner to scramble for funds and fight over a smaller budgetary pie. In fact, the RTC and funding that goes with it can make the transit funding pie bigger as a result of regional operating efficiencies that a well-managed RTC can yield.

A birds' eye view of the funding picture that is provided by an RTC is particularly helpful in areas with different transit owners, where, for example, there is an inher-ent disconnect between the need for one transit system (say, a local bus service) to bring passengers to another transit system (say, the regional rail system); yet there is often a lack of coordination and recognition that the former needs a subsidy to do so. In this context, who should be the responsible entity: the local bus pro-vider or the regional provider who is gaining ridership as well, or even the cities who benefit from decreased traffic on their streets because of the transit riders? Timed transfers and free transfers are key components to lessen this disconnect between the local transit service and the regional service. An RTC with a proper mandate and tools helps resolve these issues.

\section{Expanding Sources of Public Transit Funding}

Transit funding in the case study regions comes from a wide variety of sources, varying from country to country and city to city. Further analysis of Vancouver's approach to funding public transit provides a useful illustration.

The Vancouver region has seen dramatic increases in transit ridership since 2000. From 2000 to 2016, ridership increased 80 percent, while population only in-creased 20 percent. ${ }^{136}$ Clearly, Vancouver is doing something right. Nevertheless, this rapid growth has strained the region's existing funding sources. While ade-quate to keep current operations going, TransLink realized they needed to expand their services to accommodate future growth, and as a result, to expand their rev-enues. ${ }^{137}$

To address this need, TransLink has developed a 10-year capital improvement and investment plan that identifies new transit services, capital investments, and new sources of funding to pay for them. According to the plan, these improvements "... will require $\$ 10.5$ billion for capital investments, $\$ 15.1$ billion for operating in-vestments, and $\$ 2.5$ billion for financing costs." 138

The provincial government of British Columbia has committed to funding 40 percent of the capital costs of this plan, with additional investments coming from the federal government. Thus, TransLink has expressed confidence that these federal and provincial contributions will give the region "...a chance to improve the trans-portation system at a substantially lower cost to local taxpayers." 139

As for the local (Vancouver region's) contribution, the plan calls for increased rev-enues to come from a wide variety of local and regional sources, indicating the political strength (and popularity) of TransLink as well as the authority it 
was granted by the Province of British Colombia to impose and collect taxes. These funding sources include gas tax revenues; transit fare revenue, both existing and anticipated increased fare revenues from ridership growth; property taxes; parking taxes; commercial revenues on TransLink property; and development cost charges.

According to the plan, "[t]hese changes are intended to be modest and balanced across Metro Vancouver residents, affecting transit users, drivers, property owners, and real estate developers." 140

As discussed above, Vancouver has achieved remarkably high levels of ridership (compared to other North American regions) while maintaining a highly cost-effective transit system, a testament to the possibilities of regional transit agency consolidation. However, an important element to their success is their RTC's (TransLink's) ability to raise taxes while also drawing from a variety of existing revenue sources from throughout their region.

\section{GENERAL OBSERVATIONS}

\section{Relationship of Governmental Political Jurisdictions to Transit Agen- cies}

In the ten case studies, there is a direct relationship between the transit system owner (what the U.S. would call the transit agency) and the governmental political jurisdictions. It is the cities, counties, and states (and in two cases, a regional government) who are directly responsible for providing public transit within their political boundaries, and ensuring that it is planned, funded, and operated. In short, the entities who provide the funding and are responsible for providing the transit service are the same. The fact that these governmental political jurisdictions-which have legislative as well as taxation authority-are also the transit agencies seems to provide a greater level of "ownership" in the performance of the transit network on the part of local and state governments. The German word Aufgabenträgertask carry-outer-aptly describes their role with respect to public transit.

In contrast, current and ongoing research has found that in the U.S., there is often an "us vs. them" mentality between cities and their respective transit agencies, especially when the transit agency is a special district (a quasi-independent entity established by state law). U.S. special district transit agencies are dependent on various government levels to provide funding and/or to allow them to collect tax revenue. Moreover, special district transit agencies are dependent on these separate entities, i.e. the governments, for the infrastructure they need to operate, such as bus stops, let alone to improve operations, such as bus lanes. This may explain some of the many differences between the U.S. and the case studies where transit agency owners are also governmental political jurisdictions. The differences between such agencies can be distilled to funding resources, investments, performance of transit systems, supply, coverage, modal diversity, and ultimately ridership. 
The Massachusetts Bay Transportation Authority is a unique U.S. example of this structure type: it is a State agency, controlled by MassDOT, and it is the sole agency in charge of transit planning and operation in the entire Boston region. An ENO Center for Transportation report found, "From a customer perspective, regional accessibility on transit in the Boston region is probably the most integrated and seamless of the six case studies investigated in this report." 141

\section{Other Transit Quality Aspects Not Investigated}

There are many aspects of transit quality of service and customer-apparent features; this report has touched on a few, but they and others could be evaluated more deeply. TCRP Report 165 lists the below components of transit quality-ofservice aspects of transit availability, comfort, and convenience that are important to passengers. ${ }^{142}$ These include:

- Travel time

- Frequency of services

- Hours of service / service span

- Access

- Geographic coverage

- Reliability of service

With respect to reliability, for transit to be the solution that cities and metropolitan areas so dearly need, transit reliability should be a given. ${ }^{143}$ While not investigated in this study, transit use will not be maximized unless transit is well run and reliable. This is, of course, true with and without regional transit coordination. Furthermore, excellent reliable public transit is dependent on steady funding that prevents operation funding shortfalls that are the cause of understaffing in the positions of, for example, real-time monitors, dispatchers, line supervisors, and other necessary quality control personnel. ${ }^{144}$ Thus, a steady, sufficient, reliable funding stream is the backbone to world-class and reliable transit.

\section{RECOMMENDATIONS FOR FURTHER RESEARCH}

The findings of this study suggest the following areas for complementary research.

- A comparison of specific U.S. metropolitan area transit networks with the findings of this research, particularly with respect to the coordination of agencies within the same metropolitan area and institution of single unified fare policies across operators.

- An analysis of the relation between regional transit coordination and regional governance. 
- Case studies of successful regional governance models particularly in regions with rings of suburban communities surrounding medium and large cities. ${ }^{145}$

- Identification of the key elements that Regional Transit Coordinators need in their authorization that give them both the mandate and the tools to be effective.

- Presence and density of several layers of rail transit (urban and regional) in metropolitan areas with excellent transit (e.g., kilometers of rail lines, reflecting spatial coverage, and vehicle-kilometers, reflecting amount of service per square kilometer and per capita), and the role of complementary versus redundant service.

- Comparison of bus-only lane networks of various metropolitan areas with excellent public transit.

- Cost savings that accrue from coordination endeavors such as savings from procurement of rolling stocks and single websites for marketing and travel planning.

- Travel time comparison of transit trips versus automobile trips in various metropolitan areas.

- Travel time comparison of total public transit trips, including transfers and waiting times, in areas with excellent public transit.

- Comparison of investment in rail transit into expanding and extending rail lines: light rail, metro, and suburban rail. This should consider both absolute miles and miles normalized per population and per square kilometer.

- Sources of public funding for transit systems in areas with excellent public transit.

- In areas with complete fare integration, especially those areas that also have multiple system owners, what are the policies for allocating fare revenue among the different modes and systems?

- Comparisons of when and how rural and low-density areas have public transit, including regional public transit, in various western countries.

- Techniques and management strategies to ensure schedule adherence, particularly for timed transfer connections. Are there differences when there is consolidation versus coordination? 
- Analysis of transit driver pay and performance bonuses as well as operations staffing levels in areas with excellent public transit. How do these features relate to schedule adherence?

- For areas with multiple transit system owners, analysis of how labor rules and other management issues are reconciled among the different transit system owners under Regional Transit Coordination.

- Case studies of win/win situations: where improved transit labor rules also improve transit reliability and customer experience (e.g., adequately staffing real-time monitoring and dispatching, bonuses for driving the most challenging routes, bonuses for beginning scheduled routes on time after taking rest breaks).

- Ensuring the viability of public transit in the wake of COVID-19 and the ramifications for transit agencies that may stem from the pandemic. 


\section{APPENDIX A: HEAVY RAIL AGENCIES IN THE USA}

\begin{tabular}{|l|l|}
\hline Name of Agency & $\begin{array}{l}\text { Transit Agency } \\
\text { Urbanized Area }\end{array}$ \\
\hline MTA New York City Transit (NYCT) & New York, NY \\
\hline Washington Metro. Area Transit Authority (WMATA) & Washington, DC \\
\hline Chicago Transit Authority (CTA) & Chicago, IL \\
\hline Massachusetts Bay Transportation Auth. (MBTA) & Boston, MA \\
\hline San Francisco Bay Area Rapid Transit District (BART) & San Francisco, CA \\
\hline Southeastern Pennsylvania Transp. Auth. (SEPTA) & Philadelphia, PA \\
\hline Port Authority Trans-Hudson Corporation (PATH) & New York, NY \\
\hline Metropolitan Atlanta Rapid Transit Authority (MARTA) & Atlanta, GA \\
\hline Los Angeles County Metro. Transp. Auth. (LACMTA) & Los Angeles, CA \\
\hline Miami-Dade Transit (MDT) & Miami, FL \\
\hline Maryland Transit Administration (MTA) & Baltimore, MD \\
\hline Port Authority Transit Corporation (PATCO) & Philadelphia, PA \\
\hline Staten Island Rapid Transit Operating Auth. (SIRTOA) & New York, NY \\
\hline Alternativa de Transporte Integrado: ATI (PRHTA) & Cleveland, OH \\
\hline Greater Cleveland Reg. Transit Authority (GCRTA) & Juan, PR \\
\hline
\end{tabular}

Source: Table 12 from 2018 Public Transportation Fact Book. APTA. December 2018. 


\section{ABBREVIATIONS AND ACRONYMS}

ABS

AMAT

AMB

ATM

ATM

AUD

CAD

COURLY

EMTA

FRR

$\mathrm{GGH}$

GMCA

GMITA

GTHA

GVRD

kph

LGA

$\mathrm{mph}$

MTA

OECD

PTA

RMV
Australia Bureau of Statistics

Mobility, Environment and Territory Agency of Milan

Àrea Metropolitana de Barcelona (Barcelona Metropolitan Area Agency)

Azienda Trasporti Milanesi (Milan Transport Agency)

Authority of Metropolitan Transport of Barcelona

Australian Dollar

Canadian Dollar

Communauté Urbaine de Lyon (Urban Community of Lyon)

European Metropolitan Transport Authorities

Farebox Recovery Ratio

Greater Golden Horseshoe

Greater Manchester Combined Authority

Greater Manchester Integrated Transport Authority

Greater Toronto and Hamilton Area

Greater Vancouver Regional District (now known as Metro Vancouver)

Kilometers per hour

Local Government Area (Australia)

Miles per hour

Metropolitan Transport Authority (also known as an RTC)

Organization for Economic Cooperation and Development

Public Transport Authority of the State of Western Australia

Rhein-Main-Verkehrsverbund (Rhine/Main Regional Transport Association) 


\begin{tabular}{|c|c|}
\hline RTC & Regional Transit Coordinator (also known as an MTA) \\
\hline SEK & Swedish Krona \\
\hline SITAM & Transportation Integrated System in the Milan Area \\
\hline SL & AB Storstockholms Lokaltrafik (Stockholm Public Transport) \\
\hline SSB & $\begin{array}{l}\text { Stuttgarter Strassenbahnen AG (Stuttgart public transport } \\
\text { company) }\end{array}$ \\
\hline SYTRAL & $\begin{array}{l}\text { Lyon Syndicat des Transports de l'Agglomération Lyonnaise } \\
\text { (Mixed Transport Union for the Rhône and the Lyon urban } \\
\text { area) }\end{array}$ \\
\hline TCL & Transports en Commun Lyonnais (Lyon Transport) \\
\hline TCRP & Transit Cooperative Research Program \\
\hline TFV & $\begin{array}{l}\text { Trafikförvaltningen (Stockholm County (or Regional) Public } \\
\text { Transport Administration) }\end{array}$ \\
\hline TfGM & Transport for Greater Manchester \\
\hline TfNSW & Transport for New South Wales \\
\hline TPL & $\begin{array}{l}\text { Agenzia del Trasporto Pubblico Locale del Bacino di Milano, } \\
\text { Monza e Brianza, Lodi e Pavia (Local Public Transport } \\
\text { Agency of the Basin of Milan, Monza, Pavia and Lod)i }\end{array}$ \\
\hline TTC & Toronto Transportation Commission \\
\hline TTS & Toronto Tomorrow Survey \\
\hline USD & United States Dollar \\
\hline VRS & Verband Region Stuttgart (VRS) \\
\hline VS & $\begin{array}{l}\text { Verkehrsverbund Tarifverbund Stuttgart (Tariff and Transit } \\
\text { Agency, also translated as Stuttgart Integrated Public } \\
\text { Transport Network }\end{array}$ \\
\hline VV & Verkehrsverbund (tariff and transit organization) \\
\hline
\end{tabular}




\section{ENDNOTES}

1 Jeremy Mattson, Assistant Professor, Department of Transportation, Logistics, and Finance, Small Urban and Rural Center on Mobility, Upper Great Plains Transportation Institute, North Dakota State University; information from the Federal Transit Administration National Transit Database; personal communication with Michelle DeRobertis, June 2, 2020.

2 The MBTA is overseen by two governing bodies: the Massachusetts Department of Transportation (MassDOT) Board and the Fiscal and Management Control Board (FMCB). Source: "Leadership," Massachusetts Bay Transportation Authority, June 11, 2020, https://www.mbta.com/leadership.

${ }^{3}$ ENO Foundation, "Getting to the Route of Priorities," Washington, D.C., 2015, p. 28.

${ }^{4}$ Gisela Gräfin von Schlieffen. "Public Transportation in Germany- The Rhein Main Transport Authority." April 2019. Downloaded from https://www.spur.org/sites/default/files/events_pdfs/Presentation\%20by\%20Gisela.pdf

${ }^{5}$ It should be emphasized that establishing a clear contrast between a typical European and a typical U.S. model is difficult since these public transit entities are very context-specific in relation to their roles and tasks; even within the same country there will be many differences. Fabio Hirschhorn Zonana (Delft University of Technology, Netherlands), personal communication with Michelle DeRobertis, March 3, 2020. This discussion is provided as a birds' eye view of the differences, since they vary in their specifics.

${ }^{6}$ Some VVB perform more route scheduling than others, with crucial input from the public transit operators. Government jurisdictions determine the overall level and types of infrastructure investment but with the advice of VVB planners. In most cases, public transit firms directly supervise the projects, which are usually contracted out to construction firms. These are only generalizations, as there is considerable variation from one VVB to another. R. Buehler, J. Pucher, and O. Dummler, "Verkehrsverbund: The Evolution and Spread of Fully Integrated Regional Public Transport in Germany, Austria, and Switzerland," International Journal of Sustainable Transportation 0 , no. 0 (2018): 1-15, https://doi.org/10.1080/15568318.2018.1431821.

7 In Vancouver it is TransLink, a state-authorized regional district, which is a unique governmental level with more power than a regional coordinating district but less than a county; see Chapter III. 
${ }^{8}$ Some large transit systems, particularly at the national or state level, have transitioned to become private joint-stock companies, with the public agency being the single or largest shareholder. For the purposes of this report, this still indicates the government body as the transit system owner.

${ }^{9}$ Public ownership of transit companies can get quite complicated. For example, "the Region of Lombardy is a shareholder of TreNord via Gruppo FNM (LeNORD), a regional railway company. Gruppo FNM has $50 \%$ of the shares of TreNord, the rest is owned by Trenitalia (Gruppo Ferrovie dello Stato Italiane). TreNord was born in order to optimise and rationalise the service in Lombardy. Of course the company operates it under a PSO contract, so that TreNord receives public subsidies as any other Public Transport company in Italy." Source: Cosimo Chiffi, personal communication with Michelle DeRobertis, May 19, 2020. Add to the mix that EU laws favor tendering out operations to private companies, as another researcher said, "It is mindboggling and very complicated. You almost need a law degree" to understand it. Personal communication with Michelle DeRobertis, April 4, 2020.

${ }^{10}$ Indeed, there is an EU directive which states, "Contracts for national rail, regional rail and public transportation should be awarded on the basis of competitive bidding" and "A public authority has two choices regarding who will provide the public transit services: Competitive Tendering (Europe-wide) and Award contract to cityowned company." This could explain the high amount of private company operators in many European areas.

${ }^{11}$ For example, the Region of Lombardy is responsible for planning and financing the regional railway service. In turn, it contracts the service to the railway company TreNord (of which it is one of the shareholders), which "operates the service defined by the Lombardy Region on the strength of a Service Contract with the Region." This information is correct as of early 2020 (pre-COVID-19). TreNord carries 820,000 passengers every day on trains throughout the region, making approximately 2,300 trips a day. The regional rail service is entrusted to TreNord until 2020 (dgr 1263/2014), with a production of over 40 million train-km per year. The contract specifies service and quality levels to be respected by TreNord (and the related penalties in case of non-compliance). Regione Lombardia verifies compliance with the contract on a daily basis, monitoring the performance of the service and checking the level of quality provided. For further details, consult the Regione Lombardia website: https://www.regione.lombardia.it/wps/portal/istituzionale/HP/DettaglioRedazionale/istituzione/x-legislatura/direzione-generaleinfrastrutture-e-mobilita/contratto-servizio-trenord/contratto-servizio-ferroviario. 
Personal communication between Michelle DeRobertis and TreNord, Direzione Commerciale Servizio e Assistenza alla Clientela, response received, June 9, 2020.

${ }^{12}$ Greater Manchester is the unique English level of government called a Combined Authority. Greater Manchester has an elected mayor, but it does not have a separate directly elected council or legislature, as do cities, counties, and states; therefore, this report would consider it a state-authorized regional district. https://www.greatermanchester-ca.gov.uk.

${ }^{13}$ C. Ferrell, B. Appleyard, and M. Taecker, Livable Transit Corridors: Methods, Metrics and Strategies, Transit Cooperative Research Program, Report No. 187 (TCRP H-45), 2017, https://www.nap.edu/catalog/23630/livable-transit-corridorsmethods-metrics-and-strategies.

14 TCRP Research Report 209: Analysis of Recent Public Transit Ridership Trends. Washington, D.C.: The National Academies Press, 2019. https://doi.org/10.17226/25635.

${ }^{15}$ Documented by several reports including TCRP Research Report 209 Analysis of Recent Public Transit Ridership Trends, Washington, D.C.: The National Academies Press (2019); E. Blumenberg, et al., "What's Behind Recent Transit Ridership Trends in the Bay Area?" UCLA Institute of Transportation Studies, 2020; and M. Manville et al., Falling Transit Ridership: California and Southern California, UCLA Institute of Transportation Studies, 2018.

16 The research team initially considered including U.S regions, but it was determined that outside of New York, no U.S. metro areas has achieved regionwide transit mode shares above 15\%. The four that came closest, (Philadelphia, Chicago, San Francisco Bay Area and Washington D.C., with transit commute shares between $9.8-13 \%$ ) only did so for work trips and not for leisure and discretionary travel. Source: U.S. Census Bureau: American Community Survey, 2018 data found at:

\section{https://www.vitalsigns.mtc.ca.gov/commute-mode-choice. August 102020}

${ }^{17}$ A monocentric metropolitan region is defined as a collection of towns and cities that are organized around a single, dominant employment center, or "central business district" (CBD). A polycentric metropolitan region is defined as a region where there are multiple CBDs. See Daniel Arribas-Bel \& Fernando Sanz-Gracia (2014) "The validity of the monocentric city model in a polycentric age: US metropolitan 
areas in 1990, 2000 and 2010," Urban Geography, 35:7, 980-997, DOI: $10.1080 / 02723638.2014 .940693$

${ }^{18} \mathrm{~F}$. Hirschhorn, W. Veeneman, and D. van de Velde, "Organisation and Performance of Public Transport: A Systematic Cross-Case Comparison of Metropolitan Areas in Europe, Australia, and Canada," Transportation Research Part A: Policy and Practice 124 (2019): 419-432, https://doi.org/10.1016/j.tra.2019.04.008.

19 The preface to this report describes some of the differences in terminology.

${ }^{20}$ Frankfurt, Stuttgart, Lyon, Milan, Stockholm, Toronto, Vancouver, Sydney and Perth metropolitan area population data from Organization for Economic Co-Operation and Development, "Metropolitan Area Population," 2018 (April 2020), https://stats.oecd.org/Index.aspx?DataSetCode=CITIES (accessed April 24, 2020). Barcelona metropolitan area population data from EMTA-European Metropolitan Transport Authorities, EMTA Barometer: 2019 - Based on 2017 Data (Paris, France: EMTA-European Metropolitan Transport Authorities, 2019). City of Frankfurt population from Wikipedia, "Frankfurt," (2018) https://en.wikipedia.org/wiki/Frankfurt (accessed April 24, 2020). City of Stuttgart population from Wikipedia, "Stuttgart," (2018) https://en.wikipedia.org/wiki/Stuttgart (accessed April 24, 2020). City of Lyon population from Wikipedia, "Lyon," (2017) https://en.wikipedia.org/wiki/Lyon (accessed April 24, 2020). City of Milan population from Wikipedia, "Milan," (2019) https://en.wikipedia.org/wiki/Milan (accessed April 24, 2020). City of Stockholm population from Wikipedia, "List of metropolitan areas in Sweden," (2018) https://en.wikipedia.org/wiki/List_of_metropolitan_areas_in_Sweden\#Metropolitan_Stockholm (accessed April 24,2020$)$. City of Toronto population from City of Toronto, "Toronto," (2020) https://www.toronto.ca (accessed April 24, 2020). City of Vancouver population from Wikipedia, "Vancouver," (2016) https://en.wikipedia.org/wiki/Vancouver (accessed April 24, 2020). City of Perth population from Wikipedia, "City of Perth," (2018) https://en.wikipedia.org/wiki/City_of_Perth (accessed April 24, 2020). City of Sydney population from Wikipedia, "City of Sydney," (2018) https://en.wikipedia.org/wiki/City_of_Sydney (accessed April 24, 2020). City of Barcelona population from Wikipedia, "Barcelona," (2018) https://en.wikipedia.org/wiki/Barcelona (accessed April 24, 2020).

${ }^{21}$ Primacy is defined as "the largest city's preeminence in economic, social, and political affairs" or as "a city's predominance within an area" in Johnston, R. 2009. "Primate City, The Law of." In The Dictionary of Human Geography, edited by D. Gregory et al., 5th ed., 580. Chichester: Wiley-Blackwell.

${ }^{22}$ See population data sources for Figure 2. 
${ }^{23}$ See population data sources for Figure 2. Surface area data from same sources as population data.

${ }^{24}$ Frankfurt, Stuttgart, Lyon, Stockholm, and Barcelona metropolitan area transit ridership data from EMTA-European Metropolitan Transport Authorities, EMTA Barometer: 2019 - Based on 2017 Data (Paris, France: EMTA-European Metropolitan Transport Authorities, 2019). Milan metropolitan area transit ridership data from ATM Group, Annual Report - 2016 (Milan, Italy: ATM Group, 2016). Toronto metropolitan area transit ridership data from Tricia Wood, "Toronto's transit ridership is in a league of its own," (November 22, 2017), https://torontoist.com/2017/11/torontos-transit-ridership-league/ (accessed April 24, 2020). Vancouver metropolitan area transit ridership data from TransLink, Phase Two of the 10-Year Vision 2018 - 2027 Investment Plan (Vancouver, BC: TransLink, 2018). Perth metropolitan area transit ridership data from The Government of Western Australia Public Transport Authority, Annual Report 2018 - 2019 (Perth, Australia: The Government of Western Australia Public Transport Authority, 2019). Sydney metropolitan area transit ridership data from State Transit Authority of NSW, Annual Report 18 - 19, Volume 1 (Sydney, Australia: State Transit Authority of NSW, 2019), from State Transit Authority of NSW, Sydney Trains 18 - 19, Volume 1 (Sydney, Australia: State Transit Authority of NSW, 2019), and from Sydney Metro of NSW, Corporate Plan 2019 - 21 (Sydney, Australia: Sydney Metro of NSW, 2019).

${ }^{25}$ See transit ridership data sources for Figure 5 and population data for Figure 2.

26 Àrea Metropolitana de Barcelona, April 28, 2020, https://www.metropolis.org/partners/area-metropolitana-de-barcelona-amb. The new public metropolitan administration replaced the three entities existing until 2011: Mancomunitat de Municipis de l'Àrea Metropolitana de Barcelona (Union of Municipalities of the Metropolitan Area of Barcelona), Environmental Agency, and Transport Metropolitan Agency.

${ }^{27}$ Barcelona Metropolitan Area, April 28, 2020, https://en.wikipedia.org/wiki/Barcelona metropolitan area.

${ }^{28}$ EMTA, April 1, 2020, https://www.emta.com/spip.php?article50.

${ }^{29}$ AMTU: Associació de municipis per la Mobilitat i el Transport Urbà, May 1, 2020, https://www.amtu.cat/index.php/amtu.

30 Autoritat del Transport Metropolità (ATM), April 27, 2020, https://www.atm.cat/web/index.php. 
${ }^{31} \mathrm{https}: / / \mathrm{www} . a t m . c a t / w e b / i n d e x . p h p$.

32 Silvia Crivello and Luca Staricco, "Institutionalizing Metropolitan Cities In Italy. Success and Limits of a Centralistic, Simplifying Approach," Urban Research \&

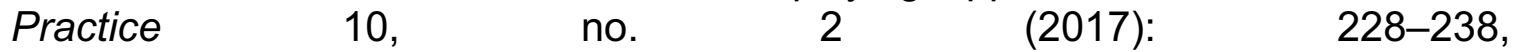
https://doi.org/10.1080/17535069.2017.1307001.

${ }^{33}$ Patrizia Malgieri (Board Member TPL), interview by Michelle DeRobertis, March 25, 2020.

${ }^{34}$ Region of Lombardy, Regional Law (Legge Regionale), April 4, 2012, n. 6: Disciplina del settore dei trasporti.

${ }^{35}$ Agenzia TPL, March 2, 2018, http://www.agenziatpl.it/agenzia/chi-siamo.

36 Agenzia TPL, Organi societari (Corporate Bodies), 19 January 2019, http://www.agenziatpl.it/agenzia/chi-siamo/organi-societari.

${ }^{37}$ ATM, March 15, 2020, atm.it.

${ }^{38}$ Agenzia TPL, March 2, 2020, http://www.agenziatpl.it/agenzia/chi-siamo.

39 Le SYTRAL, March 20, 2020, https://fr.wikipedia.org/wiki/Syndicat_mixte_des_transports_pour_le_Rh\%C3\%B4ne_et_l\%27agglom\%C3\%A9ration_lyonnaise.

40 TCL Lyon, https://www.tcl.fr/en/tcl-network

${ }^{41}$ SYTRAL, http://www.sytral.fr/113-equipes-operationnelles.htm.

${ }^{42}$ Source: http://www.sytral.fr/.

${ }^{43}$ http://www.sytral.fr/.

${ }^{44}$ SYTRAL Territoire de compétences, http://www.sytral.fr/115-territoire-competence.htm.

${ }^{45}$ See the preface of this report for an explanation of foreign terms and words.

${ }^{46}$ In Germany, the smaller towns (but not the larger cities) are part of a Landkreis or "rural district" which is more or less the equivalent of a county, i.e., an intermediate level of administration between the state (or Land) and the municipal 
governments. They are called rural districts because larger cities and towns do not belong to this level of government.

${ }^{47}$ Region Stuttgart at a Glance, October 2019, https://www.region-stuttgart.org/andere-laender/english/.

${ }^{48}$ Ralph Buehler (Associate Professor, Virginia Tech Research Center (VTRC)), interviewed by Michelle DeRobertis, April 14, 2020.

49 https://www.vvs.de/presse/ueber-den-vvs/; PowerPoint presentation from SSB, 2009.

${ }^{50}$ VVS, http://www.vvs.de/presse/ueber-den-vvs/.

$51 \quad$ https://web.archive.org/web/20141021045136, /http://www.region-frankfurt.de/Regional-Authority?La=2.

52 Gisela Gräfin von Schlieffen, RMV, personal communication with Michelle DeRobertis, July 8, 2020.

53 Rhein-Main-Verkehrsbund (RMV), https://www.rmv.de/c/en/homepage/ and https://www.rmv.de/c/en/information-on-rmv/rmv/a-story-of-success-rmv-sets-thepace-for-the-region/.

${ }^{54}$ Region Stockholm, https://www.sll.se/om-regionstockholm/Information-in-English1/.

55 Stockholm Regional Assembly, https://www.sll.se/om-regionstockholm/Information-in-English1/About-Stockholm-Region-Assembly/.

${ }^{56}$ EMTA-Stockholm, https://www.emta.com/spip.php?article61.

${ }^{57}$ John Hultén (Director, K2: The Swedish Knowledge Centre for Public Transport), interviewed by Michelle DeRobertis, March 12, 2020.

${ }^{58}$ Metro Vancouver, http://www.metrovancouver.org/.

59 Trevor Wales, "The Road Less Travelled: TransLink's Improbable Journey from 1999 to 2008," TransLink, 2008.

60 TransLink, https://www.translink.ca/About-Us/Governance-and-Board/Governance-Model.aspx. 
61 TransLink. https://www.translink.ca/About-Us/Corporate-Overview/OperatingCompanies/Overview.aspx

62 The independent Screening Panel is convened annually. The following entities must each appoint one member by June 30 of each year: Greater Vancouver Gateway Society; Organization of Chartered Professional Accountants of British Columbia; Mayors' Council on Regional Transportation; Minister Responsible for TransLink; and Vancouver Board of Trade.

63 TransLink, About us, https://www.translink.ca/About-Us.aspx.

64 TransLink, Taxes and Charges, https://www.translink.ca/About-Us/Taxes.aspx (accessed May 6, 2020); TransLink, Bylaws, https://www.translink.ca/About-Us/Governance-and-Board/Bylaws.aspx (accessed May 6, 2020).

65 Malatest, Summaries For The Greater Toronto \& Hamilton Area: Transportation Tomorrow Survey 2016, Toronto, March 2018, http://dmg.utoronto.ca/transportation-tomorrow-survey/tts-reports.

${ }^{66}$ Malatest, Summaries For The Greater Toronto \& Hamilton Area: Transportation Tomorrow Survey 2016, Toronto, March 2018, http://dmg.utoronto.ca/transportation-tomorrow-survey/tts-reports.

67 Malatest, Toronto Travel Survey (TTS) 2016.

${ }^{68}$ Malatest, Toronto Travel Survey (TTS) 2016.

69 Metrolinx, http://www.metrolinx.com/en/aboutus/about_us_index.aspx and http://www.metrolinx.com/en/aboutus/metrolinxoverview/metrolinx_overview.aspx.

70 Metrolinx. Further Connecting the Greater Toronto and Hamilton Region - Discussion Paper for the Next Regional Transportation Plan.. July 2016, p.11.

${ }^{71}$ Metrolinx Act, 2006, S.O. 2006, c. 16, https://www.ontario.ca/laws/statute/06g16.

72 Metrolinx Act, 2006, S.O. 2006, c. 16, https://www.ontario.ca/laws/statute/06g16. 73 Toronto Transit Commission, https://www.ttc.ca/About_the_TTC/History/The_first_75_years.jsp.

74 "The Big Move," Metrolinx, 2008, available at http://www.metrolinx.com/thebigmove/en/introduction/1_3_GTHA_challenges.aspx. Current list of agencies available in drop-down menu at 
http://www.metrolinx.com/en/regionaltransit/regional_transit_index.aspx. In 2018, Metrolinx's purview was expanded to include the Greater Golden Horseshoe, but this expansion has not fully been implemented. http://www.metrolinx.com/en/regionaltransit/regional_transit_index.aspx.

${ }^{75}$ Metrolinx Act, 2006, S.O. 2006, c. 16, https://www.ontario.ca/laws/statute/06g16.

76 Metrolinx Act, 2006 S.O. 2006, c. 16, https://www.ontario.ca/laws/statute/06g16/v14

${ }^{77} \mathrm{https}: / /$ www.cityofsydney.nsw.gov.au/learn/research-and-statistics/the-city-at-aglance.

${ }^{78}$ Australian local governments have a variety of names including "borough," "city," "district," "municipality," "village," or "region." The term "local government area" or LGA is used to refer collectively to all these local governments, while the local jurisdiction itself is generally known as a council. In general, an urban or suburban LGA is called a city. An LGA may have wards or neighborhoods, which are sometimes called suburbs, but they are not independent municipalities.

79 Transport Administration Act no. 109, 1988, https://www.legislation.nsw.gov.au/\#/view/act/1988/109.

${ }^{80}$ Transport for New South Wales https://www.transport.nsw.gov.au/.

81 https://www.transport.nsw.gov.au/.

82 The position of Minister is a cabinet position appointed by the premier of the State of New South Wales from the elected members of the parliament. They could be from either of the two houses of state government: the legislative council and the legislative assembly.

${ }^{83}$ Aaron Murray (Transport for NSW), interviewed by Michelle DeRobertis, March 3, 2020.

84 Transport Administration Act no. 109, 1988, https://www.legislation.nsw.gov.au/\#/view/act/1988/109.

${ }^{85}$ Australian Bureau Statistics: Greater Perth, https://itt.abs.gov.au/itt/r.jsp?RegionSummary\&re-

gion=5GPER\&dataset=ABS_REGIONAL_ASGS2016\&geoconcept=ASGS_2016\&m 
easure=MEASURE\&datasetASGS=ABS_REGIONAL_ASGS2016\&datasetLGA=AB S_REGIONAL_LGA2018\&regionLGA=LGA_2018\&regionASGS=ASGS_2016.

${ }^{86}$ Transperth, https://www.pta.wa.gov.au/about-us/our-role/our-history.

87 Public Transport Authority Bill 2003, https://www.parliament.wa.gov.au/parliament/bills.nsf/BillProgressPopup?openForm\&ParentUNID=1698FA9CBCCDBB4748256CD80007E64D.

${ }^{88}$ Transperth, https://www.pta.wa.gov.au/about-us/our-role/our-executive.

89 https://www.pta.wa.gov.au/about-us/our-role/our-history.

${ }^{90}$ Meng Meng, Andreas Rau, Hita Mahardhika, "Public Transport Travel Time Perception: Effects of Socioeconomic Characteristics, Trip Characteristics and Facility Usage" Transportation Research Part A: Policy and Practice 114, part A (2018): 24-37. https://doi.org/10.1016/j.tra.2018.01.015.

91 Data on service speeds and vehicle-kilometers are drawn from EMTA Barometer 2019-Based on 2017 Data, EMTA, European Metropolitan Transport Authorities, June 2019.

92 Vehicle service-kilometers data for the other case study regions were not available.

${ }^{93}$ This data are not reported at the metropolitan area level in the U.S. The U.S. average was calculated as follows: December 8, 2016, U.S. Census Bureau Release Number CB16-210: New Census Data Show Differences Between Urban and Rural Populations, quotes Census Bureau Director John H. Thompson: "Rural areas cover 97 percent of the nation's land area but contain 19.3 percent of the population (about 60 million people)." Since the Census estimate of the population in 2018 was 327 million, 264 million (80.7 percent) were urban; this is the denominator used to calculate vehicle-kilometers per capita in the U.S. APTA reports that all U.S. transit agencies delivered 5 billion vehicle-miles or approximately 8.05 billion vehicle-kilometers of travel. APTA's 2017 Rural Transit Fact Book indicates that rural transit operators delivered 490 million miles or 790 million kilometers of service. This indicates that U.S. urban areas saw approximately 7.26 billion kilometers of service. This translates to 28 vehicle-kilometers of service per capita in U.S. urban areas.

${ }^{94}$ Federal Transit Administration National Transit Database, Summary sheet for MBTA and NTD Excel file showing vehicle and train hours of service for 2018; https://www.transit.dot.gov/ntd/data-product/2018-metrics; 
https://cms7.fta.dot.gov/sites/fta.dot.gov/files/transit_agency_pro-

file_doc/2018/10003.pdf and https://www.transit.dot.gov/ntd/transit-agency-profiles

95 https://metrarail.com/about-metra/reports-documents/operations-ridership-data.

96 https://www.transit.dot.gov/ntd/national-transit-database-ntd-glossary\#H

${ }^{97}$ EMTA Barometer 2019-Based on 2017 Data, EMTA, European Metropolitan Transport Authorities, June 2019.

98 EMTA Barometer 2019-Based on 2017 Data, EMTA, European Metropolitan Transport Authorities, June 2019.

99 Toronto's blue night bus network, August. 7, 2020. https://localwiki.org/Toronto/Blue_Night_Network

100 https://www.fhwa.dot.gov/policyinformation/statistics/2017/mv1.cfm.

101 Unless otherwise indicated, all Euro currency exchanges are provided in USDequivalents using the "Mid Exchange Rate" value for 2020 from "PoundSterling Live" https://www.poundsterlinglive.com/best-exchange-rates/best-euro-to-us-dollar-history (accessed August 5, 2020).

102 Fare information from Gisela Gräfin von Schlieffen, personal communication with Michelle DeRobertis, July 8, 2020.

103 https://www.vvs.de/download/Tarifzonenplan.pdf

104 https://nuovosistematariffario.atm.it/\#tariffe-row

105 Unless otherwise indicated, all Swedish Krona (SEK) currency exchanges are provided in USD-equivalents using the "Average" rate value from Friday 02/07/2020 to Monday 08/03/2020 from "Exchange Rates UK: Your Live Currency Exchange Rates Website" https://www.exchangerates.org.uk/SEK-USDexchange-rate-history.html (accessed August 5, 2020).

${ }^{106}$ Stockholm congestion tax, Wikipedia (accessed April 2, 2020).

107 Fare policies are dynamic not static; this particular issue may have changed as part of the adoption and desire to encourage the use of the Presto card. 
108 Antoine Belaieff (Metrolinx), interview by Michelle DeRobertis, Richard Lee, and Christopher Ferrell, April 9, 2020.

109 Unless otherwise indicated, all Canadian dollar currency exchanges are provided in USD-equivalents using the "Mid Exchange Rate" value for 2020 from "PoundSterling Live" https://www.poundsterlinglive.com/best-exchangerates/best-canadian-dollar-to-us-dollar-history (accessed August 5, 2020).

110 Antoine Belaieff (Metrolinx), interview by Michelle DeRobertis, Richard Lee, and Christopher Ferrell, April 9, 2020.

111 https://www.translink.ca/Fares-and-Passes/Fare-Zone-Map.aspx

112 Unless otherwise indicated, all Australian dollar currency exchanges are provided in USD-equivalents using the "Mid Exchange Rate" value for 2020 from "PoundSterling Live" https://www.poundsterlinglive.com/best-exchangerates/best-australian-dollar-to-us-dollar-history (accessed August 5, 2020).

113 Staci Haber, "Transit in Suburbia: An Analysis of Perth, Australia's Mass Transit System and How American Suburbs Can Overcome Automobile Dependency," May 2011, pp. 24-25, 31.

114 http://www.vitalsigns.mtc.ca.gov/transit-ridership.

115 Staci Haber, "Transit in Suburbia: An Analysis Of Perth, Australia's Mass Transit System and How American Suburbs Can Overcome Automobile Dependency," May 2011.

116 Transit passengers see clear benefits in uniform, regionwide fare structures, as well as from smart card systems. This point is documented in several reports, including TCRP Research Report 94, Fare Policies, Structures, and Technologies: Update, Washington, D.C.: The National Academies Press, 2002 p. 32; and Metra. Customer Satisfaction Study. Chicago: Regional Transportation Authority (RTA), 2014, pp 41-44. For example, in London, an integrated fare structure and the introduction of the Oyster (Smart) Card in 2003, resulted in higher levels of passenger satisfaction in London than in other British metropolitan areas where fare structures were not uniform and a smart card had not been introduced. Source: Charles Rivasplata, An Analysis of the Impacts of British Reforms on Transit Integration in the Metropolitan Areas. Ph.D. Dissertation, University of California, Davis, 2006.

117 EMTA, Determining Fare Structure: Evidence and Recommendations from a Qualitative Survey, EMTA Brief, 2016, p. 18. 
118 This study collected and compared operational budgets from each case study region, and in doing so, the research team worked to ensure consistency between these regions. Since there may be differences in how each agency, region, and country defines what constitutes transit "operational" expenditures or whether all transit providers and their operational budgets were captured in this study's data collection efforts, inconsistencies may remain. For example, it is not entirely clear whether the operating budgets found completely account for the costs for suburban rail (e.g., intercity railways that comprise a significant part of the public transit network). This may explain some of the discrepancies between Stockholm and Milan, for example, where it is likely these costs are included in Stockholm's regional operations budget, while it proved difficult to confirm whether Milan's regional transit operational budget includes these suburban rail costs. This study endeavored to ensure consistent definitions (and accounting methods) and sought to compare operational budgets between case study regions. This said, differences in definitions and accounting methods proved difficult to rectify. Therefore, while all case study regions separated capital and operations budgets, some included debt payments for capital service expansions in their operational budgets. This is an issue that requires further research and attention.

119 Frankfurt, Stuttgart, Lyon, Stockholm, and Barcelona metropolitan area transit operating expenditures data from EMTA-European Metropolitan Transport Authorities, EMTA Barometer: 2019 - Based on 2017 Data (Paris, France: EMTAEuropean Metropolitan Transport Authorities, 2019). Milan metropolitan area transit operating expenditures data (which does not include the 12 suburban train lines that are operated by TreNord) from Agenzia del Trasporto Pubblico Locale del Bacino di Milano, Monza-Brianza, Lodi e Pavia. Milan (TPL), Programma di Bacino - Relazione generale, Versione 3.0" (Basin Plan -General Report) (Milan, Italy: Agenzia del Trasporto Pubblico Locale del Bacino di Milano, Monza-Brianza, Lodi e Pavia. Mllan (TPL), December 2018). Toronto metropolitan area transit operating expenditures data from Toronto Transit Commission (TTC), "2020 TTC and Wheel-Trans Operating Budgets" (December 16, 2019), https://www.ttc.ca/About the TTC/Commission reports and information/Commi ssion meetings/2019/December 16/Re-

ports/1 2020 TTC and Wheel Trans Operating Budgets.pdf (accessed August 4, 2020), from York Region Rapid Transit Corporation, "2020 to 2022 Budget As Tabled on November 21, 2019" (November 21, 2019), https://www.york.ca/wps/wcm/connect/yorkpublic/572e180e-e446-4878-85853a7de5a95eab/Budget+Book+Nov+21-

TABLED+WEB+VERSION.pdf?MOD=AJPERES\&CVID=mWeQG6B (accessed August 4, 2020), from City of Mississauga "Mississauga City Business Plan and Budget: 2020-2023 Business Plan \& 2020 Budget" (2019), https://web.mississauga.ca/wp-content/uploads/2019/11/28132215/B-Executive-Summary1.pdf 
(accessed August 4, 2020), Corporation of the City of Brampton, "2020 Proposed Operating and Capital Budgets" (January 1, 2019), https://www.brampton.ca/EN/City-

Hall/budget/2020\%20Budget/2020\%200perating\%20and\%20Capital\%20Budgets/2020\%20Proposed\%200perating\%20and\%20Capital\%20Budget.pdf (accessed August 4, 2020), from Regional Municipality of Durham, Durham Region Transit "The 2020 Regional Business Plans and Budgets for Property Tax Purposes, including General Purpose, Solid Waste Management and Durham Regional Transit" (February 11, 2020), https://www.durham.ca/en/regional-government/resources/2020-Approved-Regional-Property-Tax-Supported-Budgets--Summary---page-numbered---Compressed.pdf (accessed August 4, 2020), from Jennifer Gray, Chief Financial Officer, Metrolinx, "2019-20 Metrolinx Business Plan" (June 27, 2019), http://www.metrolinx.com/en/docs/pdf/board agenda/20190627/20190627 BoardMtg 2019-

20 BusinessPlan EN.pdf (accessed August 4, 2020), from City of Burlington, "2019 Approved Budget: 2019 Operating and Capital Budgets 2020 - 2028 Capital Forecast" (2018), https://www.burlington.ca/en/your-city/resources/Budget/2019Budget/2019-Budget-Book-Combined-WEB.pdf (accessed August 4, 2020), from City of Hamilton, "2020 Tax Supported Operating Budget Report" (December 11, 2019), $\quad$ https://www.hamilton.ca/sites/default/files/media/browser/2019-1211/2020-preliminary-tax-operating-budget-book-appendix-a-report-fcs20001.pdf (accessed August 4, 2020), City of Milton, "2020 Proposed Capital and Operating Budget Book" (2019), https://www.milton.ca/en/town-hall/resources/2020-Proposed-Capital-and-Operating-Budget-Book.pdf (accessed April 15, 2020), and from Town of Oakvale, "2020 Budget Highlights" (2019), https://www.oakville.ca/townhall/2020-budget-highlights.html (accessed August 4, 2020). Vancouver metropolitan area transit operating expenditures data from TransLink, "2018 Year-End Financial and Performance Report" (2019), https://www.translink.ca//media/Documents/about_translink/corporate_overview/corporate_reports/quarterly_reports/2018/Year_End_2018_Finance_and_Performance_Report_15-32018. pdf?la=en\&hash $=\bar{A}$ 91F 0 FEBD24C455 $\overline{\mathrm{D}} 5 \mathrm{E}$ 7 $\overline{\mathrm{C}} 8142 \mathrm{BB} 5122 \mathrm{~B} 7 \mathrm{CA} 7 \overline{\mathrm{B}} 5 \mathrm{D} 6 \mathrm{~F}$ (accessed August 4, 2020). Perth metropolitan area transit operating expenditures data from The Government of Western Australia Public Transport Authority, Annual Report 2018 - 2019 (Perth, Australia: The Government of Western Australia Public Transport Authority, 2019). Sydney metropolitan area transit operating expenditures data from State Transit Authority of NSW, Annual Report $18-19$, Volume 1 (Sydney, Australia: State Transit Authority of NSW, 2019), from State Transit Authority of NSW, Sydney Trains 18 - 19, Volume 1 (Sydney, Australia: State Transit Authority of NSW, 2019), and from Sydney Metro of NSW, Corporate Plan 2019 - 21 (Sydney, Australia: Sydney Metro of NSW, 2019). Euro currency exchanges are provided in USD-equivalents using the "Mid Exchange Rate" value for 2019 from "PoundSterling Live" https://www.poundsterlinglive.com/best- 
exchange-rates/best-euro-to-us-dollar-history (accessed August 5, 2020). Swedish Krona (SEK) currency exchanges are provided in USD-equivalents using the "Mid Exchange Rate" rate value for 2019 from "Exchange Rates UK: Your Live Currency Exchange Rates Website" https://www.exchangerates.org.uk/SEKUSD-exchange-rate-history.html (accessed August 5, 2020). Canadian dollar currency exchanges are provided in USD-equivalents using the "Mid Exchange Rate" value for 2019 from "PoundSterling Live" https://www.poundsterlinglive.com/bestexchange-rates/best-canadian-dollar-to-us-dollar-history (accessed August 5, 2020). Unless otherwise indicated, all Australian dollar currency exchanges are provided in USD-equivalents using the "Mid Exchange Rate" value for 2019 from "PoundSterling Live" https://www.poundsterlinglive.com/best-exchangerates/best-australian-dollar-to-us-dollar-history (accessed August 5, 2020).

120 See metropolitan area transit expenditures data sources for Figure 26 and population data for Figure 2.

121 See metropolitan area transit expenditures data sources for Figure 26 and annual transit ridership data for Figure 5.

122 In this case, "farebox" revenues refers not only to the literal revenues collected from fareboxes, but revenues from other payment media as well.

${ }^{123}$ Frankfurt Farebox Recovery Ratio (FRR) data from Gisela Gräfin von Schlieffen. "Public Transportation in Germany- The Rhein Main Transport Authority," (April 2019), https://www.spur.org/sites/default/files/events pdfs/Presentation\%20by\%20Gisela.pdf (accessed August 6, 2020). Stuttgart FRR data calculated based on data from Verband Region Stuttgart, "What does public transport cost in the Stuttgart region?" https://www.region-stuttgart.org/nahverkehr/finanzierung/?noMo-

bile=mjhrnjlo\%25252525252525252525252525252525252525252520onfocus $\% 25252525252525252525252525252525252525253$ DblurLink\%28this\%29\% 27\%20aND\%20BeNCh-

MaRK\%282999999\%2CMd5\%28NoW\%28\%29\%29\%29\%20AnD\%20\%271 (accessed August 4, 2020). Barcelona and Lyon FRR data from EMTA-European Metropolitan Transport Authorities, EMTA Barometer: 2019 - Based on 2017 Data (Paris, France: EMTA-European Metropolitan Transport Authorities, 2019). Stockholm FRR data from Svergis Officiella Statistik, Trafik Analys, "Regional Linjetrafik 2019," (June 25, 2020), https://www.trafa.se/globalassets/statistik/kollektivtrafik/kollektivtrafik/2019/regional_linjetrafik_2019.xIsx? (accessed August 20, 2020). Milan Farebox Recovery Ratio (FRR) data from Agenzia del Trasporto Pubblico Locale del Bacino di Milano, Monza-Brianza, Lodi e Pavia. Milan (TPL), Programma di Bacino - Relazione generale, Versione 3.0" (Basin Plan -General 
Report) (Milan, Italy: Agenzia del Trasporto Pubblico Locale del Bacino di Milano, Monza-Brianza, Lodi e Pavia. Mllan (TPL), December 2018). Toronto and Vancouver FRR data from Canadian Urban Transit Association, CUTA DATA Canadian Conventional Transit Statistics: 2018 Operating Data (Toronto, Canada: Canadian Urban Transit Association, 2019). Perth and Sydney FRR data from Tourism and Transport Forum Australia, Ticket to Ride: Reforming Fares and Ticketing for Sustainable Public Transport (Sydney, Australia: Tourism and Transport Forum Australia, 2016).

${ }^{124}$ See metropolitan area transit FRR data sources for Figure 29 and population data for Figure 2.

${ }^{125}$ See metropolitan area transit FRR data sources for Figure 29 and annual transit ridership data for Figure 5.

${ }^{126}$ Image copyright: traffiQ, Frankfurt am Main, December 13, 2016.

${ }^{127}$ Graphic by lan Griffiths and Michelle DeRobertis.

${ }^{128}$ R. Buehler, J. Pucher, and O. Dummler, "Verkehrsverbund: The Evolution and Spread of Fully Integrated Regional Public Transport in Germany, Austria, and Switzerland," International Journal of Sustainable Transportation 13, no. 1 (2019): 36-50. https://doi.org/10.1080/15568318.2018.1431821.

129 P. Mees, Transport for Suburbia: Beyond the Automobile Age, New York, NY: Earthscan, 2010.

130 Transport for Greater Manchester, TFGM, April 10, 2020, https://tfgm.com/about-tfgm; Greater Manchester, April 15, 2020, https://www.greatermanchester-ca.gov.uk. In addition, "It should also be noted that the 1986 privatization and deregulation of transit outside of London had a longterm impact on bus service in the metropolitan area, and as a result, on the light rail network. While MetroLink did not open until 1992, its eventual coordination with other transit services was key to the development of voluntary partnerships between private operators. The 2017 Bus Services Bill provided Combined Authorities in the UK with the opportunity to bring back greater regulation, pending public support and approval by the mayor. Manchester was one of the first metropolitan areas to go down this path, effectively improving route and fare integration between the buses, local rail services and the now-publicly-owned MetroLink system. In the long-term, this could further add to system efficiencies." Personal communication by Michelle DeRobertis with Charles Rivasplata, June 11, 2020. 
131 EMTA, Determining Fare Structure: Evidence and Recommendations from a Qualitative Survey, EMTA Brief, 2016, p. 18.

${ }^{132}$ R. Buehler, J. Pucher, and O. Dummler, "Verkehrsverbund: The Evolution and Spread of Fully Integrated Regional Public Transport in Germany, Austria, and Switzerland," International Journal of Sustainable Transportation 0, no. 0 (2018): $1-15$.

${ }^{133}$ R. H. Pratt and J.E. Evans IV, TCRP Report 95: Traveler Response to Transportation System Changes, Chapter 10, Bus Routing and Coverage, Transportation Research Board of the National Academies, Washington, D.C., 2004, quoted on page 4-11 of Transit Capacity and Quality of Service Manual, 3rd Edition; Report 165, TRB, 2013, DOI: 10.17226/24766; Transit Cooperative Research Program (TCRP), http:// onlinepubs.trb.org/onlinepubsjtcrp/tcrp_rpt_9Scl0.pdf.

134 Brian Taylor, Peter Haas, Brent Boyd, and Daniel Baldwin Hess, "Increasing Transit Ridership: Lessons from the Increasing Transit Ridership in the 1990s," MTI Report 01-22, Mineta Transportation Institute, 2002.

135 Jarrett Walker, "Vancouver: Yes, you have a cost-effective transit agency!" Human Transit, updated March 27, 2015, https://humantransit.org/2015/03/vancouveryes-you-have-a-cost-effective-transit-agency.html; Todd Litman, "Twelve Reasons to Support Vancouver's Transportation Tax," Victoria Transport Policy Institute, March 28, 2015, https://www.vtpi.org/VanTransitTax.pdf.

136 South Coast British Columbia Transportation Authority (Vancouver TransLink), "Phase Two of the 10-Year Vision: 2018 - 2027 INVESTMENT PLAN," approved June 28, 2018.

137 TransLink. "Phase Two of the 10-Year Vision: 2018 - 2027 INVESTMENT PLAN," approved June 28, 2018.

138 TransLink. "Phase Two of the 10-Year Vision: 2018 - 2027 INVESTMENT PLAN," approved June 28, 2018.

139 TransLink. "Phase Two of the 10-Year Vision: 2018 - 2027 INVESTMENT PLAN," approved June 28, 2018.

140 TransLink. "Phase Two of the 10-Year Vision: 2018 - 2027 INVESTMENT PLAN," approved June 28, 2018. 
${ }^{141}$ Eno Center for Transportation, "Getting to the Route of Priorities," Washington, D.C., 2015, p. 23.

142 Transit Capacity and Quality of Service Manual Report 165, Exhibit 4-10, TRB, 2013: DOI 10.17226/24766; TRB's Transit Cooperative Research Program (TCRP) Report 165: Transit Capacity and Quality of Service Manual, Third Edition.

${ }^{143}$ When analyzing the performance of the road system, analysts do not discuss capacity and then caution that, for example, the roads should not have any potholes or that the traffic signals should work. It is a given that the roads and traffic signals are maintained. Similarly, it should be a given that staffing and maintenance are sufficient to ensure that buses and trains meet the published schedules. This basic reliability is considered to be a given for a world-class transit system.

${ }^{144}$ In the U.S., some transit agencies have compensated for low pay increases by having or retaining antiquated work rules which in fact come at the expense of riders and reliability. Examples of such work rules include assigning routes based on seniority, such that the least experienced drivers are assigned the most challenging routes, negatively impacting employee recruitment and retention; allowing up to a specified number of missed work days per year without drivers having to notify the transit agency that they will be missing their shift, resulting in substitute drivers being assigned to affected routes too late to ensure on-time service; and lack of pay bonuses to reward drivers for good performance. Low pay and route assignment based on seniority resulted in severe driver shortages in the San Francisco Bay Area as the economy emerged from the Great Recession after 2010, resulting in missed trips, affecting bus service reliability. During this time, the equipping of buses with GPS provided transit operators with great quantities of data on transit operations, but without adequate staffing to use the data in real time to adjust service.

145 Such as in this article published May 7, 2020: Tracy Hadden Loh and Annelies Goger, "In the age of American 'megaregions,' we must rethink governance across jurisdictions," The Brookings Institute, https://www.brookings.edu/research/in-theage-of-american-megaregions-we-must-rethink-governance-across-jurisdictions 


\section{BIBLIOGRAPHY}

Agenzia del Trasporto Pubblico Locale del Bacino di Milano, Monza e Brianza, Lodi, e Pavia. Milan (TPL), Programma di Bacino - Relazione generale, Versione 3.0 (Basin Plan -General Report version 3.0). Milan, Italy. December 2018.

Agenzia del Trasporto Pubblico Locale del Bacino di Milano, Monza e Brianza, Lodi, e Pavia. Milan (TPL) March 2, 2020. http://www.agenziatpl.it/agenzia/chi-siamo.

Área Metropolitana de Barcelona, AMB. April 28, 2020. https://www.metropolis.org/partners/area-metropolitana-de-barcelonaamb.

Arribas-Bel, Daniel \& Fernando Sanz-Gracia. "The validity of the monocentric city model in a polycentric age: US metropolitan areas in 1990, 2000 and 2010," Urban Geography, 35:7, (2014). 980-997, DOI:

10.1080/02723638.2014.940693

Associació de municipis per la Mobilitat i el Transport Urbà, (AMTU). May 1, 2020. https://www.amtu.cat/index.php/amtu

Autoritat del Transport Metropolità (ATM). April 27, 2020.

https://www.atm.cat/web/index.php.

Australian Bureau of Statistics. Census 2016.

https://quickstats.censusdata.abs.gov.au/census services/getproduct/cen sus/2016/quickstat/LGA57080?opendocument (April 20, 2020).

Azienda Trasporti Milanesi (ATM) Group, Annual Report - 2016 (Milan, Italy: ATM Group, 2016).

Azienda Trasporti Milanesi (ATM). March 15, 2020. https://www.atm.cat/web/index.php.

Blumenberg, Evelyn et al. "What's Behind Recent Transit Ridership Trends in the Bay Area?" UCLA Institute of Transportation Studies, 2020. Available at: www.its.ucla.edu/publication/bay-area-transit-ridership-trends/

Buehler, Ralph, John Pucher, and Oliver Dümmler. "Verkehrsverbund: The Evolution and Spread of Fully Integrated Regional Public Transport in Germany, Austria, and Switzerland." International Journal of Sustainable Transportation 13, no. 1 (2019): 36-50. https://doi.org/10.1080/15568318.2018.1431821.

Canadian Urban Transit Association, CUTA DATA Canadian Conventional Transit Statistics: 2018 Operating Data. Toronto, Canada: Canadian Urban Transit Association, 2019.

City of Burlington. "2019 Approved Budget: 2019 Operating and Capital Budgets 2020 - 2028 Capital Forecast." 2018. https://www.burlington.ca/en/your- 
city/resources/Budget/2019-Budget/2019-Budget-Book-Combined-

WEB.pdf (accessed August 4, 2020).

City of Hamilton. "2020 Tax Supported Operating Budget Report." December 11, 2019. https://www.hamilton.ca/sites/default/files/media/browser/2019-1211/2020-preliminary-tax-operating-budget-book-appendix-a-reportfcs20001.pdf (accessed August 4, 2020).

City of Milton. "2020 Proposed Capital and Operating Budget Book." 2019. https://www.milton.ca/en/town-hall/resources/2020-Proposed-Capital-andOperating-Budget-Book.pdf (accessed April 15, 2020).

City of Mississauga. "Mississauga City Business Plan and Budget: 2020-2023 Business Plan \& 2020 Budget." 2019. https://web.mississauga.ca/wpcontent/uploads/2019/11/28132215/B-Executive-Summary1.pdf (accessed August 4, 2020).

City of Sydney. https://www.cityofsydney.nsw.gov.au/learn/research-andstatistics/the-city-at-a-glance.

City of Toronto. "Toronto," 2020. https://www.toronto.ca (accessed April 24, 2020).

Corporation of the City of Brampton. "2020 Proposed Operating and Capital Budgets." January 1, 2019. https://www.brampton.ca/EN/CityHall/budget/2020\%20Budget/2020\%20Operating\%20and\%20Capital\%20 Budgets/2020\%20Proposed\%20Operating\%20and\%20Capital\%20Budget .pdf (accessed August 4, 2020).

Crivello, Silvia, and Luca Staricco. "Institutionalizing Metropolitan Cities In Italy. Success and Limits of a Centralistic, Simplifying Approach." Urban Research \& Practice 10, no. 2 (2017): 228-238. https://doi.org/10.1080/17535069.2017.1307001.

Donati, Anna, Francesco Petracchini, Carlotta Gasparini, and Laura Tomassetti. Politiche Di Mobilità E Qualità Dell'aria Nelle 14 Città E Aree Metropolitane 2017-2018, April 2019, pp. 46 and 103. Istituto sull'Inquinamento Atmosferico del Consiglio Nazionale delle Ricerche (CNR-IIA).

EMTA. April 1, 2020. https://www.emta.com/spip.php?article50.

EMTA. EMTA Barometer 2019-Based on 2017 Data. EMTA, European Metropolitan Transport Authorities, June 2019.

EMTA. "Determining Fare Structure: Evidence and Recommendations from a Qualitative Survey." EMTA Brief, 2016.

ENO Foundation. "Getting to the Route of Priorities." 2015. Eno Center for Transportation. Washington, D.C.

Eurostat. Energy, Transport and Environment Statistics, 2019 edition. European Union, 2019. 
https://ec.europa.eu/eurostat/documents/3217494/10165279/KS-DK-19-

001-EN-N.pdf/76651a29-b817-eed4-f9f2-92bf692e1ed9 and https://ec.europa.eu/eurostat/web/products-statistical-books/-/KS-DK-19001?inheritRedirect=true\&redirect $=\% 2$ Feurostat $\% 2$ Fpublications $\% 2$ Fstatis tical-books (accessed April 16, 2020).

"Exchange Rates UK: Your Live Currency Exchange Rates Website." https://www.exchangerates.org.uk/SEK-USD-exchange-rate-history.html (accessed August 5, 2020).

Ferrell, Christopher, Bruce Appleyard, and Matthew Taecker. Livable Transit Corridors: Methods, Metrics and Strategies. Transit Cooperative Research Program, Report No. 187 (TCRP H-45), Washington, D.C.: The National Academies Press. 2017. https://www.nap.edu/catalog/23630/livabletransit-corridors-methods-metrics-and-strategies.

Gräfin von Schlieffen, Gisela. "Public Transportation in Germany- The Rhein Main Transport Authority." April 2019. https://www.spur.org/sites/default/files/events pdfs/Presentation $\% 20 b y \% 2$ 0Gisela.pdf (accessed August 6, 2020).

Gray, Jennifer, Chief Financial Officer, Metrolinx. 2019-20 Metrolinx Business Plan. June 27, 2019. http://www.metrolinx.com/en/docs/pdf/board agenda/20190627/20190627 BoardMtg 2019-20 BusinessPlan EN.pdf (accessed August 4, 2020).

Haber, Staci A. "Transit in Suburbia: An Analysis of Perth, Australia's Mass Transit System and How American Suburbs Can Overcome Automobile Dependency." New College of Florida, 2011. http://imaginecities.com/test/wp-content/uploads/2014/02/TransitSuburbs.pdf.

Hirschhorn, Fabio, Wijnand Veeneman, and Didier van de Velde. "Organisation and Performance of Public Transport: A Systematic Cross-Case Comparison of Metropolitan Areas in Europe, Australia, and Canada." Transportation Research Part A: Policy and Practice 124 (2019): 419-432. https://doi.org/10.1016/j.tra.2019.04.008.

Johnston, R. "Primate City, The Law of." In The Dictionary of Human Geography, edited by D. Gregory et al., 5th ed., 580. Chichester: Wiley-Blackwell, 2009.

Litman, Todd. "Twelve Reasons to Support Vancouver's Transportation Tax," Victoria Transport Policy Institute. March 28, 2015. https://www.vtpi.org/VanTransitTax.pdf.

Loh, Tracy Hadden and Annelies Goger. "In the Age of American Megaregions, We Must Rethink Governance Across Jurisdictions". The Brookings Institute. May 7, 2020. https://www.brookings.edu/research/in-the-age-ofamerican-megaregions-we-must-rethink-governance-across-jurisdictions/. 
Lönnroth, Måns. Governance Of Metropolitan Transport in Nine Countries in Western Europe. VREF Research Synthesis Project, 2019.

Malatest. Summaries For The Greater Toronto \& Hamilton Area. Transportation Tomorrow Survey 2016. Toronto, March 2018.

Manville, Michael, Brian Taylor, and Evelyn Blumenberg. Falling Transit Ridership: California and Southern California, UCLA Institute of Transportation Studies, 2018.

Mees, Paul. Transport for Suburbia: Beyond the Automobile Age. New York, NY: Earthscan, 2010.

Meng Meng, Andreas Rau, Hita Mahardhika. "Public Transport Travel Time Perception: Effects of Socioeconomic Characteristics, Trip Characteristics and Facility Usage." Transportation Research Part A: Policy and Practice 114, part A (August 2018): 24-37. https://doi.org/10.1016/j.tra.2018.01.015.

Metra. 2014. Customer Satisfaction Study. Chicago: Regional Transportation Authority (RTA), pp. 41-44. https://metrarail.com/sites/default/files/assets/aboutmetra/2014 css survey.pdf

Metro Vancouver. May 20, 2020. http://www.metrovancouver.org/.

Metrolinx. May 20, 2020. http://www.metrolinx.com/en/aboutus/about us index.aspx

Metrolinx, The Big Move, 2008. Available at http://www.metrolinx.com/thebigmove/en/introduction/1 3 GTHA challen ges.aspx

Metrolinx, "The 2041 Regional Transportation Plan", available at http://www.metrolinx.com/en/regionalplanning/rtp/

Metrolinx Act, 2006, S.O. 2006, c. 16, https://www.ontario.ca/laws/statute/06g16.

Metrolinx. Further Connecting the Greater Toronto and Hamilton RegionDiscussion Paper for the Next Regional Transportation Plan. July 2016.

Multisystems, Inc., Mundle \& Associates, Inc. and Simon \& Simon Research Associates, Inc. 2002. Fare Policies, Structures, and Technologies: Update, TCRP Report 94. Washington, DC. http://onlinepubs.trb.org/onlinepubs/tcrp/tcrp_rpt_94.pdf

NHCRP Project 20-65, Task 69. Consolidation of Rural Public Transportation Services Guidebook. November 2017. Available at: http://onlinepubs.trb.org/onlinepubs/nchrp/docs/NCHRP2065(69) Guidebook.pdf. 
Organization for Economic Co-Operation and Development (OECD).

"Metropolitan Area Population 2018" (April 2020).

https://stats.oecd.org/Index.aspx?DataSetCode=CITIES (April 24, 2020).

"PoundSterling Live." https://www.poundsterlinglive.com/best-exchangerates/best-australian-dollar-to-us-dollar-history (accessed August 5, 2020).

"PoundSterling Live." https://www.poundsterlinglive.com/best-exchangerates/best-canadian-dollar-to-us-dollar-history (accessed August 5, 2020).

"PoundSterling Live." https://www.poundsterlinglive.com/best-exchangerates/best-euro-to-us-dollar-history (August 5, 2020).

Pratt, Richard H., and John E. Evans IV. TCRP Report 95: Traveler Response to Transportation System Changes. "Chapter 10: Bus Routing and Coverage". Transportation Research Board of the National Academies: Washington, D.C., 2004. http://onlinepubs.trb.org/onlinepubsjtcrp/tcrp rpt 9Scl0.

Public Transport Authority. March 20, 2020. https://www.pta.wa.gov.au/aboutus/our-role/our-history.

Public Transport Authority, Annual Report 2018 - 2019. Perth, Australia: The Government of Western Australia Public Transport Authority, 2019.I

Regional Authority Frankfurt Rhein-Main (Regionalverband FrankfurtRheinMain). http://www.region-frankfurt.de/Regional-Authority?La=2.

Regional Municipality of Durham, Durham Region Transit. "The 2020 Regional Business Plans and Budgets for Property Tax Purposes, including General Purpose, Solid Waste Management and Durham Regional Transit." February 11, 2020. https://www.durham.ca/en/regionalgovernment/resources/2020-Approved-Regional-Property-Tax-SupportedBudgets---Summary---page-numbered---Compressed.pdf (August 4, 2020).

Rhein-Main-Verkehrsbund (RMV). https://www.rmv.de/c/en/homepage/

Rivasplata, Charles. "An Analysis of the Impacts of British Reforms on Transit Integration in the Metropolitan Areas". Ph.D. Dissertation, University of California, Davis, 2006.

Sharaby Nir and Yoram Shiftan. "The Impact of Fare Integration on Travel Behavior and Transit Ridership." Transport Policy 21 (2012): 63-70.

Stuttgarter Strassenbahnen AG (SSB). Powerpoint presentation. 2009

State of New South Wales, Australia. Transport Administration Act no. 109, 1988, https://www.legislation.nsw.gov.au/\#/view/act/1988/109 
State of New South Wales, Australia. Transport Administration Act no. 109, 1988, https://www.legislation.nsw.gov.au/\#/view/act/1988/109

State of Western Australia. Public Transport Authority Bill 2003. https://www.parliament.wa.gov.au/parliament/bills.nsf/BillProgressPopup? openForm\&ParentUNID=1698FA9CBCCDBB4748256CD80007E64D

State of Western Australia. Annual Report 2018-19. Public Transport Authority, State of Western Australia. 2019.

State Transit Authority of New South Wales. Annual Report 18 - 19, Volume 1. Sydney, Australia: State Transit Authority of NSW, 2019.

State Transit Authority of New South Wales. https://www.transport.nsw.gov.au/.

Stockholm Regional Assembly, https://www.sll.se/om-regionstockholm/Informationin-English1/About-Stockholm-Region-Assembly/

Svergis Officiella Statistik, Trafik Analys. "Regional Linjetrafik 2019." June 25, 2020

https://www.trafa.se/globalassets/statistik/kollektivtrafik/kollektivtrafik/2019 /regional_linjetrafik_2019.xlsx? (accessed August 20, 2020).

Sydney Metro of NSW, Corporate Plan 2019 - 21. Sydney, Australia: Sydney Metro of NSW, 2019.

SYTRAL. March 20, 2020. http://www.sytral.fr/113-equipes-operationnelles.htm

Taylor, Brian, Peter Haas, Brent Boyd, and Daniel Baldwin Hess, "Increasing Transit Ridership: Lessons from the Increasing Transit Ridership in the 1990s," MTI Report 01-22, Mineta Transportation Institute, 2002.

TCRP Research Report 165: Transit Capacity and Quality of Service Manual Report 165, Exhibit 4-10, Washington, D.C.: The National Academies Press 2013: DOI 10.17226/24766.

Toronto Transit Commission. (TTC) https://www.ttc.ca/About_the_TTC/History/The_first_75_years.jsp.

Toronto Transit Commission (TTC). "2020 TTC and Wheel-Trans Operating Budgets." December 16, 2019.

https://www.ttc.ca/About the TTC/Commission reports and information/ Commission meetings/2019/December 16/Reports/1 2020 TTC and W heel Trans Operating Budgets.pdf (August 4, 2020).

Tourism and Transport Forum Australia. Ticket to Ride: Reforming Fares and Ticketing for Sustainable Public Transport. Sydney, Australia: Tourism and Transport Forum Australia, 2016.

Town of Oakvale. "2020 Budget Highlights." 2019.

https://www.oakville.ca/townhall/2020-budget-highlights.html (August 4, 2020). 
TransLink. May 20, 2020. https://www.translink.ca/About-Us.aspx

TransLink. Taxes and Charges. May 6, 2020 https://www.translink.ca/AboutUs/Taxes.aspx

TransLink.Bylaws. May 6, 2020. https://www.translink.ca/About-Us/Governanceand-Board/Bylaws.aspx.

TransLink. "2018 Year-End Financial and Performance Report." 2019, https://www.translink.ca/-

/media/Documents/about_translink/corporate_overview/corporate_reports/ quarterly_reports/2018/Year_End_2018_Finance_and_Performance_Rep ort_15-3-

2018. pdf?la=en\&hash=A91F0FEBD24C455D5E7C8142BB5122B7CA7B5 D6F (August 4, 2020).

TransLink. Phase Two of the 10-Year Vision 2018- 2027 Investment Plan Vancouver, BC: TransLink, 2018.

Transports en Commun Lyonnais (TCL) (Lyon Transport). March 20, 2020. https://www.tcl.fr/en/tcl-network

U.S. Census Bureau. American Community Survey, 2018. August 10, 2020. https://www.vitalsigns.mtc.ca.gov/commute-mode-choice.

U.S. Federal Transit Administration, National Transit Database, Summary sheets. https://www.transit.dot.gov/ntd/data-product/2018-metrics; https://cms7.fta.dot.gov/sites/fta.dot.gov/files/transit_agency_profile_doc/2 018/10003.pdf

U.S. Federal Transit Administration, National Transit Database. Transit Agency Profiles. https://www.transit.dot.gov/ntd/transit-agency-profiles

U.S. Federal Highway Administration. https://www.fhwa.dot.gov/policyinformation/statistics/2017/mv1.cfm.

Vancouver Trip Diary. Interactive website. Accessed April 17, 2020 : https://public.tableau.com/profile/translink\#!/vizhome/Trip Diary 2017/Trip Diary2017 (April 17, 2020).

Verband Region Stuttgart. "What does public transport cost in the ?" https://www.regionstuttgart.org/nahverkehr/finanzierung/?noMobile=mjhrnjlo\%252525252525 25252525252525252525252525252520 onfocus $\% 2525252525252525252$ 5252525252525252525253 DblurLink\%28this\%29\%27\%20aND\%20BeNC hMaRK\%282999999\%2CMd5\%28NoW\%28\%29\%29\%29\%20AnD\%20\%2 71 (August 4, 2020).

Verband Region Stuttgart (VRS). "Region Stuttgart at a Glance". October 2019, https://www.region-stuttgart.org/andere-laender/english/. 
Verkehrsverbund Tarifverbund Stuttgart (VVS), http://www.vvs.de/presse/ueber-denvvs/.

Wales, Trevor. The Road Less Travelled: TransLink's Improbable Journey from 1999 to 2008. TransLink, 2008.

Walker, Jarrett. "Vancouver: Yes, you have a cost-effective transit agency!" Human Transit. March 27, 2015, https://humantransit.org/2015/03/vancouveryes-you-have-a-cost-effective-transit-agency.html

Watkins, Kari, Simon Berrebi, Chandler Diffee, Becca Kiriazes, and David Ederer. TCRP Research Report 209: Analysis of Recent Public Transit Ridership Trends. Washington, D.C.: The National Academies Press, 2019. https://doi.org/10.17226/25635.

Wikipedia, "Barcelona," (2018). https://en.wikipedia.org/wiki/Barcelona (April 24, 2020).

Wikipedia, "City of Perth," (2018). https://en.wikipedia.org/wiki/City_of_Perth (April 24, 2020).

Wikipedia, "City of Sydney," (2018). https://en.wikipedia.org/wiki/City_of_Sydney (aApril 24, 2020).

Wikipedia, "Frankfurt," (2018). https://en.wikipedia.org/wiki/Frankfurt (April 24, 2020).

Wikipedia, "List of metropolitan areas in Sweden," (2018).

https://en.wikipedia.org/wiki/List_of_metropolitan_areas_in_Sweden\#Metr opolitan_Stockholm (April 24, 2020).

Wikipedia, "Lyon," (2017). https://en.wikipedia.org/wiki/Lyon (April 24, 2020).

Wikipedia, "Milan,” (2019). https://en.wikipedia.org/wiki/Milan (April 24, 2020).

Wikipedia, "Stuttgart," (2018). https://en.wikipedia.org/wiki/Stuttgart (April 24, 2020).

Wikipedia, "Vancouver," (2016). https://en.wikipedia.org/wiki/Vancouver (April 24, 2020).

Wood, Tricia, "Toronto's transit ridership is in a league of its own," (November 22, 2017), https://torontoist.com/2017/11/torontos-transit-ridership-league/ (April 24, 2020).

York Region Rapid Transit Corporation, "2020 to 2022 Budget As Tabled on November 21, 2019." November 21, 2019.

https://www.york.ca/wps/wcm/connect/yorkpublic/572e180e-e446-48788585-3a7de5a95eab/Budget+Book+Nov+21-

TABLED+WEB+VERSION.pdf?MOD=AJPERES\&CVID=mWeQG6B (August 4, 2020). 


\section{ABOUT THE AUTHORS}

\section{MICHELLE DeROBERTIS, PhD}

Dr. DeRobertis has a PhD from the University of Brescia, Italy, and a BS and MS in Civil Engineering from the University of California at Berkeley. She was a consulting transportation engineer for 20 years and then spent ten years in the public sector focusing on sustainable transportation design and policy. She is currently a Principal at Transportation Choices for Sustainable Communities, a non-profit research and educational institute, as well as a Research Associate with Mineta Transportation Institute. Her current research interests are assessing the benefits of trafficreducing strategies on livability and improving public transit in the U.S. In 2014 she founded and chaired the ITE Committee on Transit and Traffic Impact Studies, a multiyear effort to document whether and how public transit is considered in Traffic Impact Studies in the U.S. and Canada; the ITE State of the Practice Informational Report was published February 2019. She subsequently served on the ITE committee that rewrote the ITE Recommended Practice for conducting multimodal and traffic impact studies. In 2009, she was the recipient of a fellowship from the German Marshall Fund in the Comparative Domestic Policy Program, where she researched Land Development and Transportation Policies for Transit-Oriented Development in Germany and Italy. She is a registered Professional Engineer in California in both Civil Engineering and Traffic Engineering.

\section{CHRISTOPHER E. FERRELL, PhD}

Dr. Ferrell began his career in 1995 as a planner for the Metropolitan Transportation Commission (MTC). He completed his doctoral studies in City and Regional Planning at the University of California at Berkeley in 2005 and worked as a consultant with Dowling Associates, Inc. for 10 years before leaving to help form CFA Consultants in 2010. $\mathrm{He}$ is currently the Executive Director for Transportation Choices for Sustainable Communities. He has been the principal investigator for six research projects for the Mineta Transportation Institute, where he has been a Research Associate since 2005. His research focuses on the relationships between transportation and land use, livability, travel behavior, transportation policy, and planning-related institutional structures. His research experience includes the study of multimodal transit and freeway corridors, the best practices for building successful transit-oriented development, the effects of transit-oriented development on surrounding property values, the effects of neighborhood crime on transportation mode choice, and a set of methods, metrics, and strategies for evaluating transit corridor livability. As a practitioner, he has planned mixed-use, infill and transit-oriented development projects, analyzed the impacts of specific and general plans, planned and implemented intelligent transportation systems, and developed bicycle and pedestrian plans. He has taught several quantitative methods classes in the San José State 
State University Urban Planning Department as well as a course in transportation and land use in the City and Regional Planning Department at the University of California at Berkeley.

\section{RICHARD W. LEE, PhD}

Richard Lee is an adjunct lecturer in the Urban and Regional Planning Department at San José State University and a course instructor for UC Berkeley's Transportation Tech Transfer program. He has been a research associate with the Mineta Transportation Institute (MTI) for over 20 years. For MTI, Richard has led major research studies of general plans and sustainability, airport planning, and sustainability indicators for transportation. From 1995 through 2002, he was a full-time academic, teaching transportation planning and leading research projects at Massey University, New Zealand, UCLA, and Cal Poly San Luis Obispo. Richard is also Director of Innovation and Sustainability at VRPA Technologies, Inc., a California-based consulting firm, as well as a Principal at Transportation Choices for Sustainable Communities, a non-profit research and educational institute. Dr. Lee's 35 years of academic and consulting experience include management of regional transportation plans, general plan studies, and high-speed rail. He has planned transit improvements for systems ranging from BART to single-route systems in the San Joaquin Valley and covering all transit modes. He recently led both a long-range transit plan for the Fresno region and a short-term route restructuring study for the City of Fresno's transit system to incorporate bus rapid transit. Dr. Lee holds master's degrees in Civil Engineering (1984) and City and Regional Planning (1985) as well as a PhD in City and Regional Planning (1995), all from the University of California at Berkeley.

\section{JOHN M. EELLS, MCP}

John M. Eells is a transportation planner with 42 years of experience preparing comprehensive transportation plans and developing sustainable transportation projects at the local and regional level. John's experience includes two years in the Legislative Analyst Office in the California State Legislature, five years with the California Department of Transportation (Caltrans), seven years as the Transportation Planning Coordinator for Marin County, and 28 years as a consultant. John is currently a Principal at Transportation Choices for Sustainable Communities and a researcher with the Mineta Transportation Institute.

He holds a bachelor's degree in Architecture and a master's degree in City Planning from the University of California at Berkeley. John has assisted in the preparation of Regional Transportation Plans for Sacramento and Lake Tahoe and has reviewed Regional Transportation Plans throughout California for conformance with State greenhouse gas reduction requirements for the California Attorney General's Office. He participated in a joint effort by Caltrans and the California Council on Science and Technology to develop a proposal for a new California Center for Transportation 
Innovation to coordinate transportation research activities in California. John has also managed major multi-modal transportation studies, evaluated the feasibility of proposal ferry services, and worked on the implementation of several rail transit projects including the Sacramento Light Rail project, the ACE Commuter Rail Service from Stockton to San José, the SMART Commuter Rail Service from Cloverdale to Larkspur, the proposed AMTRAK line from Oakland to Reno, and the proposed highspeed Maglev Service from Los Angeles to Las Vegas. 


\section{PEER REVIEW}

San José State University, of the California State University system, and the Mineta Transportation Institute (MTI) Board of Trustees have agreed upon a peer review process required for all research published by MTI. The purpose of the review process is to ensure that the results presented are based upon a professionally acceptable research protocol. 


\section{MTI BOARD OF TRUSTEES}

Founder, Honorable

Norman Mineta*

Secretary (ret.),

US Department of Transportation

\section{Chair,}

Abbas Mohaddes

President \& $\mathrm{COO}$

Econolite Group Inc.

\section{Vice Chair,}

\section{Will Kempton}

Executive Director

Sacramento Transportation Authority

\section{Executive Director,}

Karen Philbrick, PhD*

Mineta Transportation Institute

San José State University

\section{Winsome Bowen}

Chief Regional Transportation

Strategy

Facebook

\section{David Castagnetti}

\section{Co-Founder}

Mehlman Castagnetti

Rosen \& Thomas

\section{Maria Cino}

Vice President

America \& U.S. Government

Relations Hewlett-Packard Enterprise

\author{
Grace Crunican** \\ Owner \\ Crunican LLC
}

\section{Donna DeMartino \\ Managing Director \\ Los Angeles-San Diego-San Luis \\ Obispo Rail Corridor Agency}

\section{Nuria Fernandez**}

General Manager \& CEO

Santa Clara Valley

Transportation Authority (VTA)

\section{John Flaherty}

Senior Fellow

Silicon Valley American

Leadership Form

\section{William Flynn * \\ President \& CEO \\ Amtrak}

\section{Rose Guilbault}

Board Member

Peninsula Corridor

Joint Powers Board

Ian Jefferies*

President \& CEO

Association of American Railroads
Diane Woodend Jones

Principal \& Chair of Board

Lea + Elliott, Inc.

David S. Kim*

Secretary

California State Transportation

Agency (CALSTA)

\section{Therese McMillan}

Executive Director

Metropolitan Transportation

Commission (MTC)

\section{Bradley Mims}

President \& CEO

Conference of Minority

Transportation Officials (COMTO)

Jeff Morales

Managing Principal

InfraStrategies, LLC

Dan Moshavi, PhD*

Dean, Lucas College and

Graduate School of Business

San José State University

Toks Omishakin*

Director

California Department of

Transportation (Caltrans)
Takayoshi Oshima

Chairman \& CEO

Allied Telesis, Inc.

Paul Skoutelas*

President \& CEO

American Public Transportation

Association (APTA)

Beverley Swaim-Staley

President

Union Station Redevelopment

Corporation

Jim Tymon*

Executive Director

American Association of

State Highway and Transportation

Officials (AASHTO)

\section{Larry Willis*}

President

Transportation Trades

Dept.,AFL-CIO

$*$ = Ex-Officio

** = Past Chair, Board of Trustees

\section{Directors}

\section{Karen Philbrick, PhD}

Executive Director

\section{Hilary Nixon, PhD}

Deputy Executive Director

\section{Asha Weinstein Agrawal, PhD}

\section{Education Director}

National Transportation Finance

Center Director

\section{Brian Michael Jenkins}

National Transportation Security

Center Director

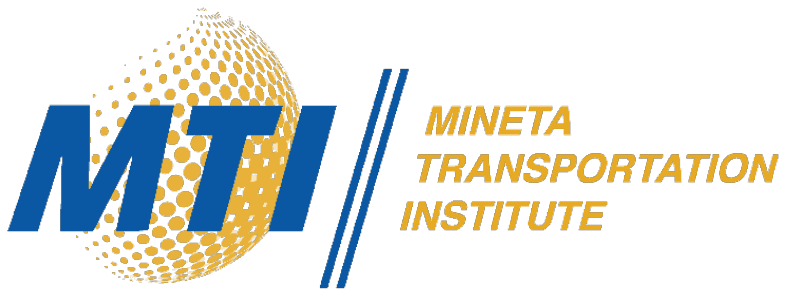

